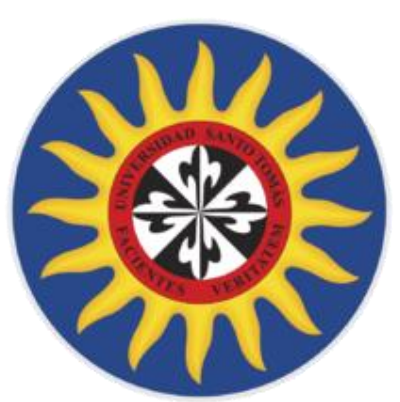

Presentado por

\author{
Miguel Ángel Nope Rivera \\ Juan Camilo Cuervo Rincón
}

Para optar al título:

Profesional en Administración de Empresas

Directora de trabajo de grado:

Sara Teresa Sandoval Gómez

UNIVERSIDAD SANTO TOMÁS

ADMINISTRACIÓN DE EMPRESAS

BOGOTÁ

2019 


\section{Tabla de contenido}

1 Resumen. 6

2 Introducción.

3 Objetivos. $\quad 8$

3.1 General. $\quad 8$

3.2 Específicos. $\quad 8$

4 Revisión de la literatura. $\quad 8$

4.1 Gestión del talento humano. 9

4.2 Planeación estratégica del talento humano. 9

4.3 Funciones de la gestión del talento humano. 10

$\begin{array}{lll}\text { 4.3.1 Reclutamiento. } & 11\end{array}$

$\begin{array}{lll}\text { 4.3.2 Selección. } & 11\end{array}$

$\begin{array}{lll}\text { 4.3.3 Inducción. } & 12\end{array}$

$\begin{array}{lll}\text { 4.3.4 Capacitación. } & 12\end{array}$

$\begin{array}{ll}\text { 4.3.5 Evaluación de desempeño. } & 13\end{array}$

$\begin{array}{lll}\text { 4.3.6 Remuneración. } & 14\end{array}$

$\begin{array}{lll}\text { 4.3.7 } & \text { Bienestar social. } & 14\end{array}$

$\begin{array}{lll}\text { 4.3.8 Salud ocupacional. } & 15\end{array}$

4.4 Innovación en el área de talento humano. 15

$\begin{array}{lll}4.5 & \text { Fortalecimiento empresarial. } & 16\end{array}$

5 Metodología y presentación de resultados. 18

$\begin{array}{lll}5.1 & \text { Metodología de trabajo. } & 18\end{array}$

$\begin{array}{lll}\text { 5.1.1 Muestra poblacional. } & 19\end{array}$

$\begin{array}{lll}\text { 5.1.2 Herramienta metodológica. } & 19\end{array}$

$\begin{array}{lll}\text { 5.1.3 Etapas del proyecto. } & 20\end{array}$

5.1.3.1 Etapa 1: revisión de la literatura. 20

5.1.3.2 Etapa 2: procedimiento. 20

5.1.3.3 Etapa 3: Presentación de resultados. 21

5.1.3.4 Etapa 4: análisis y discusión de los resultados. 21

5.1.3.5 Etapa 5: conclusión y propuestas 21

5.2 Presentación de resultados. 22

5.2.1 Metodología. 22

$\begin{array}{lll}\text { 5.2.2 Muestra poblacional } & 22\end{array}$ 
5.2.4 Presentación de Resultados. 23

5.2.4.1 Caracterización de la población 23

5.2.4.1.1 Bienestar Social 23

5.2.4.1.2 Capacitación 26

5.2.4.1.3 Compensación $\quad 29$

5.2.4.1.4 Contratación 31

5.2.4.1.5 Entrenamiento 33

5.2.4.1.6 Estructuración del plan de gestión humana. 34

5.2.4.1.7 Evaluación de desarrollo. $\quad 35$

5.2.4.1.8 Implementación y seguimiento plan estratégico G.H. 37

$\begin{array}{lll}\text { 5.2.4.1.9 Inducción } & 38\end{array}$

5.2.4.1.10 Manejo Laboral 40

5.2.4.1.11 Promoción. 41

5.2.4.1.12 Reclutamiento 42

5.2.4.1.13 Salud ocupacional 44

5.2.4.1.14 Selección 46

6 Discusión de resultados. $\quad 48$

7 Conclusiones.

8 Recomendaciones. 56

9 Agradecimientos. $\quad 57$

10 Referencias. $\quad 58$

11 Anexos. 60

\section{Índice de graficas}

Gráfica 1: Resultados desarrollo y seguimiento de los programas de Bienestar Social. 24 Gráfica 2: Resultados de la aplicación de mecanismos de comunicación para dar a conocer a los empleados los programas de bienestar.

Gráfica 3: Resultados de los programas que generan un ambiente que propicie la colaboración y voluntad del colaborador, se evidencian con indicadores en todas las áreas o procesos.

Gráfica 4: Resultados sobre las estadísticas que reflejen el aumento de la productividad, disminución de ausentismo y accidentes de trabajo, como consecuencia de la implementación y ejecución de programas de bienestar. 
Gráfica 5: Resultados sobre la capacitación se desarrolla sobre criterios claros conocidos y utilizados por todas las áreas de la organización.

Gráfica 6: Resultados sobre los programas de capacitación se desarrollan permanentemente y son aprovechados por los trabajadores de la organización.

Gráfica 7: Resultados sobre la evidencia de los logros en los funcionarios capacitados y la aplicación de los conceptos adquiridos en su labor diaria, operativa o técnica en todas las áreas o procesos.

Gráfica 8: Resultados sobre la realización del mejoramiento e innovación de los programas de capacitación en todas las áreas y/o procesos de la empresa.

Gráfica 9: Resultados sobre el sistema de pago de nómina funciona de manera óptima y con la última tecnología en el sector.

Gráfica 10: Resultados sobre la aplicación de criterios con equidad para determinar el salario asignado a un puesto de trabajo, la periodicidad de su reajuste y las políticas salariales.

Gráfica 11: Resultados sobre la aplicación de indicadores de gestión para determinar la escala salarial frente a su industria.

Gráfica 12: Resultados sobre las fuentes internas o externas de consulta en la elaboración de los contratos laborales.

Gráfica 13: Resultados sobre las políticas de contratación.

Gráfica 14: Resultados sobre la utilización permanentemente de modelos de contrato.

Gráfica 15: Resultados sobre la aplicación de los criterios que evalúan el desarrollo del empleado en su labor diaria.

Gráfica 16: Resultados sobre los logros obtenidos en la aplicación del proceso de entrenamiento en los funcionarios, tanto en el ámbito administrativo como operativo o técnico, se evidencian por medio de indicadores en todas las áreas o procesos.

Gráfica 17: Resultados sobre el plan estratégico de gestión humana está alineado totalmente al direccionamiento estratégico de la empresa.

Gráfica 18: Resultados en cuanto la misión, políticas, metas y estrategias de gestión humana, son conocidas y se están trabajando uniformemente en toda la empresa.

Gráfica 19: Resultados en cuanto la aplicación de un proceso de valoración y méritos que revela necesidades de mejoramiento en los trabajadores funciona de manera óptima. $\quad 36$ Gráfica 20: Resultados sobre un sistema de evaluación de desempeño con objetivos y factores significativos para cada cargo, proceso o área de trabajo.

Gráfica 21:Resultados sobre el plan de gestión humana que se evalúa permanentemente en toda la empresa.

Gráfica 22: Resultados sobre la ejecución del plan de gestión humana integrado a las otras áreas de la empresa.

Gráfica 23: Resultados sobre mecanismos para informar al nuevo empleado aspectos básicos de la empresa.

Gráfica 24: Resultados sobre la utilización de mecanismos para promover y medir la adaptación de un (a) trabajador (a) nuevo (a).

Gráfica 25: Resultados sobre el proceso para la liquidación del personal. $\quad 40$

Gráfica 26: Resultados sobre la aplicación del reglamento interno de trabajo.

Gráfica 27: Resultados sobre la aplicación de criterios para promover trabajadores (mérito, antigüedad, etc.). 
Gráfica 28: Resultados sobre la evidencia de todas las áreas con datos estadísticos que permiten visualizar los criterios de promoción.

Gráfica 29: Resultados sobre la documentación de las fuentes internas o externas de donde se obtiene el personal necesario.

Gráfica 30: Resultados sobre los procedimientos para registrar información actualizada de empleados potenciales.

Gráfica 31: Resultados sobre la utilización de mecanismos de evaluación y mejoramiento del proceso de reclutamiento.

Gráfica 32: Resultados sobre la aplicación de programas de mejoramiento y mantenimiento de las condiciones de vida y salud de los trabajadores.

Gráfica 33: Resultados sobre la aplicación de las medidas de protección a las personas de la organización.

Gráfica 34: Resultados sobre los programas generan prevención de todo daño para la salud de las personas, derivado de las condiciones de trabajo.

Gráfica 35: Resultados sobre la utilización permanentemente el proceso de selección (entrevistas, pruebas, verificación de antecedentes, referencias, etc.).

Gráfica 36: Resultados sobre la utilización permanentemente las prioridades de la empresa con respecto a las habilidades, aptitudes y valores de los aspirantes.

Gráfica 37: Resultados sobre la utilización de los criterios físicos y de salud para determinar si el aspirante es apto para el cargo y existencia de pruebas para su ingreso.

\section{Índice de diagramas}

Diagrama 1: Espina de pescado.

Diagrama 2: Como - Como. 


\title{
1 Resumen.
}

EL presente proyecto se orienta a la innovación y fortalecimiento empresarial en el área de talento humano en la empresa CIC TRAVEL a través de un análisis descriptivo mixto, teniendo en cuenta la fundamentación teórica y los resultados obtenidos de la aplicación de las herramientas establecidas (cuestionario desarrollado, diagrama de espina de pescado y diagrama "como - como") ajustadas a las necesidades del proyecto, conllevando a la identificación de oportunidades de mejora y fortalecimiento innovadoras para la empresa CIC TRAVEL, finalizando la etapa de investigación y desarrollo, se pudo evidenciar opciones de mejora para el proceso de selección, inducción, entrenamiento, capacitación y promoción, teniendo presente estos procesos se propuso el plan de mejora innovador con estrategias administrativas puntuales encaminadas al fortalecimiento de la satisfacción de los colaboradores y la empresa.

Palabras claves: Innovación en talento humano, fortalecimiento empresarial, funciones del talento humano.

\begin{abstract}
Abstrac
This project is oriented to innovation and business strengthening in the area of human talent in the company CIC TRAVEL through a mixed descriptive analysis, taking into account the theoretical foundation and the results obtained from the application of the established tools (questionnaire developed, fishbone diagram and "how how" diagram) adjusted to the needs of the project, leading to the identification of innovative improvement and strengthening opportunities for the company CIC TRAVEL, ending the research and development stage, it was possible to demonstrate options for improvement for the selection, induction, training and promotion processes, keeping in mind these processes, the innovative
\end{abstract}


improvement plan was proposed with specific administrative strategies aimed at strengthening the satisfaction of workers and the company.

Keywords: innovation in human talent, business strengthening, human talent functions.

\section{Introducción.}

Actualmente el área de talento humano ha venido tomando un papel importante en la proyección y alcance de los objetivos propuestos por las empresas convirtiéndose de ese modo en el área integradora de la empresa; por lo tanto, la importancia de diseñar programas que fortalezcan esta área con el fin de garantizar seguridad a los accionistas es de vital importancia ya que permite la supervivencia y diversidad de la empresa.

Es entonces, donde se debe considerar la importancia que juega en una organización contribuir al desarrollo de los colaboradores para que estos alcancen un alto desempeño como también una calidad de conducta personal y social que cubra sus necesidades y las de la empresa; de esta manera tomando necesidad de crear mecanismos que permitan a una organización generar alternativas responsables en la gestión del área de talento humano guiadas al fortalecimiento empresarial mediante mecanismos innovadores se pueden llegar a diseñar planes de fortalecimiento con mecanismos innovadores que generen dichos cambios.

Para lograr el cumplimiento de los objetivos en esta investigación se tomará la empresa de estudio CIC TRAVEL la cual es una empresa con una trayectoria de más de 20 años en el servicio turístico, donde se presentó un plan que permita el fortalecimiento del área de talento humano y a la vez creando mecanismos de fortalecimiento al interior del área, como lo es la innovación. 


\section{Objetivos.}

\subsection{General.}

Crear un programa de fortalecimiento empresarial en el área de recursos humanos para la empresa CIC TRAVEL utilizando mecanismos innovadores.

\subsection{Específicos.}

- Determinar la importancia que tiene el departamento de recursos humanos dentro de la empresa CIC TRAVEL.

- Crear mecanismos innovadores que permitan fortalecer el área de recursos humanos teniendo en cuenta las diferentes funciones que se tienen en la empresa CIC TRAVEL.

- Diseñar un programa de fortalecimiento para el área de recursos humanos de la empresa CIC TRAVEL como herramienta innovadora dentro del contexto organizacional.

\section{Revisión de la literatura.}

Como el objetivo central de este trabajo se enfoca en el área de talento humano y la innovación guiada al fortalecimiento empresarial en la empresa CIC TRAVEL, se hizo una revisión de la literatura de cada una de las funciones del área de talento humano, como también de algunos autores que explican la innovación enfocada en el área de talento humano con el objetivo de retener el talento y generar conocimiento, esto con el fin de lograr comprender cada una de las funciones que cumple esta área de recursos humanos de la 
empresa CIC TRAVEL y de este modo crear un programa que permita el fortalecimiento utilizando mecanismos innovadores.

\subsection{Gestión del talento humano.}

Para empezar a contextualizar este trabajo empezaremos identificando el área de gestión del talento humano, la cual permite dimensionar correctamente el talento de las personas que la integran. Por lo tanto, es el área que dimensiona las prácticas y políticas necesarias para manejar los asuntos que tienen que ver con las relaciones humanas del trabajo administrativo; en específico se trata de reclutar, evaluar, capacitar remunerar y ofrecer un ambiente seguro y equitativo para los empleados de la compañía. (Dessler, Gary, (2006))

Si miramos desde un punto estratégico de dirección el talento humano, su objetivo es obtener la máxima creación de valor para la organización, a través de un conjunto de acciones dirigidas a disponer en todo momento del nivel de conocimientos capacidades y habilidades en la obtención de los resultados necesarios para ser competitivo en el entorno actual y futuro. (Eslava Arnao, Edgar (2004)), lo cual permite establecer que una gestión responsable y lógica de esta aérea con el fin de fortalecer esta área.

\subsection{Planeación estratégica del talento humano.}

Para continuar es de suma importancia que si se habla que el área de talento humano es una área competitiva y dinámica (Chiavenato, Idalberto (2009)), si se quiere fortalecer se debe considerar una planeación estratégica que esté alineada a la estrategia del negocio, es decir, tener claro para dónde se dirige el negocio, teniendo en cuenta filosofía organizacional, los objetivos y la cultura de la organización. La planificación estratégica de RH debe formar parte integral de la planificación estratégica de la organización. Casi siempre, la primera busca una forma de integrar la función de la ARH a los objetivos globales de la empresa. A 
toda estrategia organizacional determinada corresponde una planificación estratégica de RH, perfectamente integrada e involucrada. (Chiavenato, Idalberto (2009))

Por otro lado, Martha Alles define la estrategia de recursos humanos como la que intenta agregar valor a la empresa y define la visión, la misión y la prioridad de la función de los recursos humanos. La organización de recursos humanos diagnóstica y mejora la función de su área para aportar servicios a la empresa. Crea un proceso que asegura las estrategias, permitiendo la posibilidad de generar una gestión responsable (Martha Alles, (2009), pág. 25)

Por eso es de gran importancia que el área del talento humano sea fortalecida, porque es la encargada de encontrar el personal idóneo que necesita la organización y como esta misma debe encargarse de mantener un buen ambiente laboral, que favorezca el desarrollo óptimo de la empresa. Es importante mencionar que los recursos humanos significan una gran inversión para la organización, por lo tanto, todo lo que se invierte es pensando en el mejoramiento de sus colaboradores, para luego verse reflejado en un mejor desempeño, significando mayores beneficios para la organización.

\subsection{Funciones de la gestión del talento humano.}

El departamento del talento humano debe cumplir ciertas funciones específicas, donde se relaciona la empresa con las personas, además este departamento debe ayudar al proceso productivo de la organización para mantener una sintonía con las demás áreas de la empresa, por ende es importante para este trabajo conocer dichas áreas ya que sobre estas se piensa desarrollar el plan de mejoramiento identificando diferentes puntos clave con el fin de aplicar mejoras innovadoras que potencien dichas funciones, las cuales las principales funciones son las siguientes. 


\subsubsection{Reclutamiento.}

El reclutamiento de personal es el proceso por el cual se realiza la búsqueda de un número suficiente de candidatos que se adecuen a las características y perfiles necesarios para un cargo específico es decir se encarga de encontrar de persona(as) con los requerimientos necesarios acordes al cargo. Este reclutamiento se lleva a cabo tanto interno y externo en la organización. Soportando lo anteriormente dicho encontramos que Chiavenato (2000) define el reclutamiento como un conjunto de técnicas y procedimientos orientados a atraer candidatos potencialmente calificados y capaces de ocupar cargos dentro de la organización (p.208) por ende si miramos este proceso como una posibilidad de cambio podemos llegar a concluir que podemos hacer conocer la empresa como ese lugar idóneo para trabajar creando mecanismos que permitan crear en las personas una imagen positiva del lugar soñado de trabajo.

\subsubsection{Selección.}

Martha Alles, (2006) dice que a selección de personal se define como un procedimiento para encontrar la persona que cubre el puesto adecuado. La importancia de seleccionar la persona indicada, según el análisis de cargo que especifica las competencias necesarias para el mismo puesto es importante puesto que si se llegase a seleccionar una persona con habilidades que no vayan acordes con las necesarias para el cargo podría generar problemas para la organización como también costos innecesarios por lo tanto una gestión responsable de esta función generaría beneficios no solo para la empresa sino también incentivaría a la atracción de conocimiento de calidad.

Buscando otros autores que definan esta función encontramos que Dunnette argumenta que la "selección consiste en asegurar que la persona adecuada está en el puesto adecuado en el momento oportuno y bajo las circunstancias concretas, partiendo de la consideración de que 
las decisiones acertadas acerca de las personas requieren conocimientos de su individualidad además de conocer cómo los talentos especiales de cada persona pueden ser conocidos con mayor precisión y utilizados en forma más acertada”. (Dunnette, 1974) además Chiavenato define La selección de recursos humanos como la escogencia del individuo adecuado para el cargo adecuado, o, en un sentido más amplio, escoger entre los candidatos reclutados a los más adecuados, para ocupar los cargos existentes en la Empresa, tratando de mantener o aumentar la eficiencia y el rendimiento del personal. (Chiavenato, Idalberto (2009)

\subsubsection{Inducción.}

Es una de las funciones donde el colaborador tiene el primer contacto con la empresa y es en este momento donde se apropia al colaborador con los objetivos de la empresa ya que la inducción es la función donde se da primera información que debe adquirir la persona que ingresa el cual siempre va guiado a dar a conocer la historia de la organización, su estructura, mercadeo y esquema comercial; políticas con respecto al personal, higiene, seguridad, medio ambiente, calidad, cultura, misión, visión y valores. (Martha Alles, (2006)) además es la parte del proceso, donde se debe integrar al nuevo colaborador a la organización teniendo como finalidad generar un impacto positivo, es la oportunidad para fidelizar al nuevo colaborador y de lograr integrarlo a su nuevo ambiente de trabajo. Un buen proceso de inducción puede disminuir la rotación en el personal y la retención del talento.

\subsubsection{Capacitación.}

Es el proceso donde se desarrolla las cualidades de los colaboradores, preparando para que sean más productivos y contribuyan mejor al logro de los objetivos de la organización. El propósito de la capacitación es influir en los comportamientos de los individuos para aumentar su productividad en su trabajo. En la capacitación se debe tener en cuenta dos 
conceptos muy importantes los cuales son entrenamiento y formación estos conceptos deben siempre tener como propósito el aprendizaje y apropiación de colaborador a su cargo.

Explicando estos conceptos según la teoría encontramos que el entrenamiento, Idalberto Chiavenato (2009) lo define como "la preparación de la persona para el cargo, en lo tanto que el propósito es preparar a la persona para enfrentar ambiente dentro o fuera del trabajo" y la formación la define según Buckley y Jim Caple como "un esfuerzo sistemático y planificado por modificar o desarrollar el conocimiento, las técnicas y las actividades a través del aprendizaje, conseguir la actuación adecuada de una actividad o rango de actividades en el mundo”.( Buckley y Jim Caple (1991))

Por lo tanto, la capacitación es una función muy importante puesto que se fundamenta en el mantenimiento en el ámbito del conocimiento.

\subsubsection{Evaluación de desempeño.}

Según Gibson (1997). “La evaluación de desempeño es un proceso sistemático mediante el cual se evalúa el desempeño del colaborador y su potencial de desarrollo hacia el futuro.” La evaluación de desempeño es el proceso por el cual se estima el rendimiento global del empleado. (Baggini, (1999))

A partir del perfil, el puesto a cubrir se debe diseñar una herramienta la cual requerirá conocimientos y competencias que se evaluarán con métodos que permitan observar comportamientos. (Martha Alles, (2009) pág. 90)

Según Dolan, Valle, Jackson y Schuler (2007), la evaluación del rendimiento se define como un procedimiento estructural y sistemático para medir, evaluar e influir sobre los atributos, comportamientos y resultados relacionados con el trabajo, con el fin de descubrir en qué medida es productivo el colaborador, y si podrá mejorar su rendimiento futuro (p.229). 
En la evaluación de desempeño se debe tener en cuenta la retroalimentación, la cual es el último pasó a la hora de realizar una evaluación, se puede definir la retroalimentación como el proceso mediante el cual se realiza un intercambio de datos, informaciones, hipótesis o teorías entre dos puntas diferentes.

Es importante debido que los colaboradores deben conocer cuáles fueron sus puntos débiles, fuertes y en que debe mejorar de acuerdo al desempeño de sus labores y de este modo identificar de oportunidades de mejora.

\subsubsection{Remuneración.}

Según Idalberto Chiavenato (2009), define: “la remuneración constituye todo lo que el empleado recibe como consecuencia del trabajo que realiza en la organización. La remuneración es un pago en especie y el salario un pago en especie" lo cual el departamento de talento humano debe diseñar un sistema de remuneración, según el cargo tomando en cuenta la reglamentación vigente establecida por el ministerio de trabajo colombiano (código del trabajador).

En la remuneración se deben tener en cuenta los factores internos y externos, para establecer los salarios según el cargo, responsabilidades, tiempo laborado, subordinación entre otros aspectos esenciales establecidos por la normatividad establecida (código del trabajador).

\subsubsection{Bienestar social.}

La organización debe preocuparse por el bienestar de sus colaboradores, es así, que el bienestar en el trabajo hace referencia a las condiciones físicas y psicológicas que los colaboradores experimentan como resultado del ambiente de trabajo proporcionado a la organización un buen clima laboral. Esto conlleva a buscar la calidad de vida laboral, lo cual (Idalberto, Chiavenato, (1999) lo define como "Calidad de vida implica crear, mantener y 
mejorar el ambiente laboral, tratase de sus condiciones físicas o de sus condiciones psicológicas y sociales.

Todo ello redunda en un ambiente laboral agradable y amigable, mejora sustancialmente la calidad de vida de las personas dentro de las organizaciones y, por extensión también fuera de ellas." El bienestar de los colaboradores, se ve reflejado en su desempeño y compromiso que tiene con la organización, esto implica que las organizaciones tienen que preocuparse por los diferentes factores que influyen en el bienestar del colaborador, buscando siempre mejorar su calidad de vida.

\subsubsection{Salud ocupacional.}

Es una actividad multidisciplinaria que promueve la protección de la salud y seguridad de los colaboradores en su área de trabajo, así mismo esta intenta prevenir y controlar los accidentes que en ella puedan ocurrir generando ambientes de trabajo físico, mental y socialmente saludables. El reto del departamento de talento humano es generar lugares de trabajos seguros, estableciendo un conjunto de normas, para prevenir accidentes. Debe ofrecer las debidas protecciones, según el cargo y el nivel de riesgo del mismo, preocupándose por la salud y el bienestar de los colaboradores.

De lo anterior el estado colombiano mediante el decreto 614 de 1984 y la ley 100 de 1993 se establecen los lineamientos generalmente admitidos que soportan la organización y administración de la salud ocupacional que debe tener toda empresa.

\subsection{Innovación en el área de talento humano.}

Para empezar a contextualizar los elementos que componen el objetivo principal de este trabajo que es fortalecer el área de talento humano por medio de mecanismos innovadores primero tendremos que identificar hallazgos de la innovación en esta área, por 
lo tanto se revisó la literatura donde se identificó pocos estudios donde se relacione el área de talento humano con la innovación ya que muchos autores consideran el área de talento humano como una área con lineamientos ya definidos con bases fuertes difíciles de modificar o reformular ya que los procesos y funciones que es esta área se manejan ya están definidos por lo tanto si se llegase a aplicar métodos innovadores que fortalezcan las funciones llevadas a cabo en el área de talento humano podemos generar cambios importantes dentro de la organización, llegando a convertir a una empresa competitiva creadora de conocimiento la cual incentive al buen ambiente laboral, buena impresión y sentido de pertenencia con los objetivos de la empresa por parte de los colaboradores como también por parte de actores externos, además la generación de nuevos campos de negocio ya que "gran parte del capital de una empresa consiste en conocimientos y organización donde el conocimiento es la máquina de producción más poderosa a nuestro alcance y la organización ayuda a la generación del conocimiento" (Nonaka y Takeuchi (1999))

\subsection{Fortalecimiento empresarial.}

Los cambios tecnológicos y la globalización han sido procesos que han impulsado la transformación, adaptación y permanencia de las organizaciones en el mercado y, es la gestión de las personas las que determinan en gran medida la administración del cambio y los resultados favorables frente a este desafío. Sin embargo, el papel del talento humano para el logro de resultados de éxito en todo proceso de transformación organizacional se centra en aspectos de actitud, desempeño y competencia entre los cuales se encuentra la falta de visión de sus directivos, no generar equipos de trabajo efectivo o un clima de esfuerzo común frente a las estrategias y beneficio frente a los resultados, no establecer la importancia del proceso y el sentido de la urgencia sobre su implementación, no establecer los cambios en la cultura organizacional y no planear técnicas para contrarrestar la resistencia al cambio. 
Con base en este último la incertidumbre que todo cambio genera, las expectativas frente a efectos negativos y los problemas de comunicación que esto genera, se han constituido en posibles barreras que retardan o entorpecen el cambio. No obstante, existen empresas que han llevado a cabo estos procesos con éxito ya que han centrado su estrategia de cambio en el fortalecimiento, desarrollo y gestión de su capital humano, mediante el empoderamiento de procesos, manejan comunicaciones claras y transparentes, establecen objetivos y metas de cambio, permiten la participación de los colaboradores en la implementación y el fortalecimiento del cambio; así como emplea estrategias efectivas de gestión de personal que faciliten este proceso. De esta manera, el desarrollo organizacional está ligado con una administración y gestión efectiva de las personas, unido a implementaciones tecnológicas y crecimiento organizacional, de esta manera el propósito central de este estudio giró en torno a comprender cómo contribuyen los programas de capacitación y desarrollo del capital humano en la transformación organizacional, en un grupo de empresas de la ciudad de Bogotá, según la visión de sus líderes de Gestión Humana, identificando en primera instancia los procesos de cambio organizacional que han atravesado las empresas estudiadas en los últimos 5 años, describiendo cuales son los programas que a nivel de capacitación y desarrollo de competencias han implementado producto de estos procesos de cambio y analizar la contribución que los líderes de Talento Humano han detectado en la implementación de los mismos, como efecto en el impacto del cambio organizacional. 


\section{Metodología y presentación de resultados.}

\subsection{Metodología de trabajo.}

Para este trabajo se quiere crear un plan de fortalecimiento en el área del talento humano, utilizando mecanismos innovadores para la empresa CIC TRAVEL, la cual es una empresa que se encuentra en el campo turístico donde se caracterizan por ser un tour operador (viaje turístico que involucra distintos lugares representativos); dicha empresa se caracteriza por ser un mayorista que acumula más de 20 años de experiencia en el mundo turístico. En la actualidad se especializa en el segmento vacacional, viajes corporativos, grupos, incentivos, golf, ferias, congresos y Meeting Planning.

A partir de lo identificado en el área de talento humano de la empresa CIC TRAVEL, los posibles puntos positivos y negativos donde se pueda establecer mejoras innovadoras que permitan dicho fortalecimiento enfocando en la generación de conocimiento y retención del talento, se quiere crear un programa consolidado aplicable a la empresa, el cual se fundamenta en mecanismos innovadores que permitan el fortalecimiento de esta área.

Por lo tanto para empezar a establecer un acercamiento a los posibles problemas que cuenta la empresa, empezaremos a analizar los puntos claves como los problemas que afectan en general el área de talento humano, como también posibles puntos donde se pueda fortalecer con alternativas innovadoras; para esto se va a iniciar realizando un reconocimiento de la empresa con el fin de identificar las distintas funciones que se desarrollan el área de talento humano, con el fin de realizar un análisis descriptivo-exploratorio de cada una de las funciones del talento humano establecidas en la teoría que podemos ver aplicadas en la empresa CIC TRAVEL; luego con el fin de evaluar e identificar problemas y oportunidades 
de mejora se va a realizar una encuesta aplicada a 10 colaboradores de la empresa de diferentes áreas, donde se va a utilizar un método mixto (cualitativo - cuantitativo).

Para finalizar se va a utilizar un diagrama de causa efecto como también el diagrama del cómo - cómo, tomado de uno de los trabajos dirigido por docentes de la Facultad de Administración de Empresas, Universidad Santo Tomás Bogotá, Héctor Horacio Murcia Cabra, Jorge Aristizábal Escobar y Johanna Carolina Suárez Guzmán en su proyecto “Gestión y fortalecimiento empresarial con innovación” llevado a cabo en el grupo de investigación GAIA, teniendo en cuenta elementos que ellos plasman en dicho trabajo con la finalidad de identificar aspectos claves a mejorar o fortalecer.

\subsubsection{Muestra poblacional.}

Para la realización de este proyecto se tomó como muestra poblacional a los directores de las áreas de ventas, análisis de producto, contabilidad, talento humano y sistemas, al igual, a algunos colaboradores de dichas áreas, dando como resultado una muestra de 10 personas, lo cual indica que se puede definir como una muestra finita no probabilística por conveniencia.

\subsubsection{Herramienta metodológica.}

Para el desarrollo de este proyecto se utilizaron tres herramientas encaminadas en la identificación, priorización y mejora respectivamente; como primera herramienta se diseñó un cuestionario cerrado con múltiple respuesta (5 opciones de respuesta "bajo, suficiente, satisfactorio, alto y excelente") de treinta y siete factores (37) en la plataforma de Google form, la cual permitió la obtención de información clave para la identificación de aspectos de mejora o fortalecimiento, dicho cuestionario fue aplicado a los individuos seleccionados utilizando las mismas preguntas, siguiendo el mismo orden y el mismo espacio virtual; de 
tal manera, el grupo investigador reunió toda la información individual obteniendo datos colectivos (González, Calleja, López, Padrino, \& Puebla, 2009).

Como segunda herramienta se realizó un diagrama conocido como espina de pescado la cual resume los resultados de la encuesta, priorizando e identificando todas las funciones del talento humano en la empresa CIC TRAVEL, lo anterior da como resultado los factores que se deben mejorar o fortalecer, como tercera herramienta se utilizó el diagrama como - como donde se estableció el programa de mejora para la empresa CIC TRAVEL (Aristizábal Escobar Jorge, Murcia Cabra Héctor Horacio y Suárez Guzmán Johanna Carolina, 2013).

\subsubsection{Etapas del proyecto.}

El diseño metodológico comprendió el desarrollo sistemático de las siguientes etapas de conformidad con los objetivos trazados:

\subsubsection{Etapa 1: revisión de la literatura.}

En la primera etapa de la investigación se procedió a consultar diferentes bases de datos desde fuentes primarias y secundarias de información sobre el objeto de estudio, el cual fue el talento humano en las empresas, las funciones del talento humano, la innovación en el talento humano y el fortalecimiento empresarial en talento humano.

\subsubsection{Etapa 2: procedimiento.}

Para el desarrollo del presente proyecto se contó con el apoyo de la Gerencia de Talento Humano de la empresa CIC TRAVEL, quienes facilitaron al grupo que adelanto el proyecto la base de datos de los colaboradores de la empresa, facilitando la identificación del cargo, antigüedad dentro de la empresa y correo corporativo. 
Posteriormente al finalizar el diseño del cuestionario, fue enviado vía correo electrónico a través de Google form, solicitando a los colaboradores seleccionados su colaboración para el diligenciamiento del mismo.

\subsubsection{Etapa 3: Presentación de resultados.}

Durante esta etapa el grupo desarrollador del proyecto procedió a sistematizar los resultados obtenidos en las etapas anteriores presentando resultados cuantitativos y cualitativos realizados en el cuestionario para después realizar el diagrama de espina de pescado y “como- como” (Aristizábal Escobar Jorge, Murcia Cabra Héctor Horacio y Suárez guzmán Johanna Carolina, 2013) para el diseño del plan de fortalecimiento y mejora.

\subsubsection{Etapa 4: análisis y discusión de los resultados.}

A partir del desarrollo de las etapas anteriores, el grupo del proyecto realizó el análisis cualitativo-descriptivo de los resultados obtenidos en las etapas anteriores como también un análisis del resultado del plan de mejora después de un mes de aplicabilidad en la empresa CIC TRAVEL.

\subsubsection{Etapa 5: conclusión y propuestas}

Se elaboraron las conclusiones pertinentes para el desarrollo del proyecto y se dio paso a la propuesta de estrategias administrativas de acuerdo con los objetivos propuestos. 


\subsection{Presentación de resultados.}

\subsubsection{Metodología.}

De acuerdo con Hernández, Fernández, y Baptista, (2014), la presente investigación sigue los lineamientos del enfoque cualitativo dado que "utiliza la recolección y análisis de los datos para afinar las preguntas de investigación o revelar nuevas interrogantes en el proceso de interpretación "encontrando la dispersión o expansión de los datos, desde un análisis descriptivo-exploratorio mixto (cualitativo-cuantitativo) a partir de la revisión de la literatura teniendo en cuenta la aplicación de una encuesta como herramienta metodológica para la obtención de información referente al área de Talento Humano en la empresa CIC TRAVEL.

\subsubsection{Muestra poblacional}

Para esta investigación se tomó como muestra poblacional 10 personas cuyos cargos son directivos, definiéndose una muestra finita no probabilística por conveniencia.

\subsubsection{Herramienta metodológica}

Se trabajó en el diseño de la encuesta tratándose de un cuestionario de treinta y siete (37) preguntas con cinco (5) opciones de respuesta siguiendo una escala Likert, estas encuestas fueron enviadas por correo con una breve introducción para poner a los directivos en contexto, para que ellos respondan a conciencia como evidencia el área de talento humano en los siguientes 14 factores (establecidos por Luz Janeth Lozano (2018)), plasmados en la encuesta:

- Bienestar Social.

- Capacitación.

- Compensación.

- Contratación. 
- Entrenamiento.

- Estructuración del plan de gestión humana.

- Evaluación de desarrollo.

- Implementación y seguimiento plan estratégico G.H.

- Inducción.

- Manejo laboral.

- Promoción.

- Reclutamiento.

- Salud ocupacional.

- Selección.

\subsubsection{Presentación de Resultados.}

A continuación, se presentan los resultados obtenidos precisando así el nivel de innovación y fortalecimiento empresarial del área de talento humano a través de un análisis descriptivo para proponer estrategias administrativas innovadoras relacionadas directamente con el objeto de estudio.

\subsubsection{Caracterización de la población}

\subsection{Bienestar Social}

Los resultados obtenidos frente a la percepción del desarrollo y seguimiento de los programas de Bienestar Social muestran que el $40 \%$ de los colaboradores siente que es excelente, mientras que el $50 \%$ dice que es alto, y el $10 \%$ muestra que es satisfactorio, en este caso la opción bajo y suficiente no registró ningún valor (Gráfica 1). 


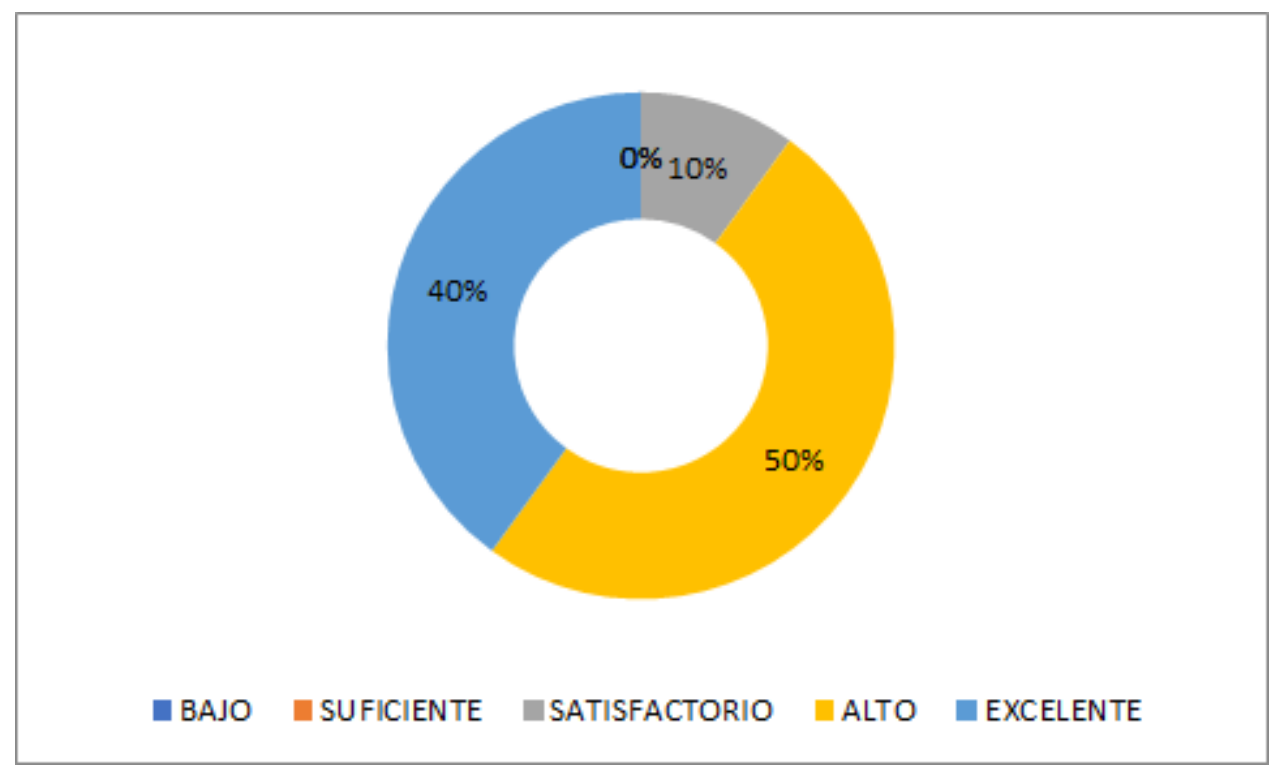

Gráfica 1: Resultados desarrollo y seguimiento de los programas de Bienestar Social.

Respecto a la aplicación de mecanismos de comunicación para dar a conocer a los empleados los programas de bienestar social, se obtuvo que el $30 \%$ de los colaboradores dice que es excelente, el $40 \%$ siente que es alto, y el $30 \%$ responde que es satisfactorio, en este caso la opción bajo y suficiente no registró ningún valor (Gráfica 2).

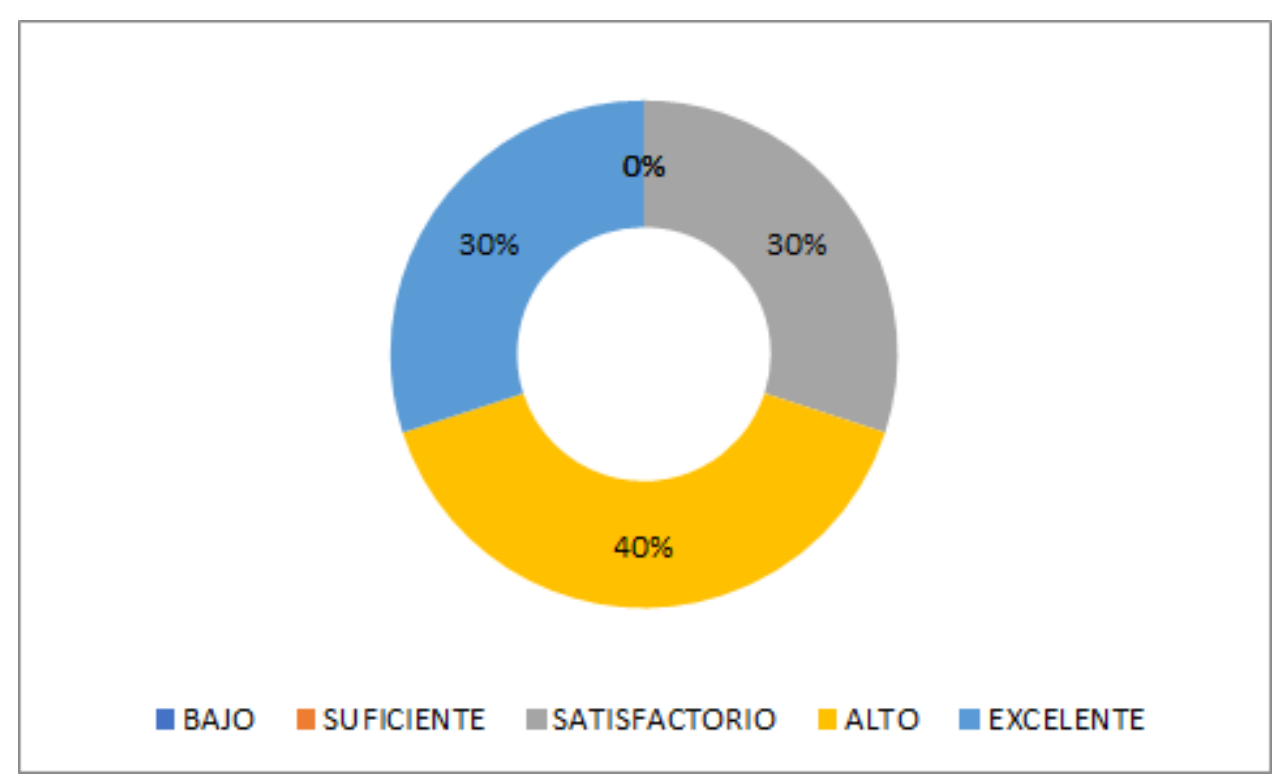

Gráfica 2: Resultados de la aplicación de mecanismos de comunicación para dar a conocer a los empleados los programas de bienestar. 
De acuerdo con los resultados obtenidos con los programas que generan un ambiente que propicie la colaboración y voluntad del colaborador, se evidencian con indicadores en todas las áreas o procesos, el 60\% de las personas dice que es excelente, el 30\% argumenta que es alto, y el $10 \%$ responde que es satisfactorio, en este caso la opción bajo y suficiente no registró ningún valor (Gráfica 3).

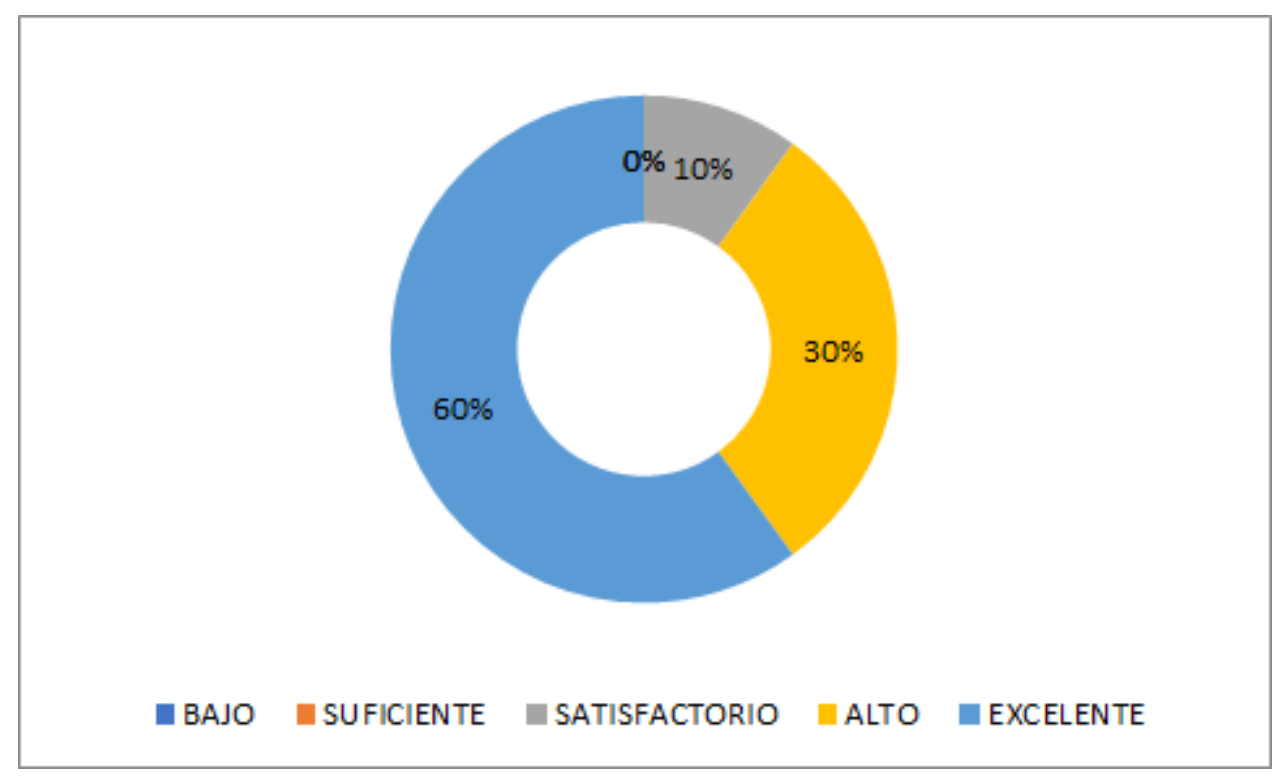

Gráfica 3: Resultados de los programas que generan un ambiente que propicie la colaboración y voluntad del colaborador, se evidencian con indicadores en todas las áreas o procesos.

Se evidencian en toda la empresa estadísticas que reflejen el aumento de la productividad, disminución de ausentismo y accidentes de trabajo, como consecuencia de la implementación y ejecución de programas de bienestar, el $40 \%$ de los colaboradores contestaron que es excelente, el $20 \%$ respondió que es alto, el $30 \%$ dice que es satisfactorio y el $10 \%$ afirma que es suficiente, en este caso la opción bajo no registró ningún valor (Gráfica 4). 


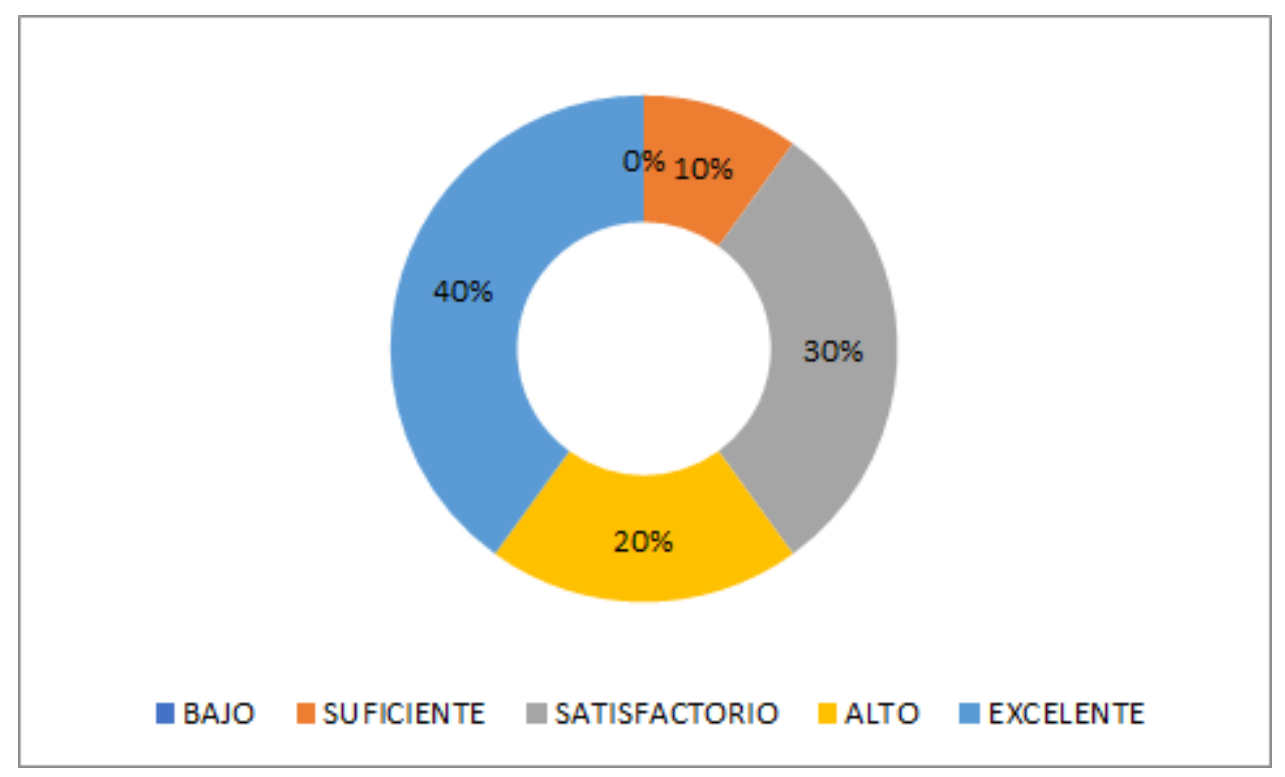

Gráfica 4: Resultados sobre las estadísticas que reflejen el aumento de la productividad, disminución de ausentismo y accidentes de trabajo, como consecuencia de la implementación y ejecución de programas de bienestar.

\subsection{Capacitación}

En la empresa CIC TRAVEL la capacitación se desarrolla sobre criterios claros conocidos y utilizados por todas las áreas de la organización, el 40\% de los colaboradores dice que es excelente, el 10\% respondió que es alto, el 30\% argumenta que es satisfactorio, el $10 \%$ contestó que es suficiente, en este caso la opción bajo no registró ningún valor (Gráfica 5).

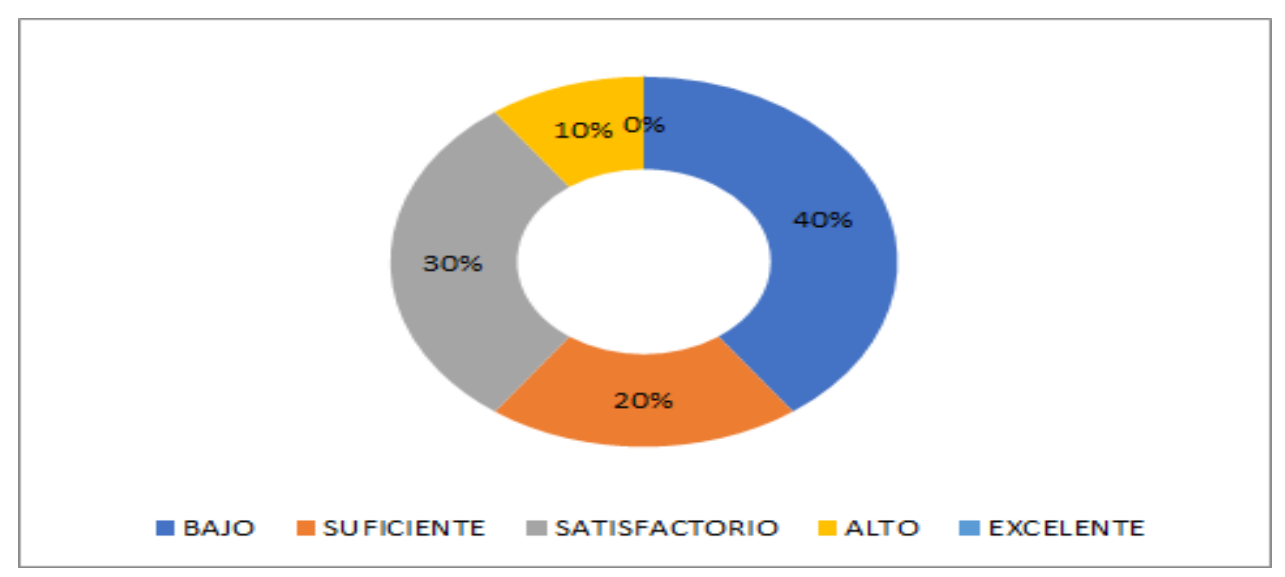

Gráfica 5: Resultados sobre la capacitación se desarrolla sobre criterios claros conocidos y utilizados por todas las áreas de la organización. 
De acuerdo a los programas de capacitación se desarrollan permanentemente y son aprovechados por los colaboradores de la organización, el 10\% de los colaboradores dice que es excelente, el $30 \%$ argumenta que es el 10\%, mientras que el 10\% respondió que es satisfactorio, pero el $40 \%$ aclara que es bajo (Gráfica 6).

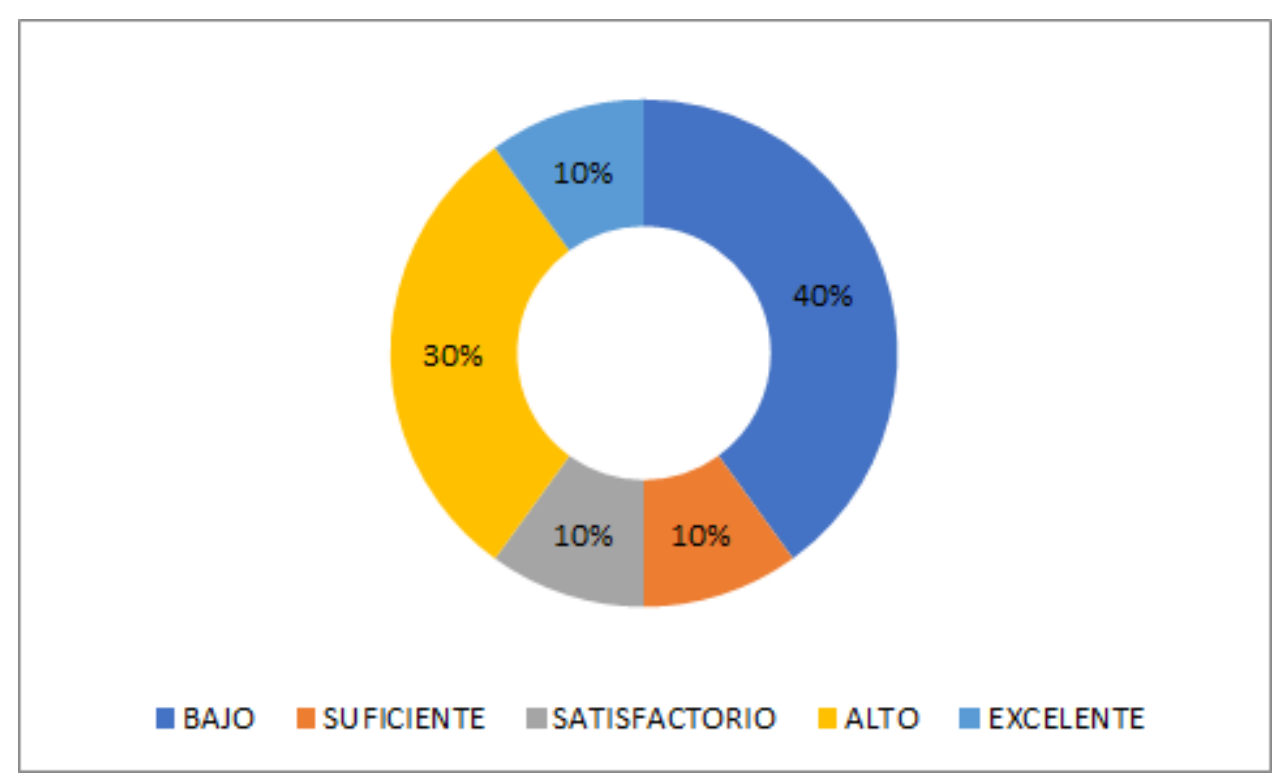

Gráfica 6: Resultados sobre los programas de capacitación se desarrollan permanentemente y son aprovechados por los trabajadores de la organización.

Los colaboradores respondieron sobre si se evidencian los logros en los funcionarios capacitados y la aplicación de los conceptos adquiridos en su labor diaria, operativa o técnica en todas las áreas o procesos, el $20 \%$ respondió que es alto, el $40 \%$ de dijo que es satisfactorio, el 10\% argumento, que el 30\% decidió el bajo, en este caso la opción excelente no registró ningún valor (Gráfica 7). 


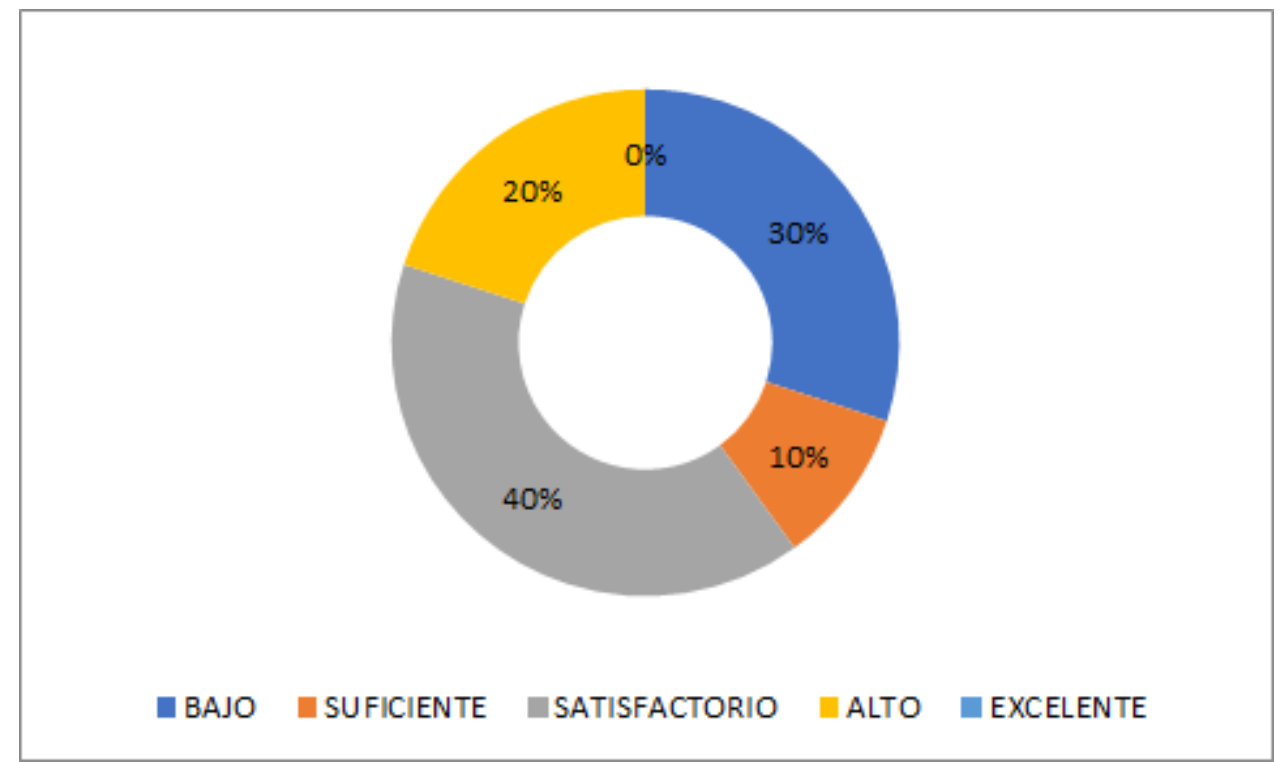

Gráfica 7: Resultados sobre la evidencia de los logros en los funcionarios capacitados y la aplicación de los conceptos adquiridos en su labor diaria, operativa o técnica en todas las áreas o procesos.

Respecto a la realización y mejoramiento e innovación de los programas de capacitación en todas las áreas y/o procesos de la empresa, el 20\% de los colaboradores dice que es alto, el $40 \%$ contestó que es satisfactorio, y el 30\% respondió que es suficiente, y el 10\% dijo que es bajo, en este caso la opción excelente no registró ningún valor (Gráfica 8).

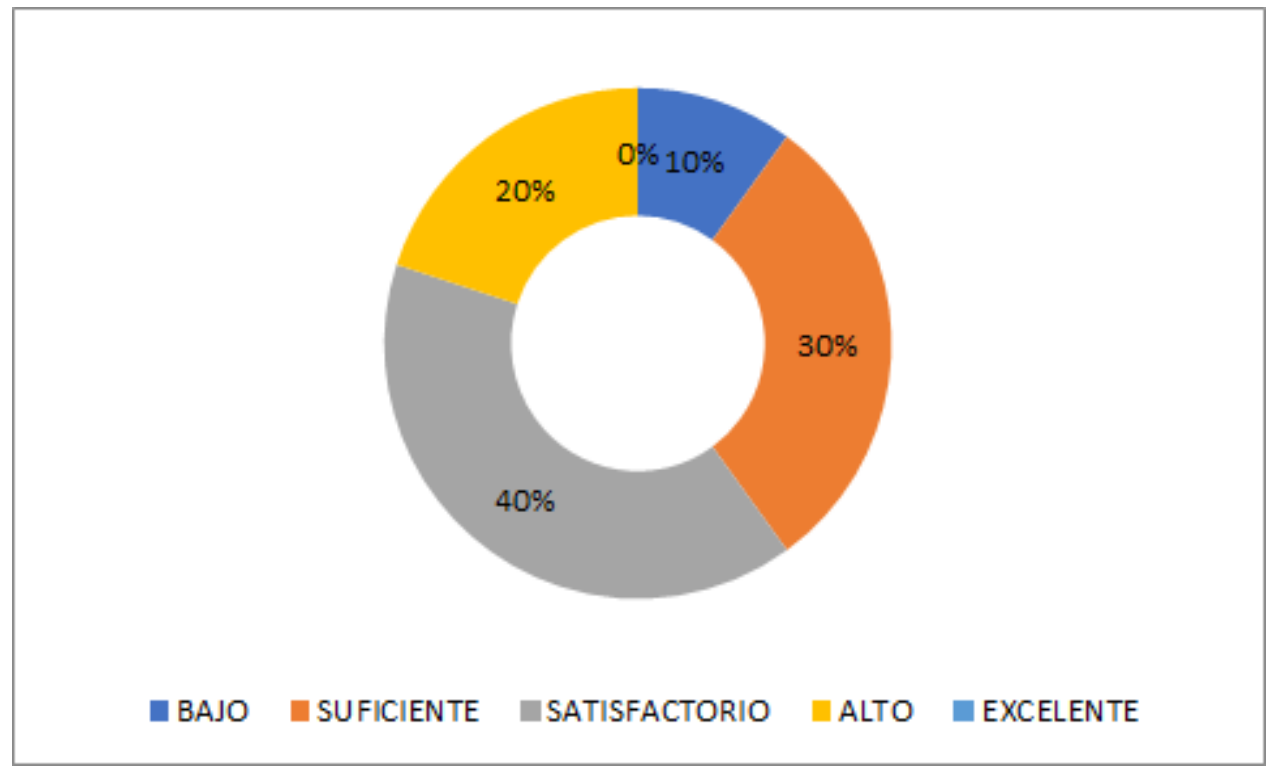

Gráfica 8: Resultados sobre la realización del mejoramiento e innovación de los programas de capacitación en todas las áreas y/o procesos de la empresa. 


\subsection{Compensación}

De acuerdo con el sistema de pago de nómina funciona de manera óptima y con la última tecnología en el sector, el $40 \%$ dice que es excelente, el $40 \%$ respondió que es alto, y el 20\% argumento que es satisfactorio, en este caso la opción excelente no registró ningún valor (Gráfica 9).

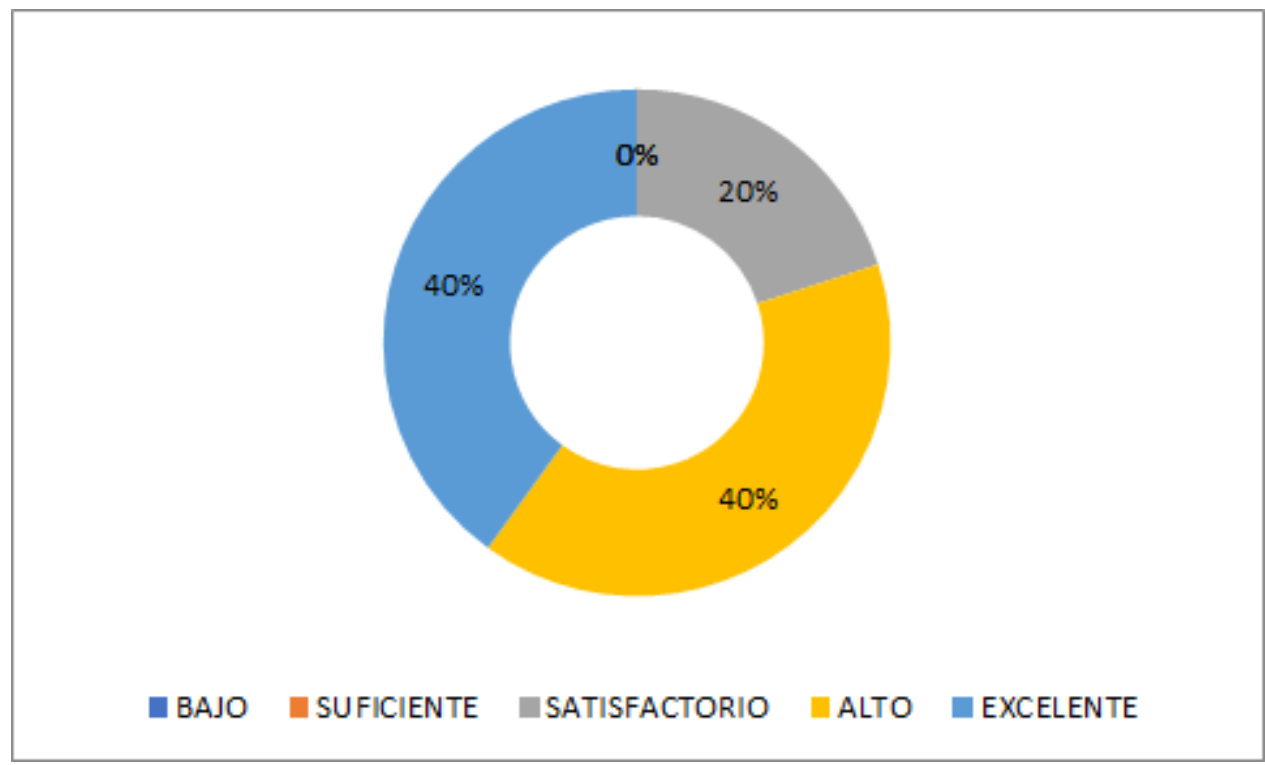

Gráfica 9: Resultados sobre el sistema de pago de nómina funciona de manera óptima y con la última tecnología en el sector.

La aplicación de criterios con equidad para determinar el salario asignado a un puesto de trabajo, la periodicidad de su reajuste y las políticas salariales, el $40 \%$ de los colaboradores respondió excelente, el $30 \%$ dijo que es alto, el 10\% contestó que es satisfactorio y el $20 \%$ dijo que es suficiente, en este caso la opción bajo no registró ningún valor (Gráfica 10). 


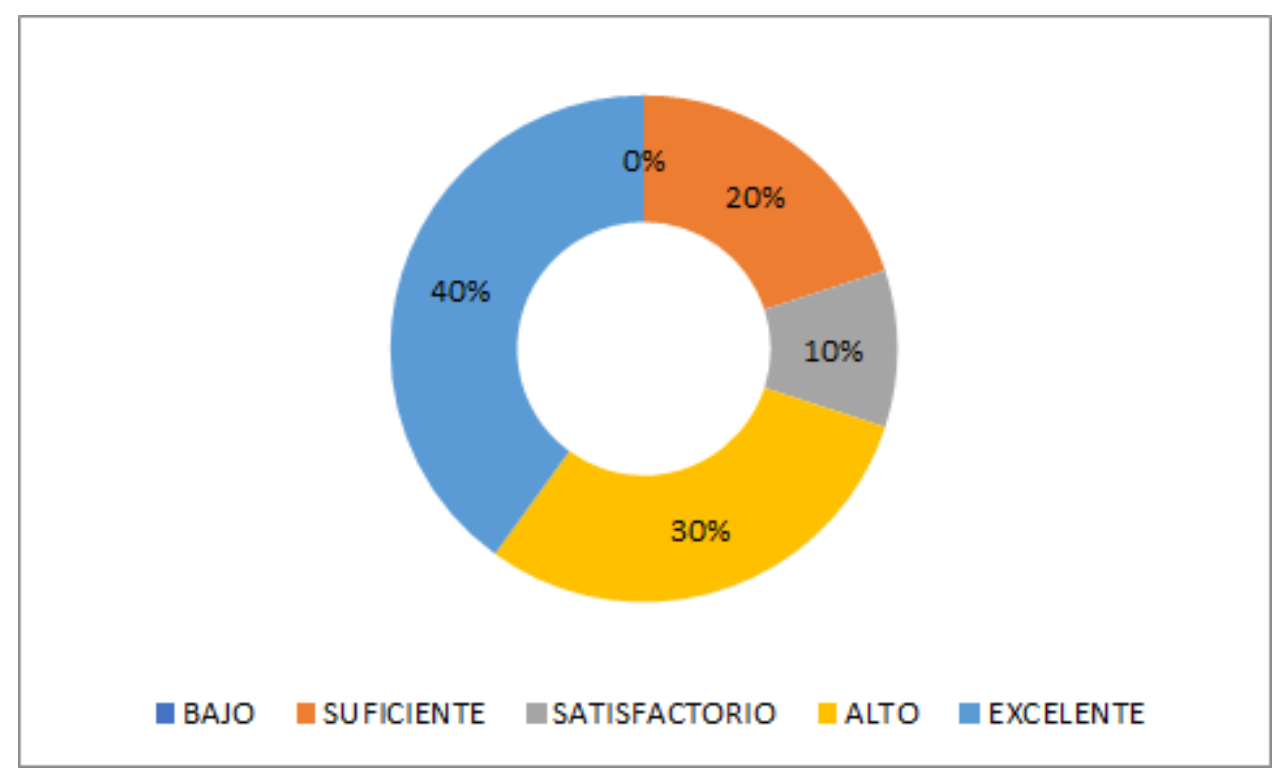

Gráfica 10: Resultados sobre la aplicación de criterios con equidad para determinar el salario asignado a un puesto de trabajo, la periodicidad de su reajuste y las políticas salariales.

Respecto a la aplicación de indicadores de gestión para determinar la escala salarial frente a su industria, el 10\% de los colaboradores dijeron que es excelente, el $80 \%$ respondió que es alto, mientras que el último $10 \%$ argumenta que es satisfactorio, en este caso la opción bajo y suficiente no registró ningún valor (Gráfica 11).

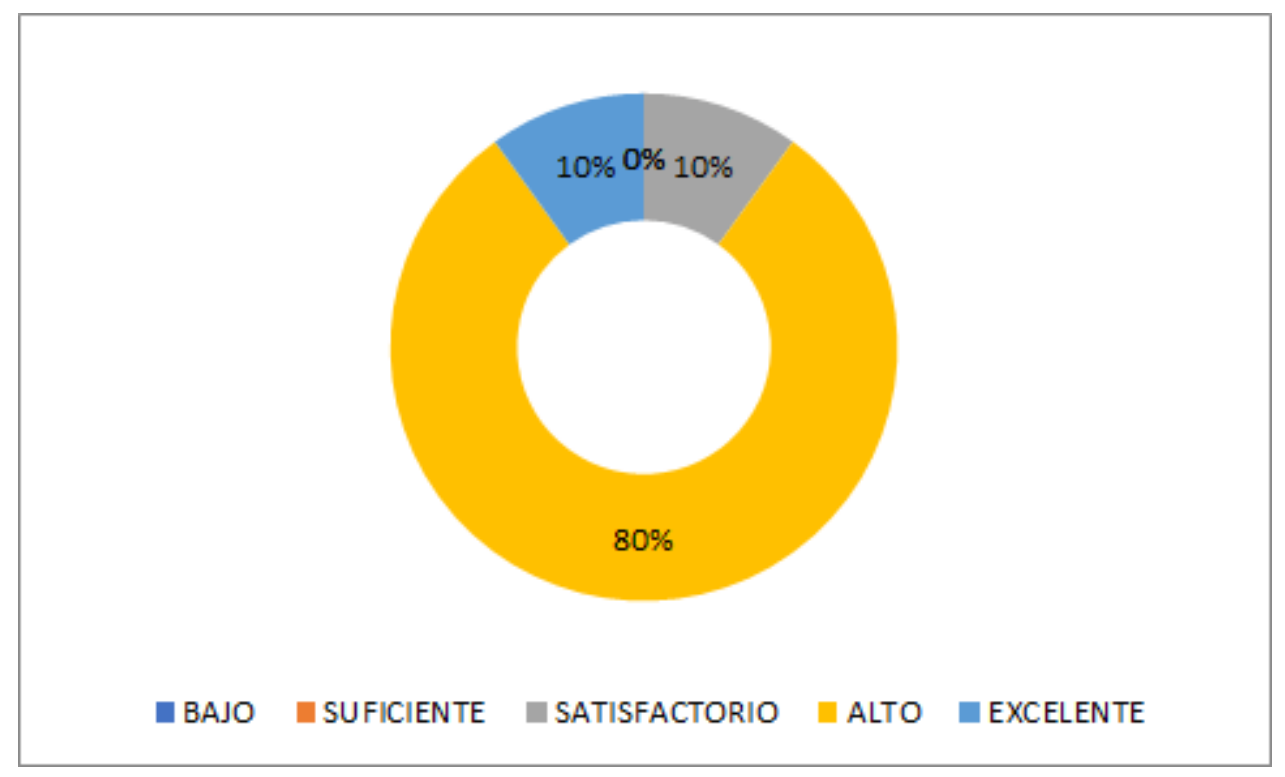

Gráfica 11: Resultados sobre la aplicación de indicadores de gestión para determinar la escala salarial frente a su industria. 


\subsection{Contratación}

Los resultados para las fuentes internas o externas de consulta en la elaboración de los contratos laborales son: el $10 \%$ de los colaboradores dijo que es excelente, el $50 \%$ respondió que es alto y el $40 \%$ siente que es satisfactorio, en este caso la opción bajo y suficiente no registró ningún valor (Gráfica 12).

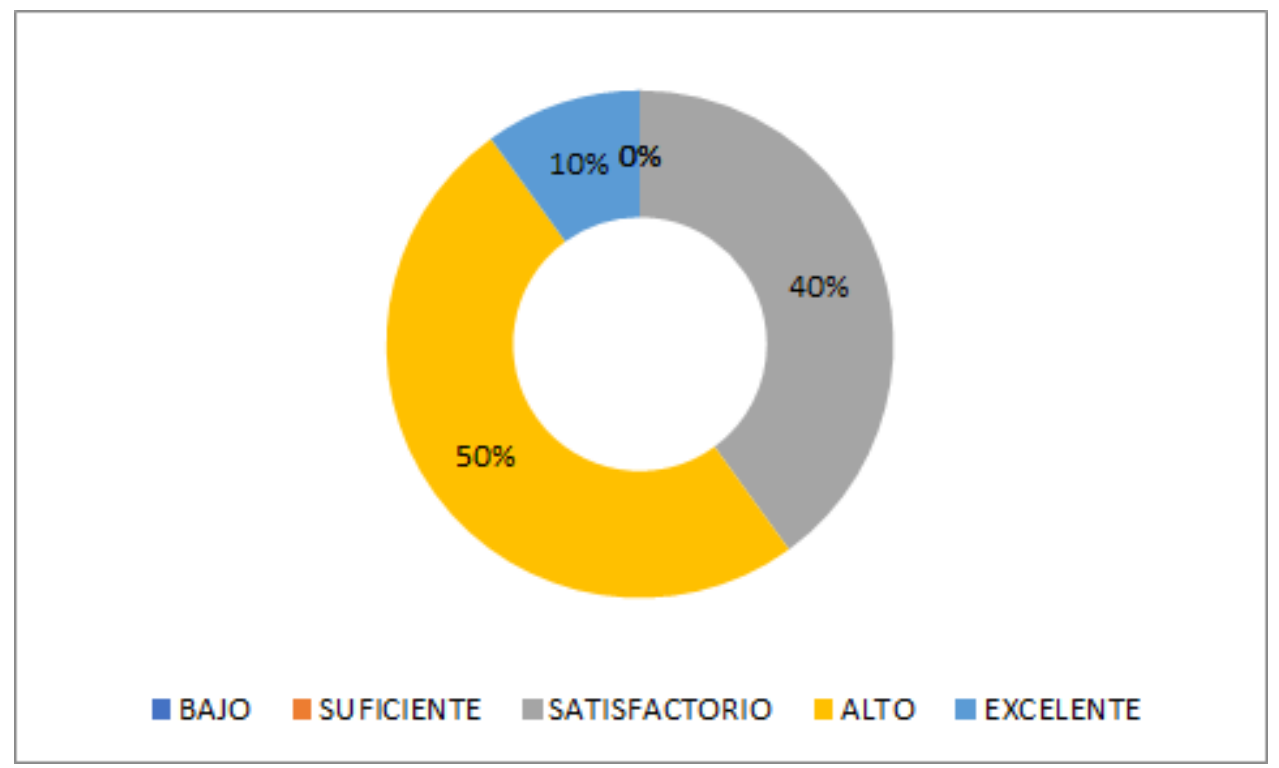

Gráfica 12: Resultados sobre las fuentes internas o externas de consulta en la elaboración de los contratos laborales.

De acuerdo con las políticas de contratación el 10\% de los colaboradores respondió que es excelente, el $50 \%$ contesto que es alto, mientras que el $20 \%$ dijo que es satisfactorio y el $10 \%$ siente que es suficiente, pero el $10 \%$ piensa que es bajo (Gráfica 13). 


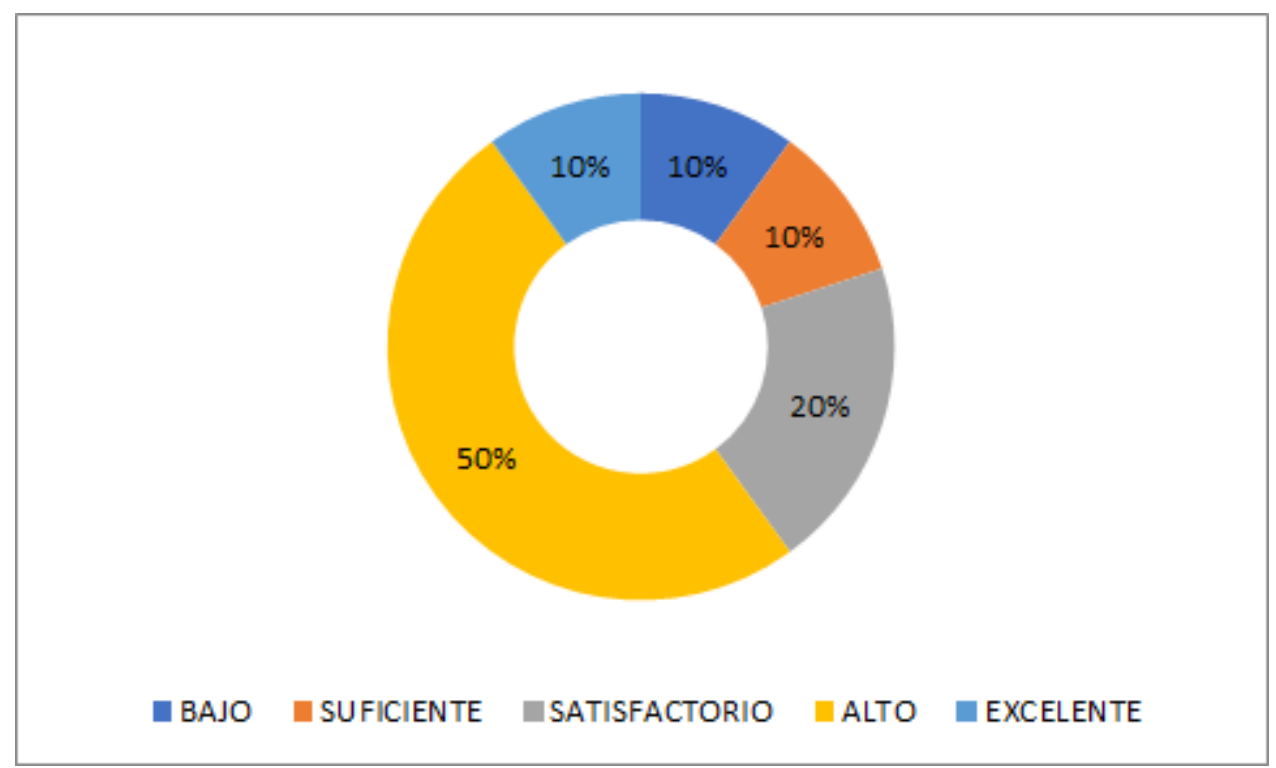

Gráfica 13: Resultados sobre las políticas de contratación.

Con la utilización permanentemente de modelos de contrato, el 30\% de los colaboradores respondió que es alto, el $50 \%$ contestó que es satisfactorio y el $20 \%$ argumento que es suficiente, en este caso la opción bajo y excelente no registró ningún valor (Gráfica 14).

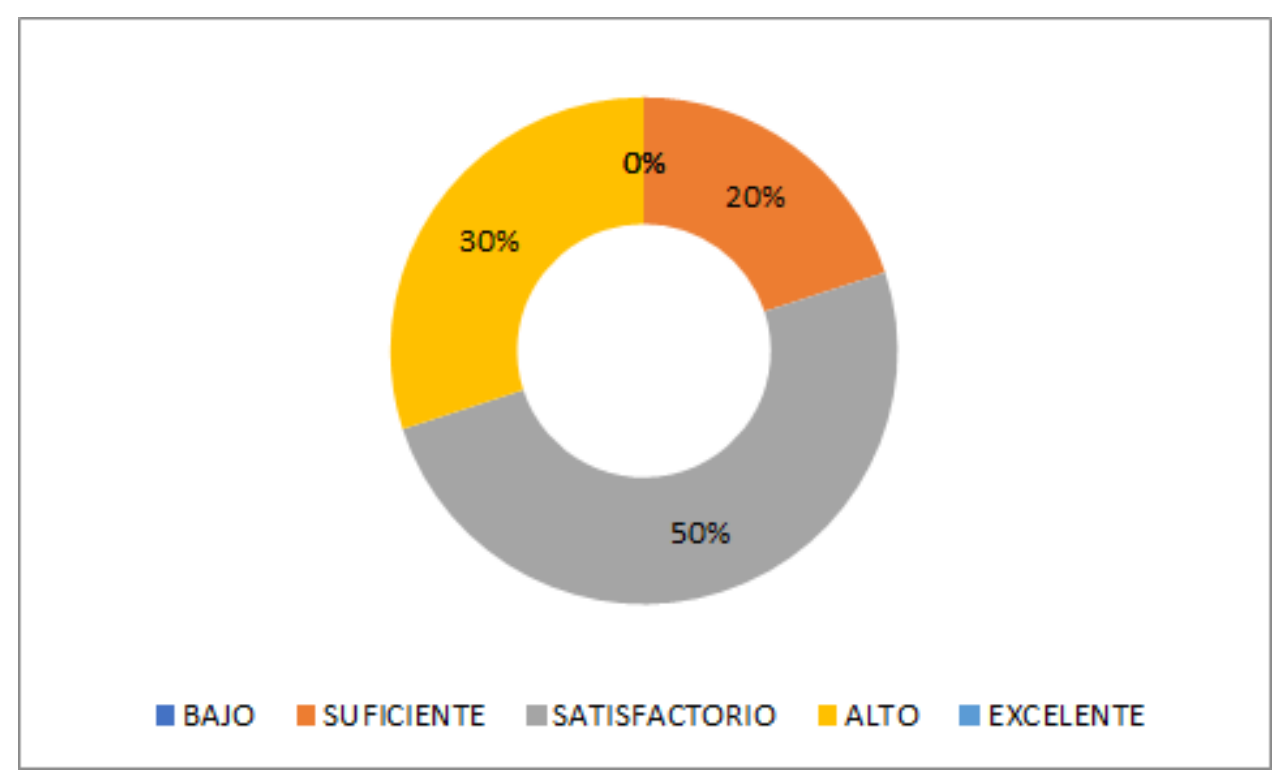

Gráfica 14: Resultados sobre la utilización permanentemente de modelos de contrato. 


\subsection{Entrenamiento}

Respecto a la aplicación de los criterios que evalúan el desarrollo del empleado en su labor diaria, el $20 \%$ de los colaboradores argumento que es alto, el $40 \%$ dijo que es satisfactorio, mientras que el 30\% respondió que es suficiente, y el 10\% dijo que es bajo, en este caso la opción excelente no registró ningún valor (Gráfica 15).

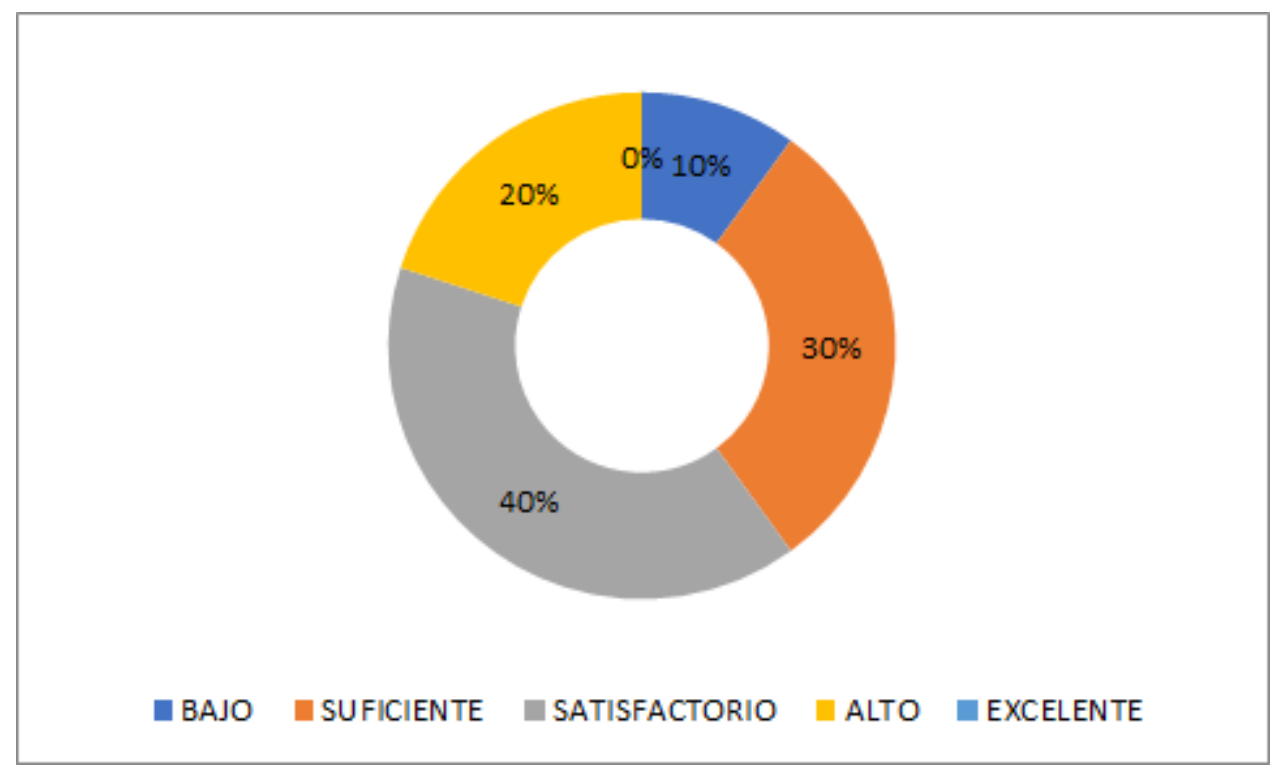

Gráfica 15: Resultados sobre la aplicación de los criterios que evalúan el desarrollo del empleado en su labor diaria.

Los logros obtenidos en la aplicación del proceso de entrenamiento en los funcionarios, tanto en el ámbito administrativo como operativo o técnico, se evidencian por medio de indicadores en todas las áreas o procesos, de acuerdo con lo anterior el $10 \%$ de los colaboradores argumentaron que es excelente, el $20 \%$ siente que es alto, mientras que $50 \%$ respondió que es satisfactorio y el $20 \%$ contestó que es suficiente, en este caso la opción bajo no registró ningún valor (Gráfica 16). 


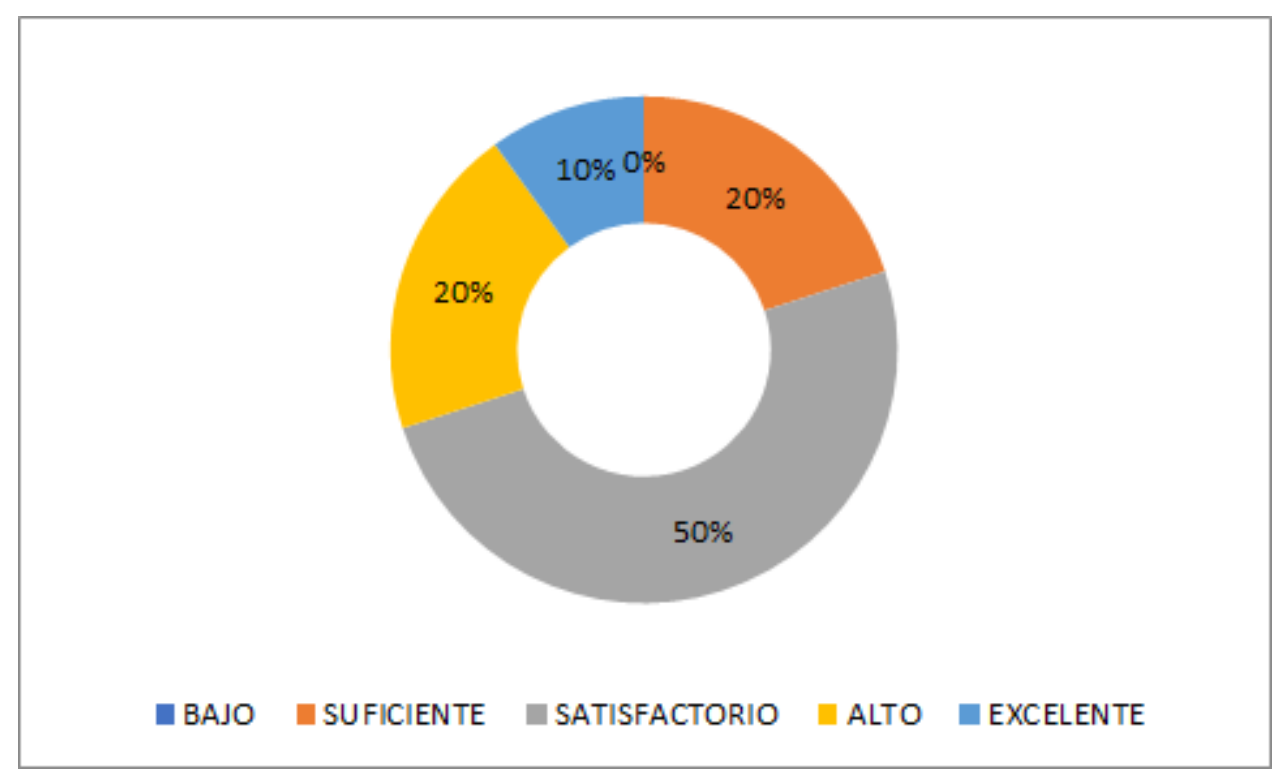

Gráfica 16: Resultados sobre los logros obtenidos en la aplicación del proceso de entrenamiento en los funcionarios, tanto en el ámbito administrativo como operativo o técnico, se evidencian por medio de indicadores en todas las áreas o procesos.

\subsection{Estructuración del plan de gestión humana.}

Respecto al plan estratégico de gestión humana está alineado totalmente al direccionamiento estratégico de la empresa, el 10\% de los colaboradores respondió que es excelente, el $40 \%$ dijo que es alto y el $50 \%$ contestó que es satisfactorio, en este caso la opción bajo y suficiente no registró ningún valor (Gráfica 17).

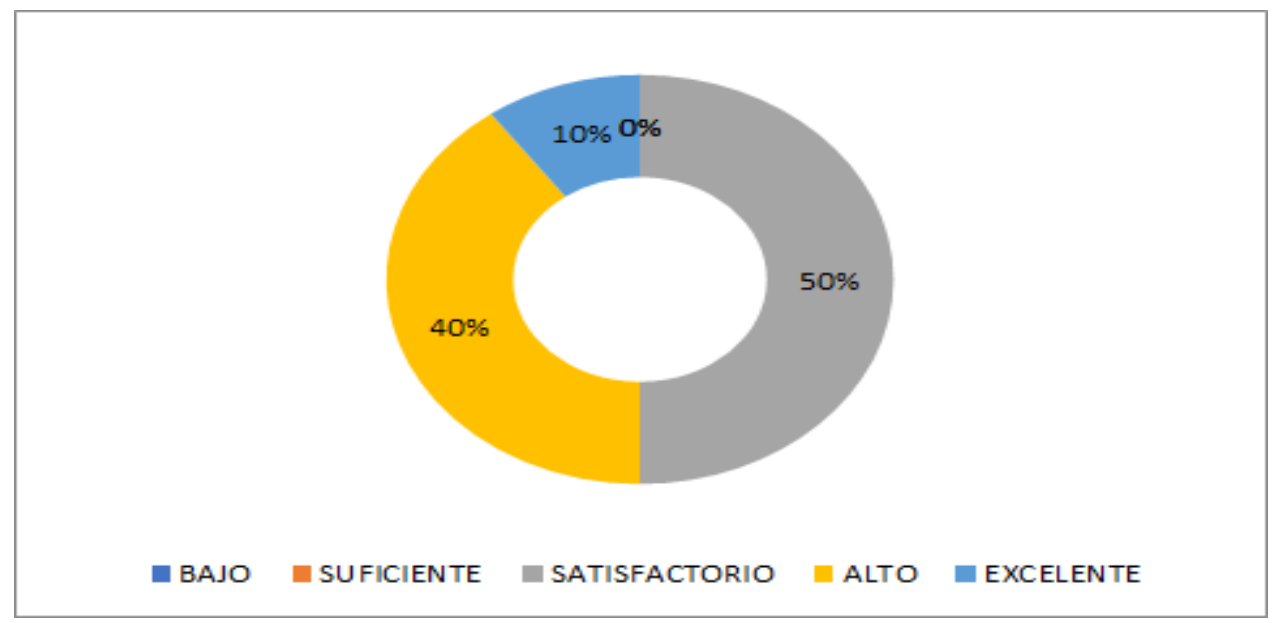

Gráfica 17: Resultados sobre el plan estratégico de gestión humana está alineado totalmente al direccionamiento estratégico de la empresa. 
Respecto a la misión, políticas, metas y estrategias de gestión humana, son conocidas y se están trabajando uniformemente en toda la empresa, el 10\% dijo que es alto, 40\% respondió que es satisfactorio y el 50\% argumentó que es suficiente, en este caso la opción bajo y excelente no registró ningún valor (Gráfica 18).

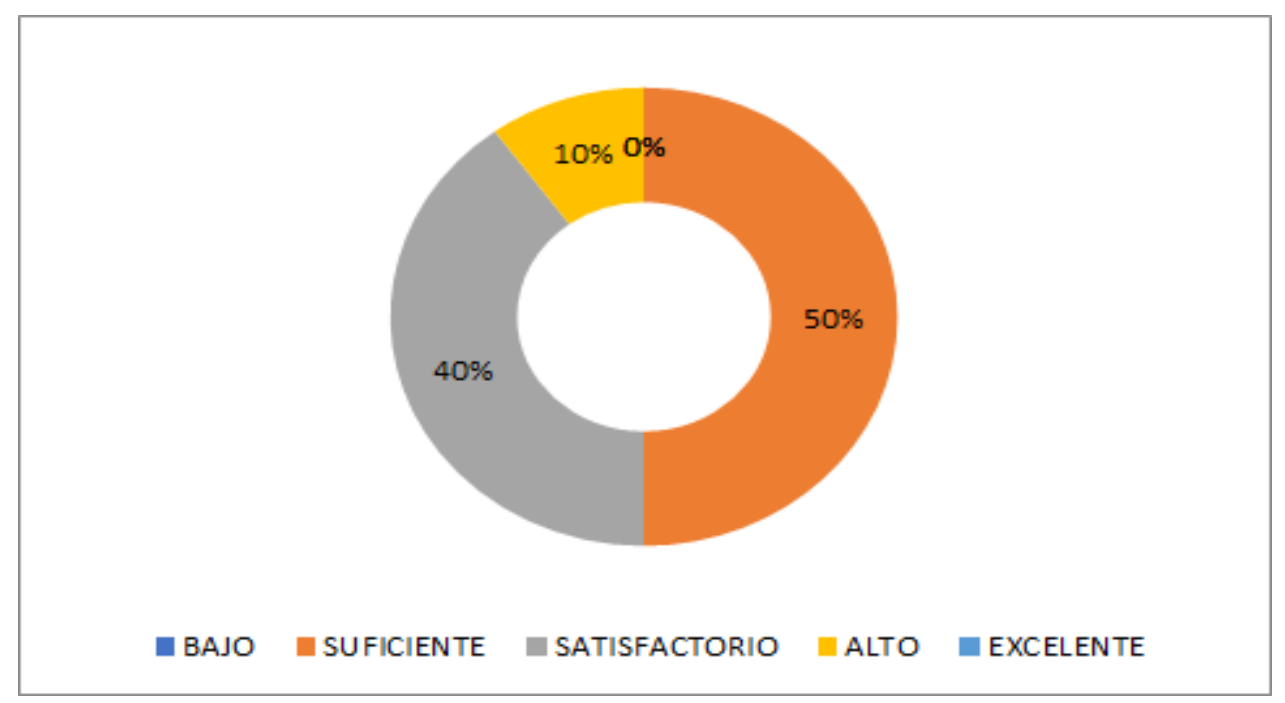

Gráfica 18: Resultados en cuanto la misión, políticas, metas y estrategias de gestión humana, son conocidas y se están trabajando uniformemente en toda la empresa.

\subsection{Evaluación de desarrollo.}

De acuerdo con la aplicación de un proceso de valoración y méritos que revela necesidades de mejoramiento en los colaboradores funciona de manera óptima, el 30\% respondió que es excelente, el $40 \%$ decidió que es alto, el 20\% dijo que es satisfactorio y el $10 \%$ contestó que es suficiente, en este caso la opción bajo no registró ningún valor (Gráfica 19). 


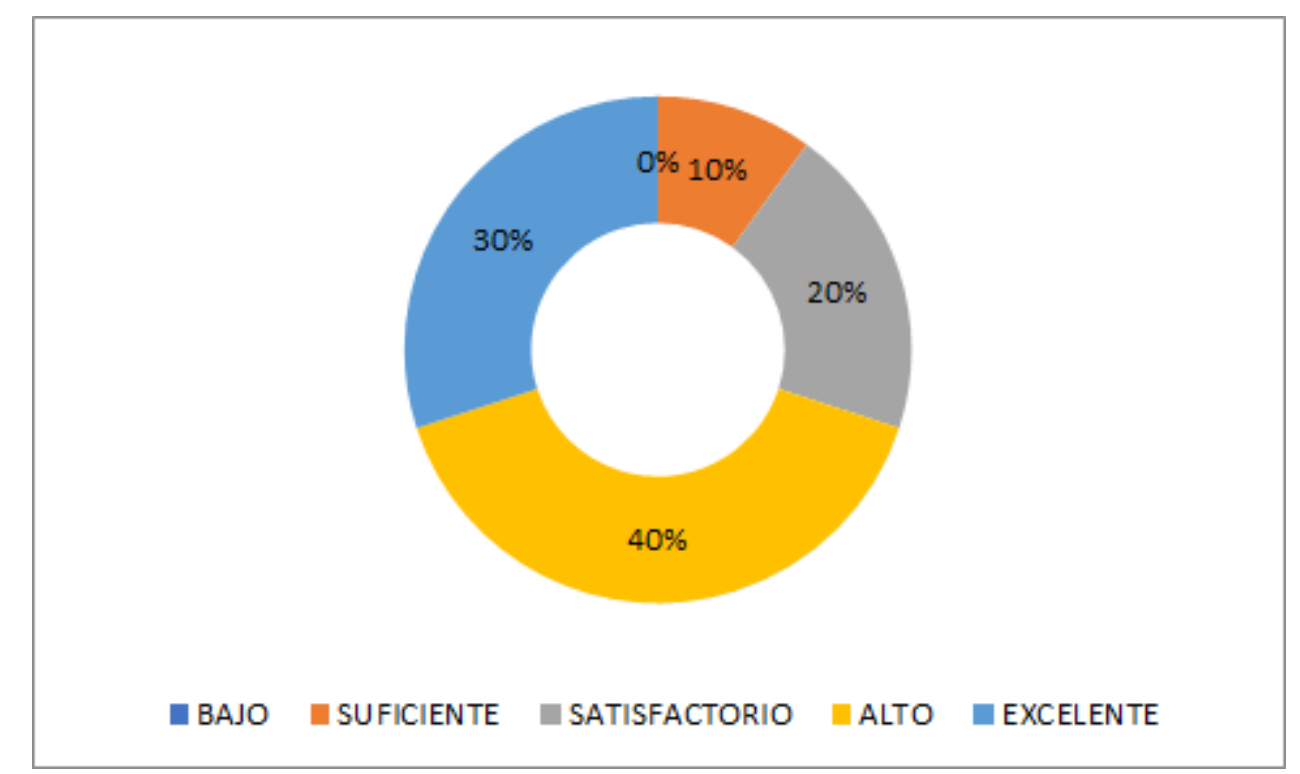

Gráfica 19: Resultados en cuanto la aplicación de un proceso de valoración y méritos que revela necesidades de mejoramiento en los trabajadores funciona de manera óptima.

En la empresa CIC TRAVEL se maneja un sistema de evaluación de desempeño con objetivos y factores significativos para cada cargo, proceso o área de trabajo, el $20 \%$ de los colaboradores decidieron que es excelente, el 30\% contestó que es alto, mientras que el 30\% dijo que es satisfactorio y el $20 \%$ afirmó que es suficiente, en este caso la opción bajo no registró ningún valor (Gráfica 20).

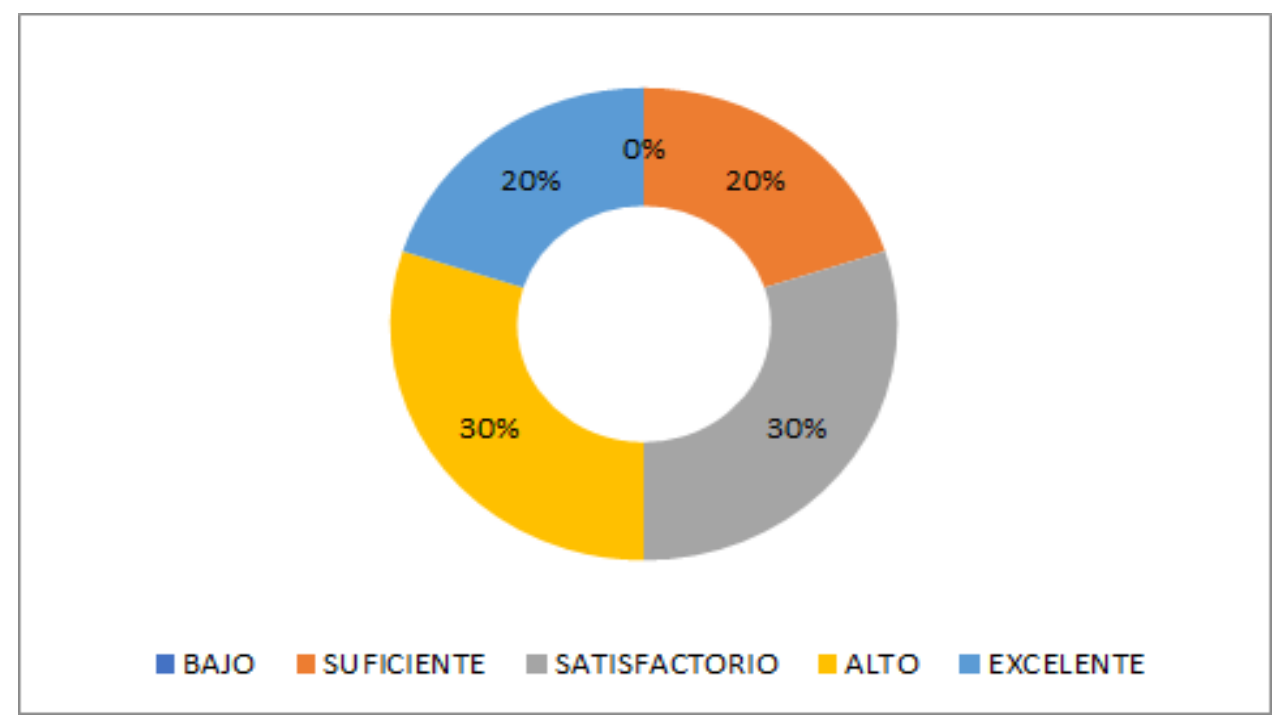

Gráfica 20: Resultados sobre un sistema de evaluación de desempeño con objetivos y factores significativos para cada cargo, proceso o área de trabajo. 


\subsection{Implementación y seguimiento plan estratégico G.H.}

Respecto al plan de gestión humana que se evalúa permanentemente en toda la empresa, el 20\% contestó que es alto, el 10\% dijo que es satisfactorio, el 10\% respondió que es suficiente, pero el $60 \%$ afirmó que es bajo, en este caso la opción excelente no registró ningún valor (Gráfica 21).

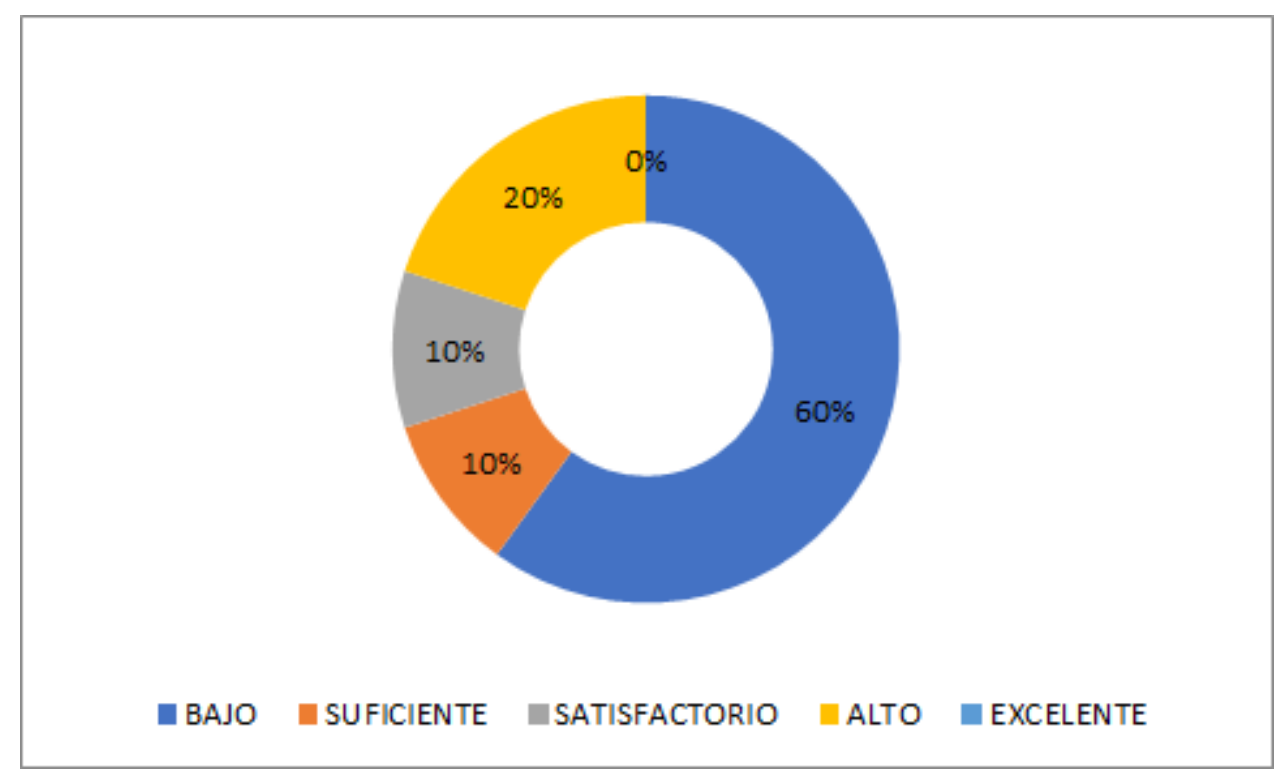

Gráfica 21: Resultados sobre el plan de gestión humana que se evalúa permanentemente en toda la empresa.

De acuerdo a la ejecución del plan de gestión humana está integrado a otras áreas de la empresa, el 10\% contestó que es alto, el 10\% dijo que es satisfactorio, el 20\% respondió que es suficiente, pero el $60 \%$ afirmó que es bajo, en este caso la opción excelente no registró ningún valor (Gráfica 22). 


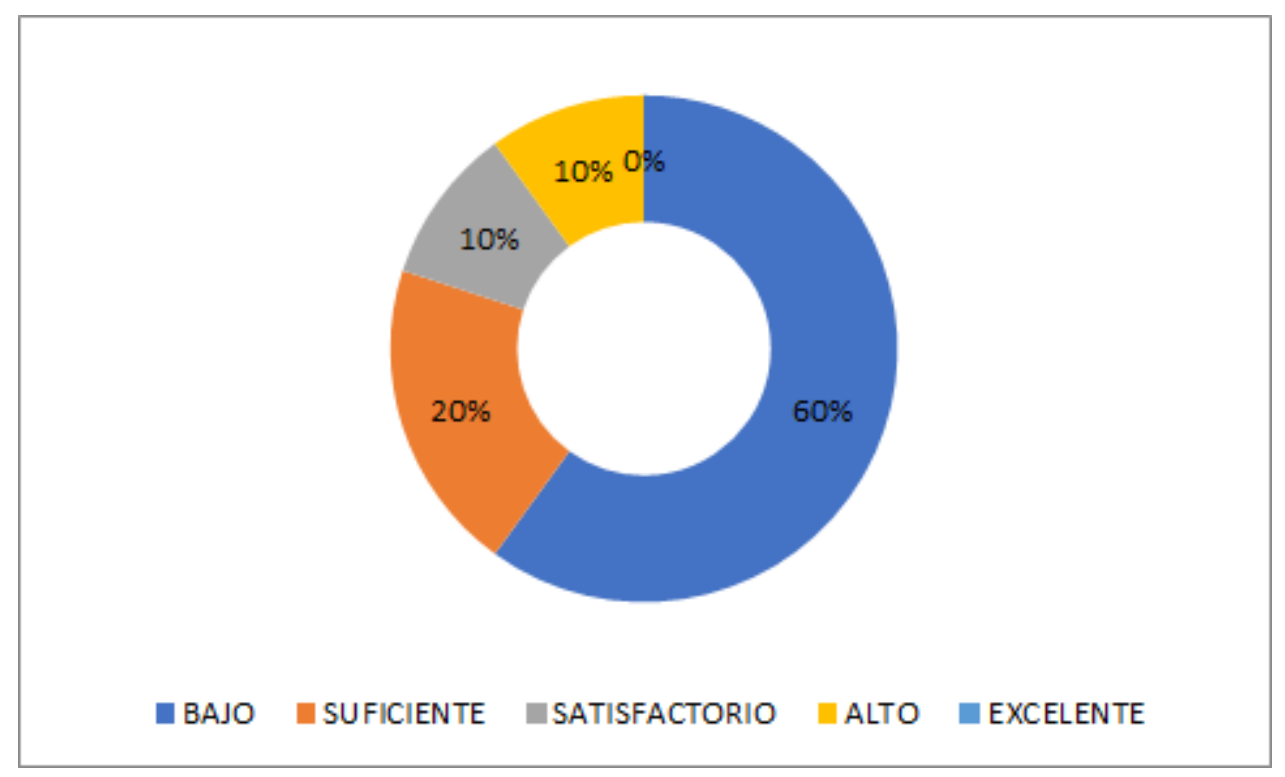

Gráfica 22: Resultados sobre la ejecución del plan de gestión humana integrado a las otras áreas de la empresa.

\subsection{Inducción}

En la empresa CIC TRAVEL se utilizan permanentemente mecanismos para informar al nuevo empleado aspectos básicos como: Historia, evolución y objetivos, Organigrama, Reglamento de Trabajo, Funciones y relaciones de coordinación con otras dependencias de la empresa, de acuerdo con lo anterior el 10\% contestó que es alto, mientras que el $80 \%$ dijo que es satisfactorio, $10 \%$ respondió que es bajo, en este caso la opción excelente y suficiente no registró ningún valor (Gráfica 23). 


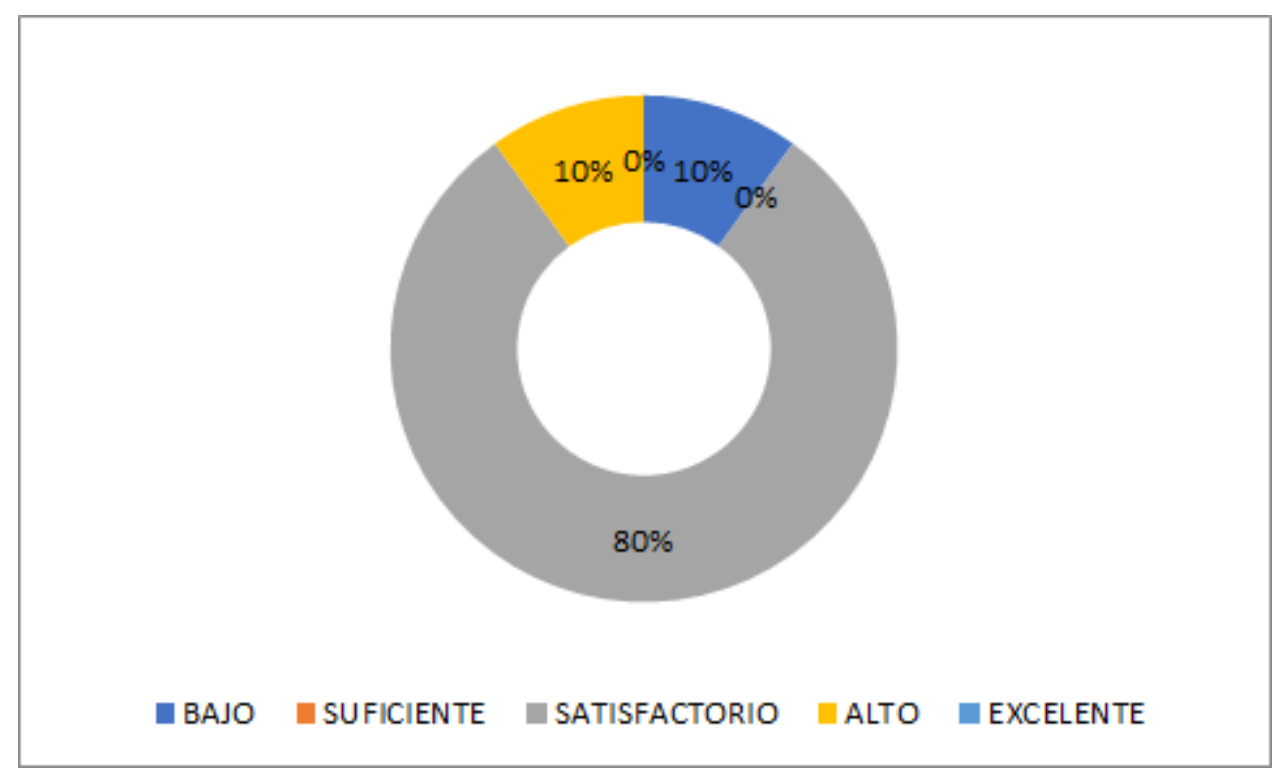

Gráfica 23: Resultados sobre mecanismos para informar al nuevo empleado aspectos básicos de la empresa.

Respecto a utilización de mecanismos para promover y medir la adaptación de un (a) colaborador (a) nuevo (a), el 10\% dijo que es alto, el 60\% respondió que es satisfactorio, mientras el $20 \%$ siente que es suficiente, y el $10 \%$ argumenta que es bajo, en este caso la opción excelente no registró ningún valor (Gráfica 24).

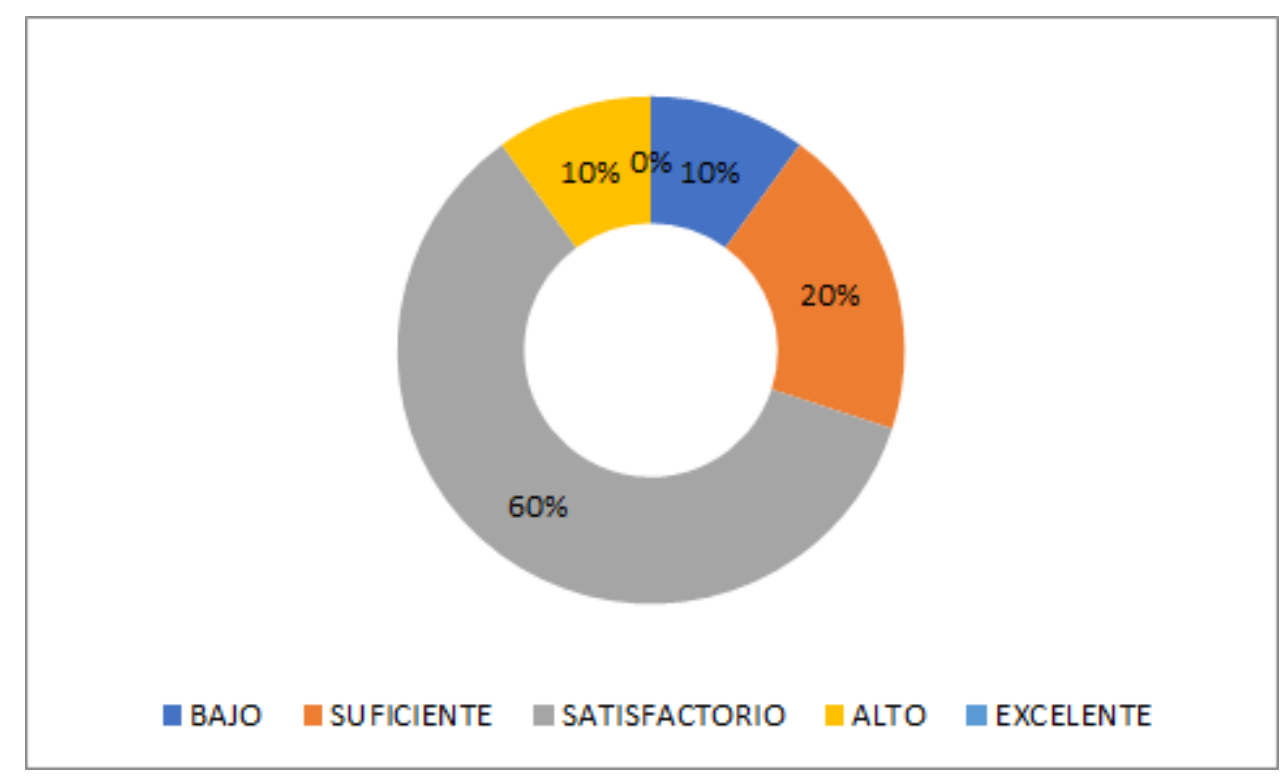

Gráfica 24: Resultados sobre la utilización de mecanismos para promover y medir la adaptación de un (a) trabajador (a) nuevo (a). 


\subsection{Manejo Laboral}

De acuerdo al proceso para la liquidación del personal funciona de manera excelente y con la última tecnología en el sector, el $60 \%$ dice que es excelente y el $40 \%$ respondió que es alto, en este caso la opción satisfactoria, suficiente y bajo no registró ningún valor (Gráfica 25).

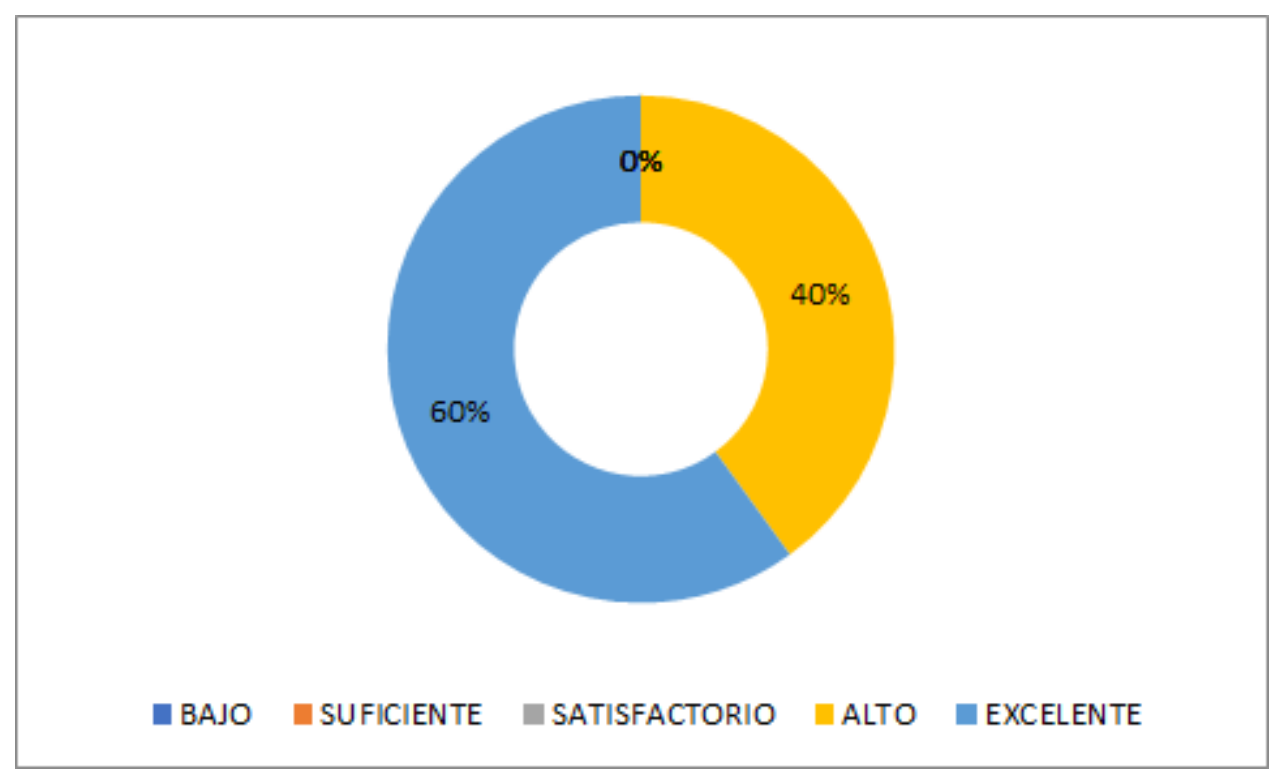

Gráfica 25: Resultados sobre el proceso para la liquidación del personal.

Respecto a la aplicación del reglamento interno de trabajo, el $60 \%$ dice que es excelente y el $10 \%$ respondió que es alto, y el 30\% contestó que es satisfactorio, en este caso la opción suficiente y bajo no registró ningún valor (Gráfica 26). 


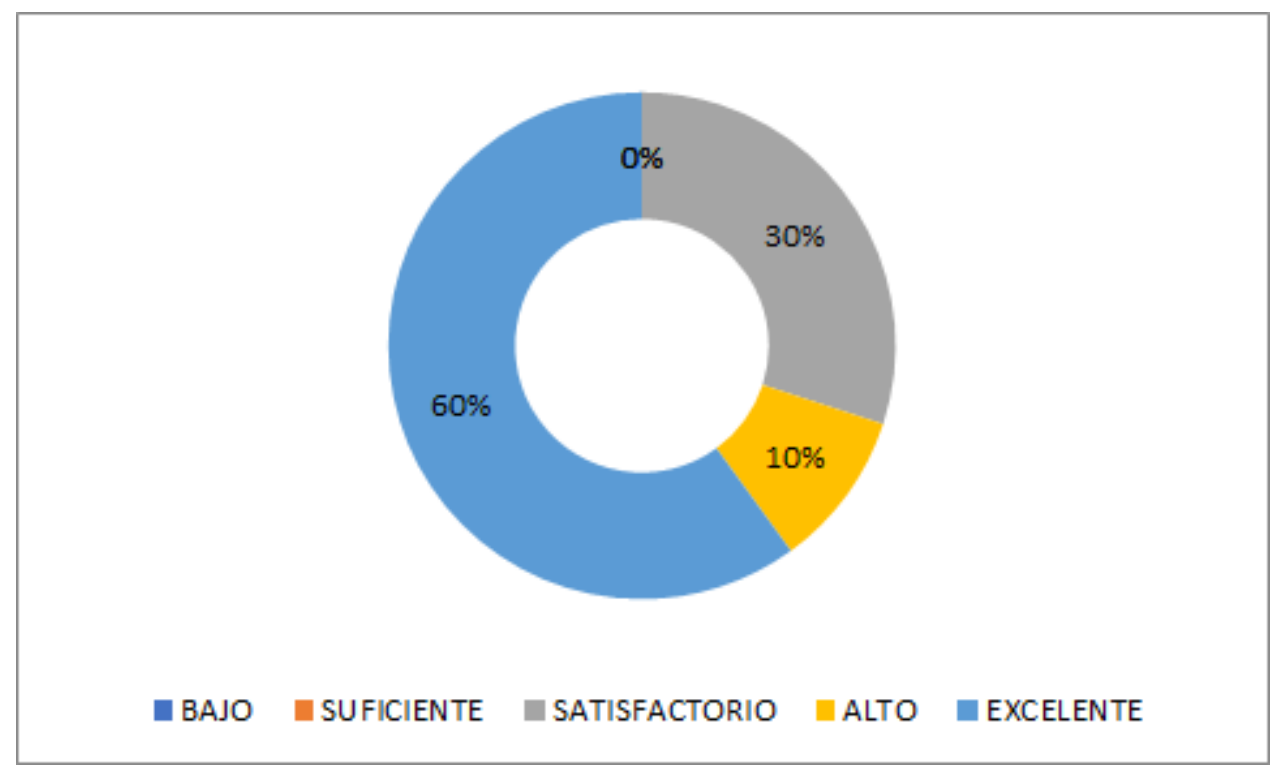

Gráfica 26: Resultados sobre la aplicación del reglamento interno de trabajo.

\subsection{Promoción.}

Con la aplicación de criterios para promover colaboradores (mérito, antigüedad, etc.) funcionan de manera óptima, el 10\% de los colaboradores sienten que es excelente, otro 10\% contestó que es alto, mientras que el $70 \%$ respondió que es satisfactorio y el $10 \%$ dijo que es suficiente, en este caso la opción bajo no registró ningún valor (Gráfica 27).

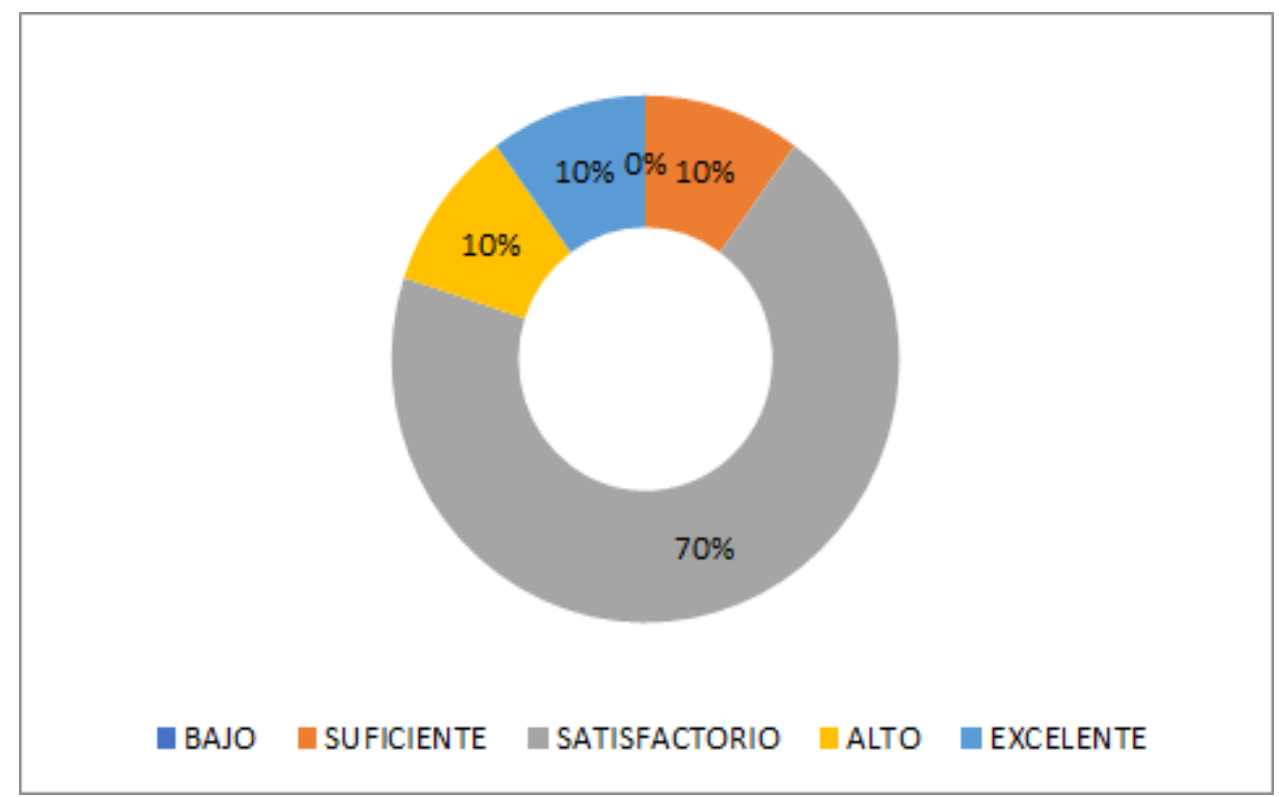

Gráfica 27: Resultados sobre la aplicación de criterios para promover trabajadores (mérito, antigüedad, etc.) 
En CIC TRAVEL se evidencian en todas las áreas o procesos, datos estadísticos que permiten visualizar los criterios de promoción, los cargos promovidos y su efectividad en la productividad de la organización, de acuerdo con lo anterior el $20 \%$ siente que es excelente, el $30 \%$ respondió que es alto, mientras que el $40 \%$ contestó que es satisfactorio y el $10 \%$ dijo que es suficiente, en este caso la opción bajo no registró ningún valor (Gráfica 28).

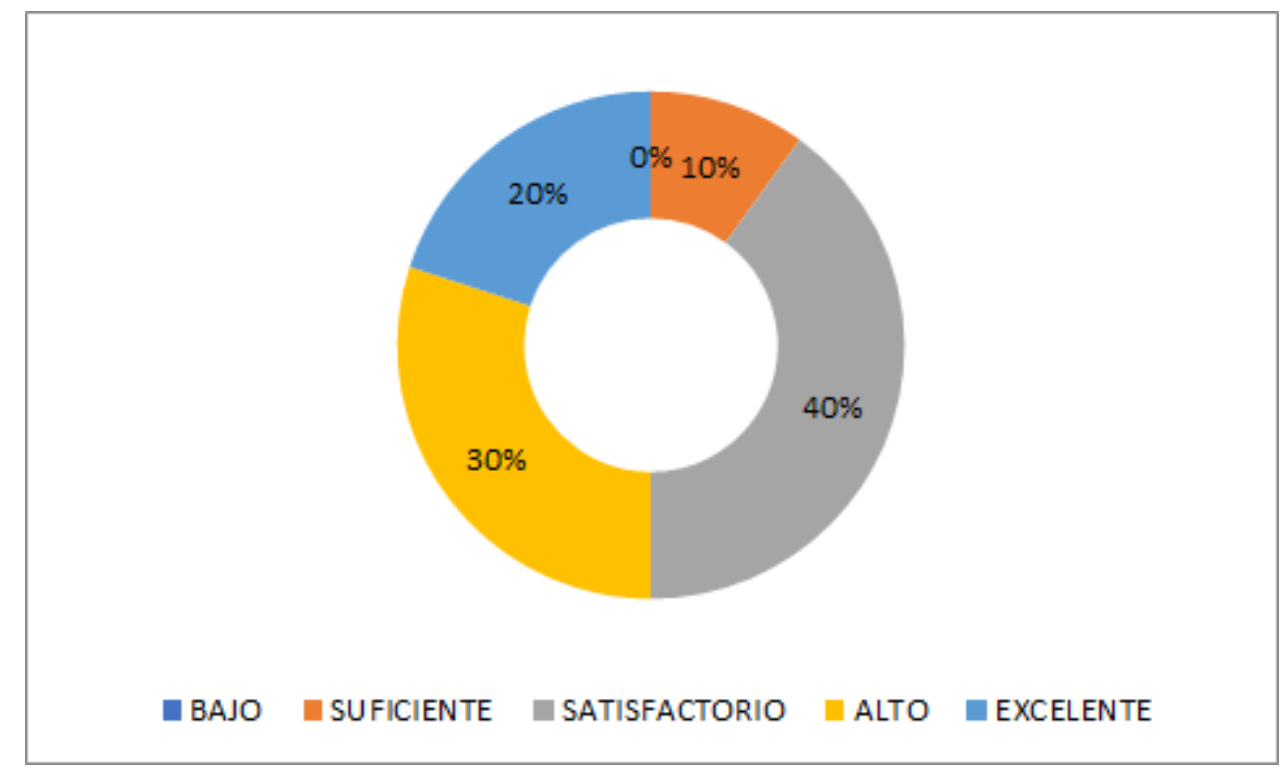

Gráfica 28: Resultados sobre la evidencia de todas las áreas con datos estadísticos que permiten visualizar los criterios de promoción.

\subsection{Reclutamiento}

De acuerdo con la documentación de las fuentes internas o externas de donde se obtiene el personal necesario, el $40 \%$ siente que es excelente, mientras que el $20 \%$ dice que es alto, el $10 \%$ contestó que es satisfactorio, el $20 \%$ dijo que es suficiente y el $10 \%$ bajo (Gráfica 29). 


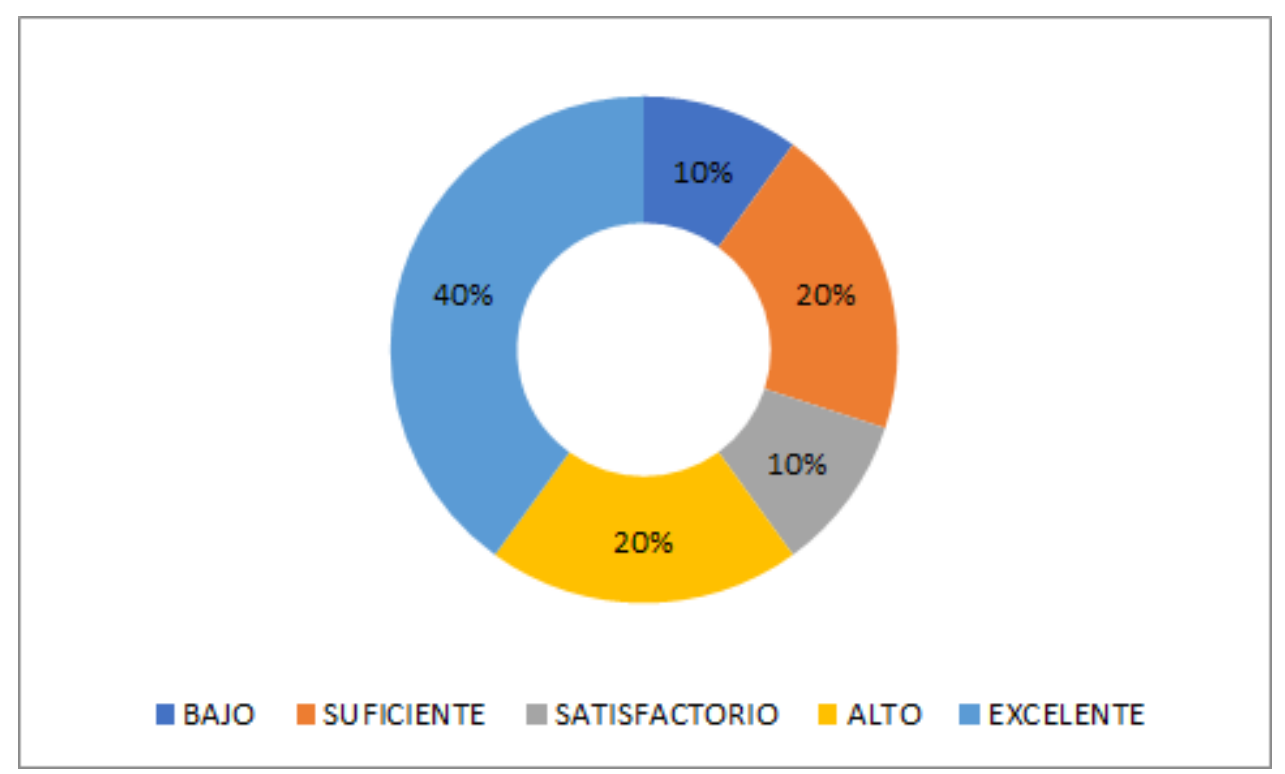

Gráfica 29: Resultados sobre la documentación de las fuentes internas o externas de donde se obtiene el personal necesario.

En la empresa se tienen procedimientos para registrar información actualizada de empleados potenciales de los cuales el $40 \%$ siente que es alto, el 50\% contestó que es satisfactorio y el $10 \%$ dijo que es suficiente, en este caso la opción excelente y bajo no registró ningún valor (Gráfica 30).

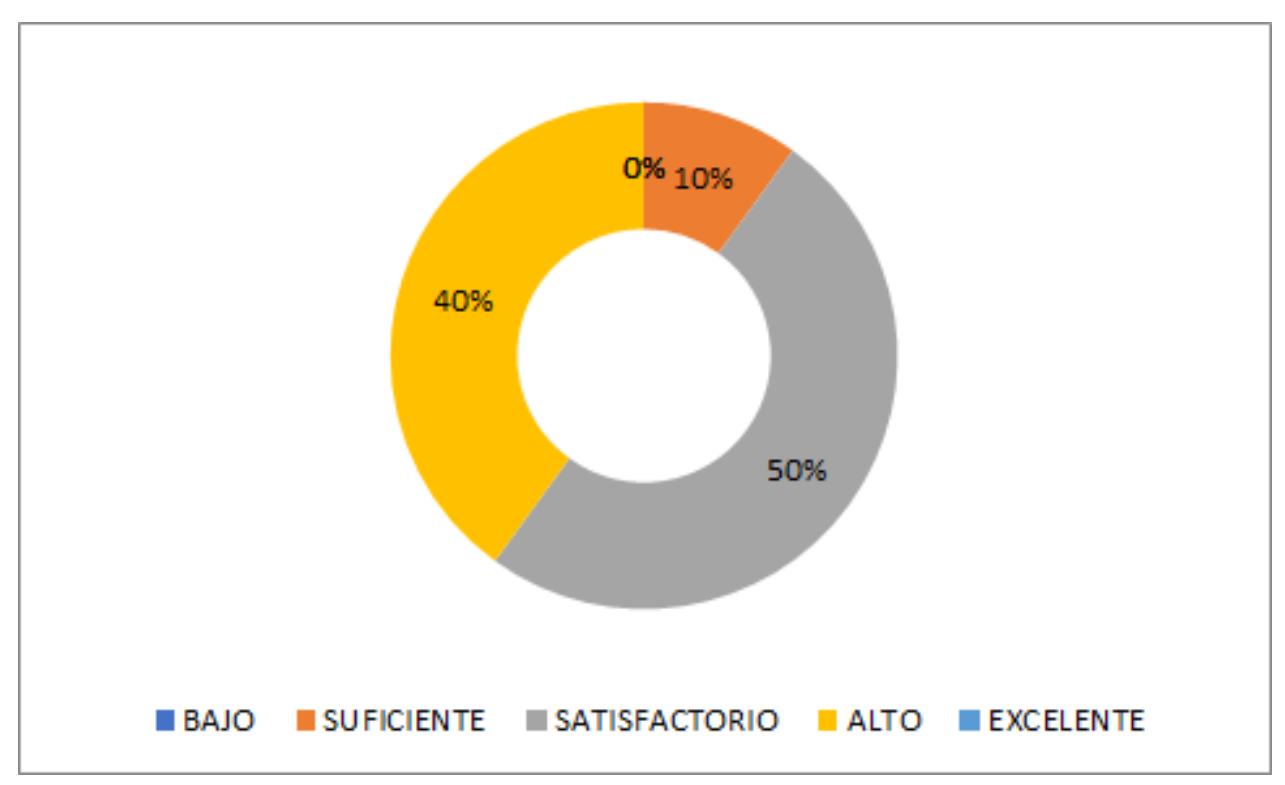

Gráfica 30: Resultados sobre los procedimientos para registrar información actualizada de empleados potenciales. 
Respecto a la utilización de mecanismos de evaluación y mejoramiento del proceso de reclutamiento, el $10 \%$ siente que es alto, el $50 \%$ contestó que es satisfactorio y el $40 \%$ dijo que es suficiente, en este caso la opción excelente y bajo no registró ningún valor (Gráfica $31)$.

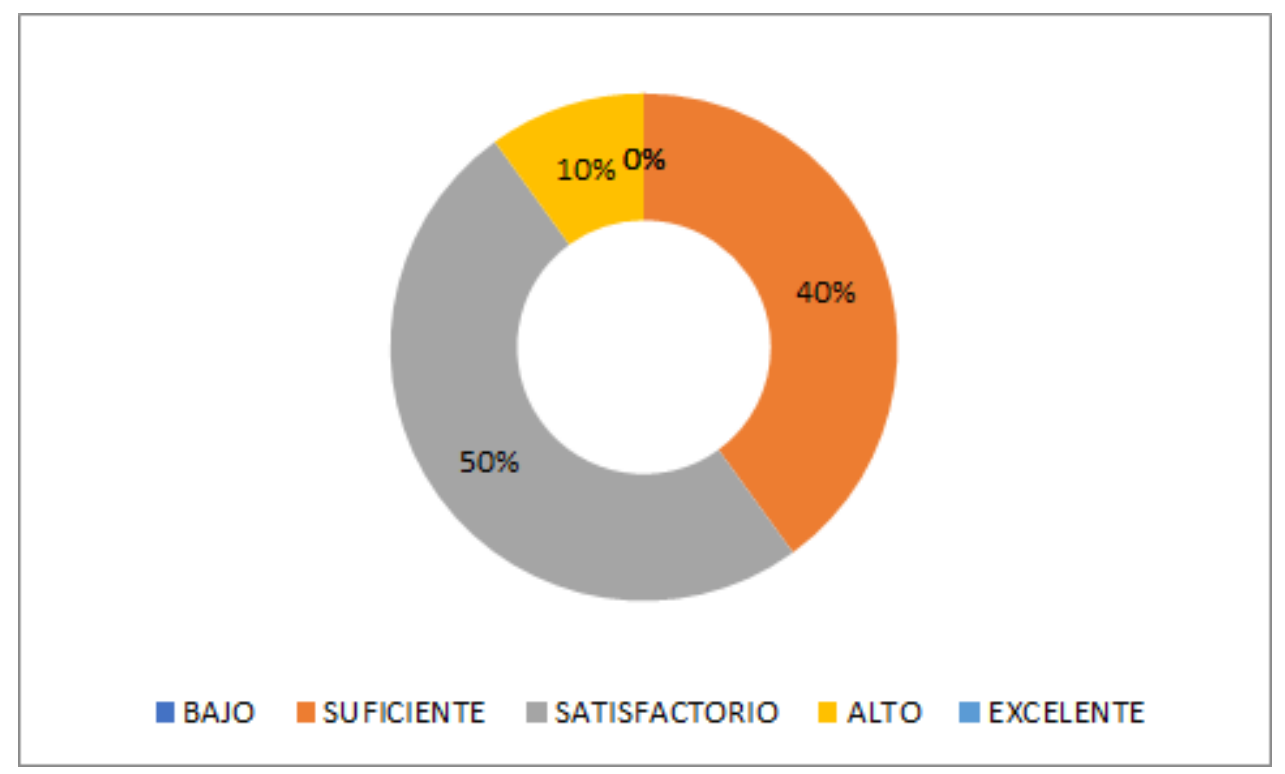

Gráfica 31: Resultados sobre la utilización de mecanismos de evaluación y mejoramiento del proceso de reclutamiento.

\subsection{Salud ocupacional}

La aplicación de programas de mejoramiento y mantenimiento de las condiciones de vida y salud de los colaboradores, el $80 \%$ siente que es excelente, el $20 \%$ contestó que es alto, en este caso la opción satisfactoria, suficiente y bajo no registró ningún valor (Gráfica 32). 


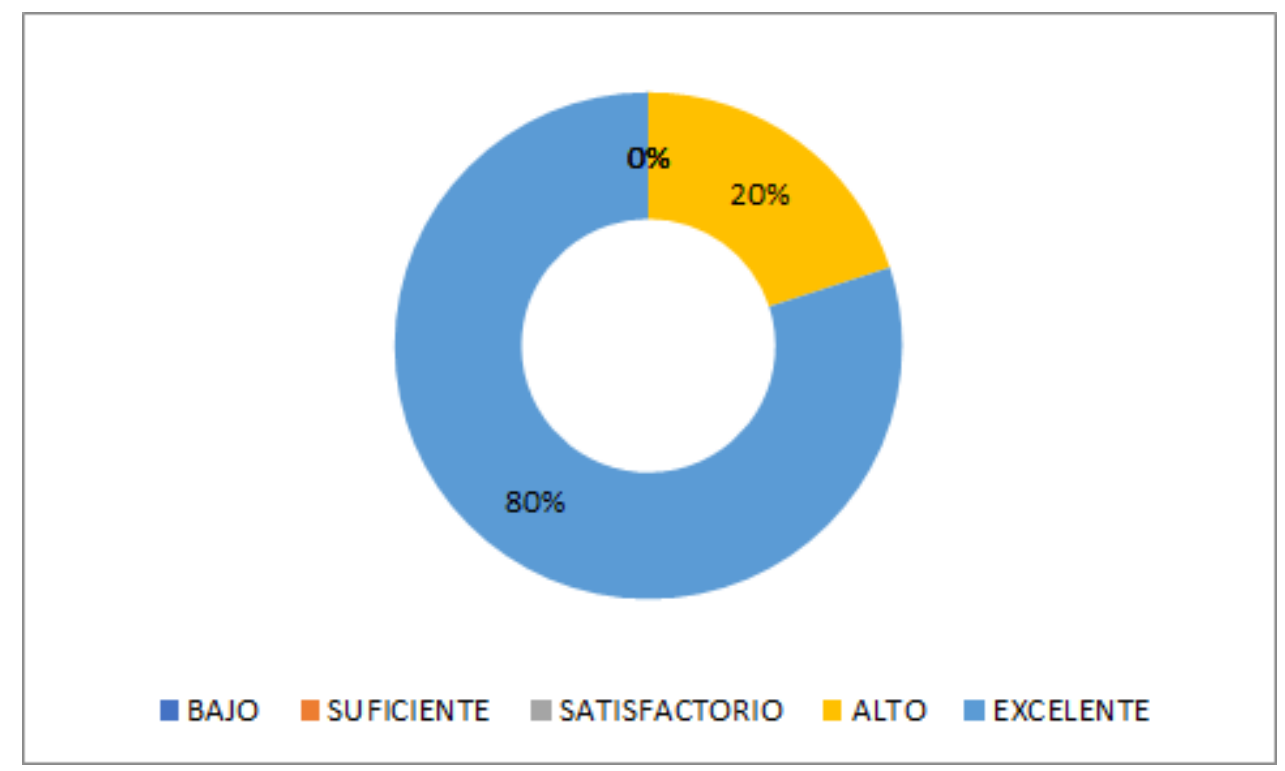

Gráfica 32: Resultados sobre la aplicación de programas de mejoramiento y mantenimiento de las condiciones de vida y salud de los trabajadores.

En la empresa la aplicación de las medidas de protección a las personas contra los riesgos derivados de la organización laboral que puedan afectar la salud individual o colectiva en los lugares de trabajo, el $90 \%$ siente que es excelente, el 10\% contestó que es alto, en este caso la opción satisfactoria, suficiente y bajo no registró ningún valor (Gráfica 33).

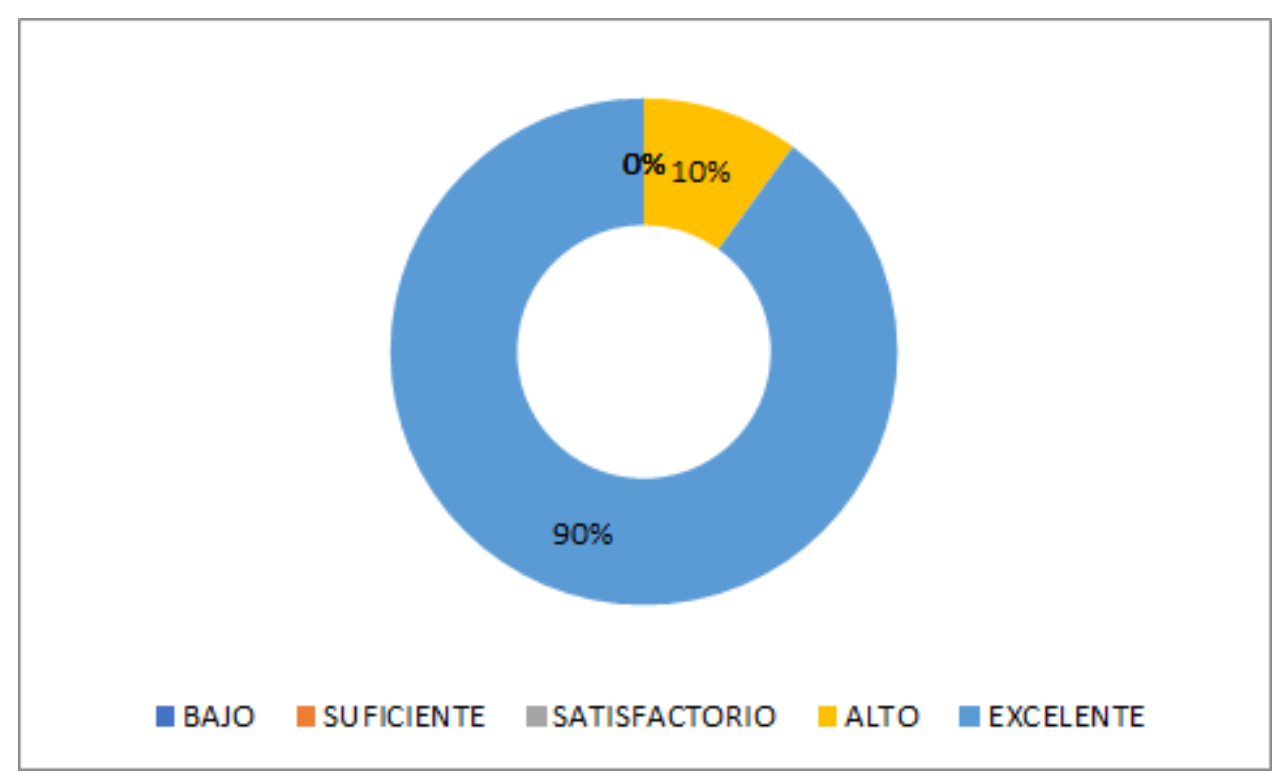

Gráfica 33: Resultados sobre la aplicación de las medidas de protección a las personas de la organización. 
Se evidencian claramente en toda la empresa, que los programas generan prevención de todo daño para la salud de las personas, derivado de las condiciones de trabajo, el 70\% siente que es excelente, el 30\% contestó que es alto, en este caso la opción satisfactoria, suficiente y bajo no registró ningún valor (Gráfica 34).

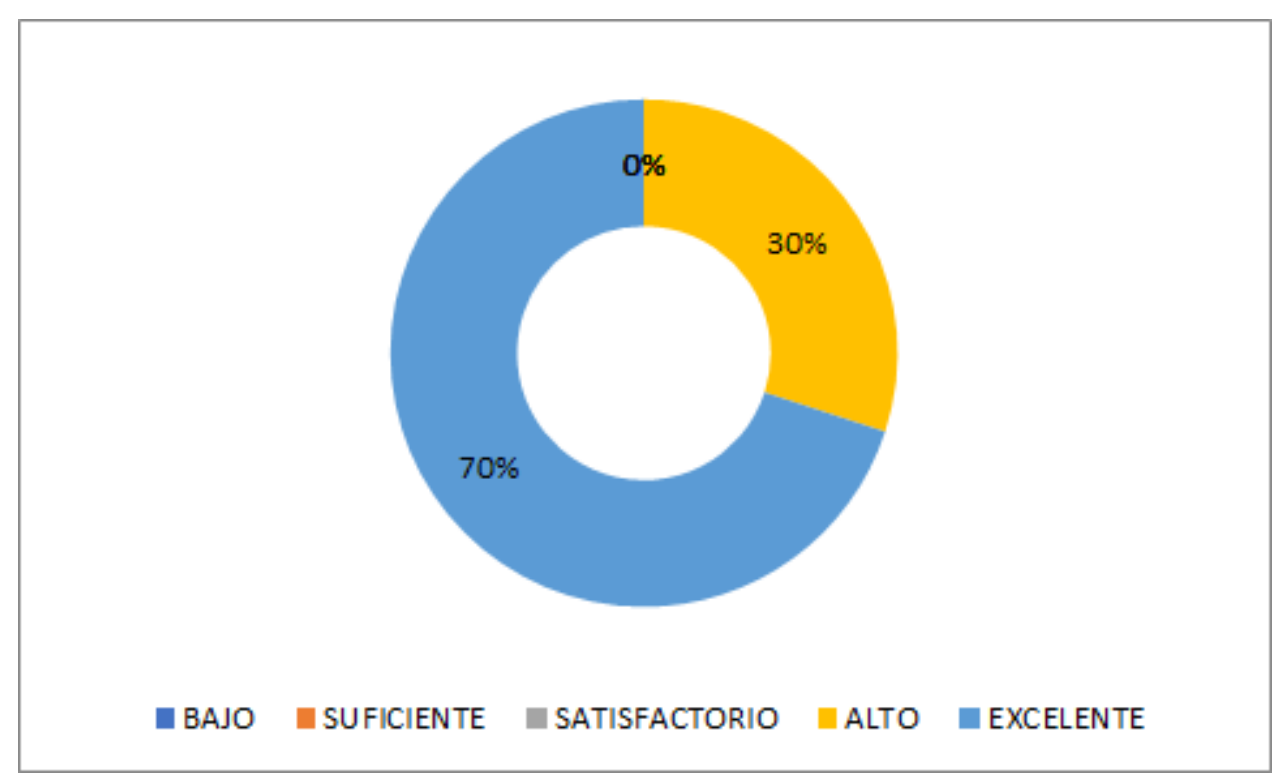

Gráfica 34: Resultados sobre los programas generan prevención de todo daño para la salud de las personas, derivado de las condiciones de trabajo.

\subsection{Selección}

En la empresa se utiliza permanentemente el proceso de selección (entrevistas, pruebas, verificación de antecedentes, referencias, etc.), el 50\% siente que es excelente, el $10 \%$ contestó que es alto, y el $40 \%$ dice que es satisfactorio, en este caso la opción suficiente y bajo no registró ningún valor (Gráfica 35). 


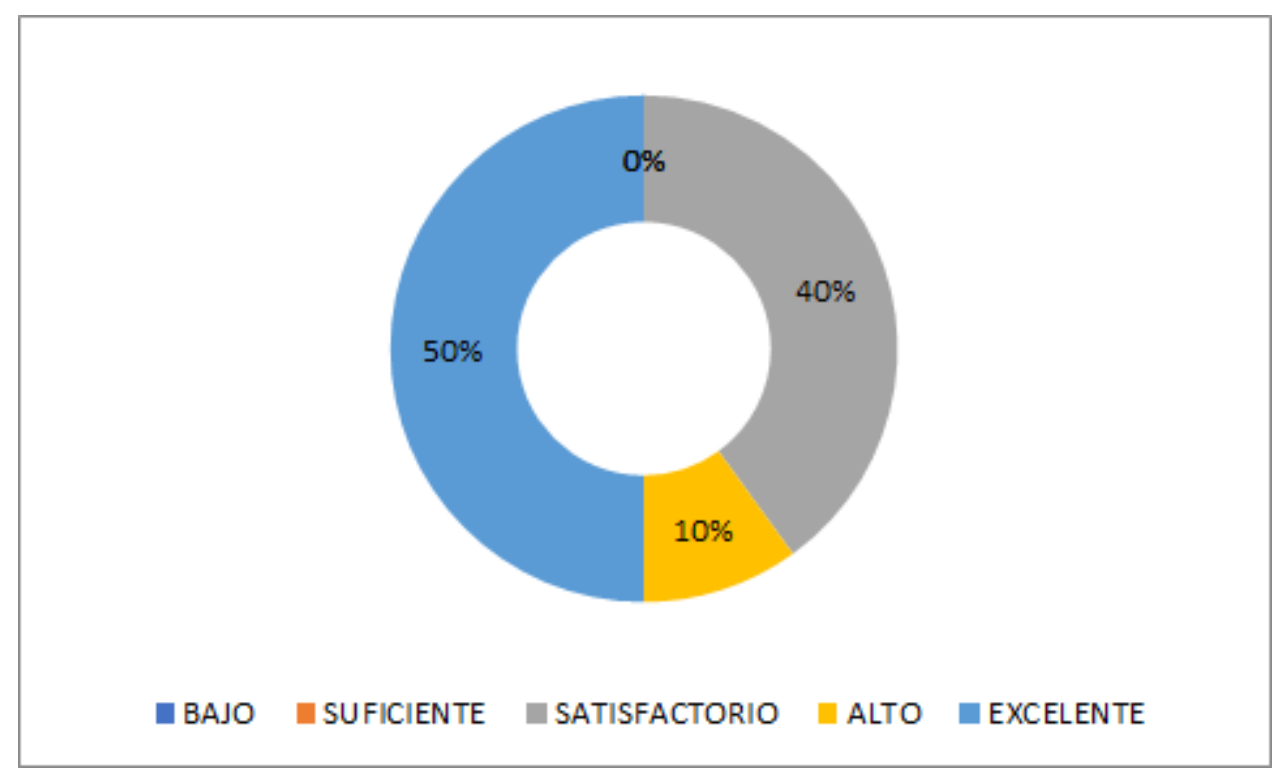

Gráfica 35: Resultados sobre la utilización permanentemente el proceso de selección (entrevistas, pruebas, verificación de antecedentes, referencias, etc.).

Se utilizan permanentemente las prioridades de la empresa con respecto a las habilidades, aptitudes y valores de los aspirantes, el 70\% siente que es excelente, el 30\% contestó que es alto, en este caso la opción satisfactoria, Suficiente y bajo no registró ningún valor (Gráfica 36).

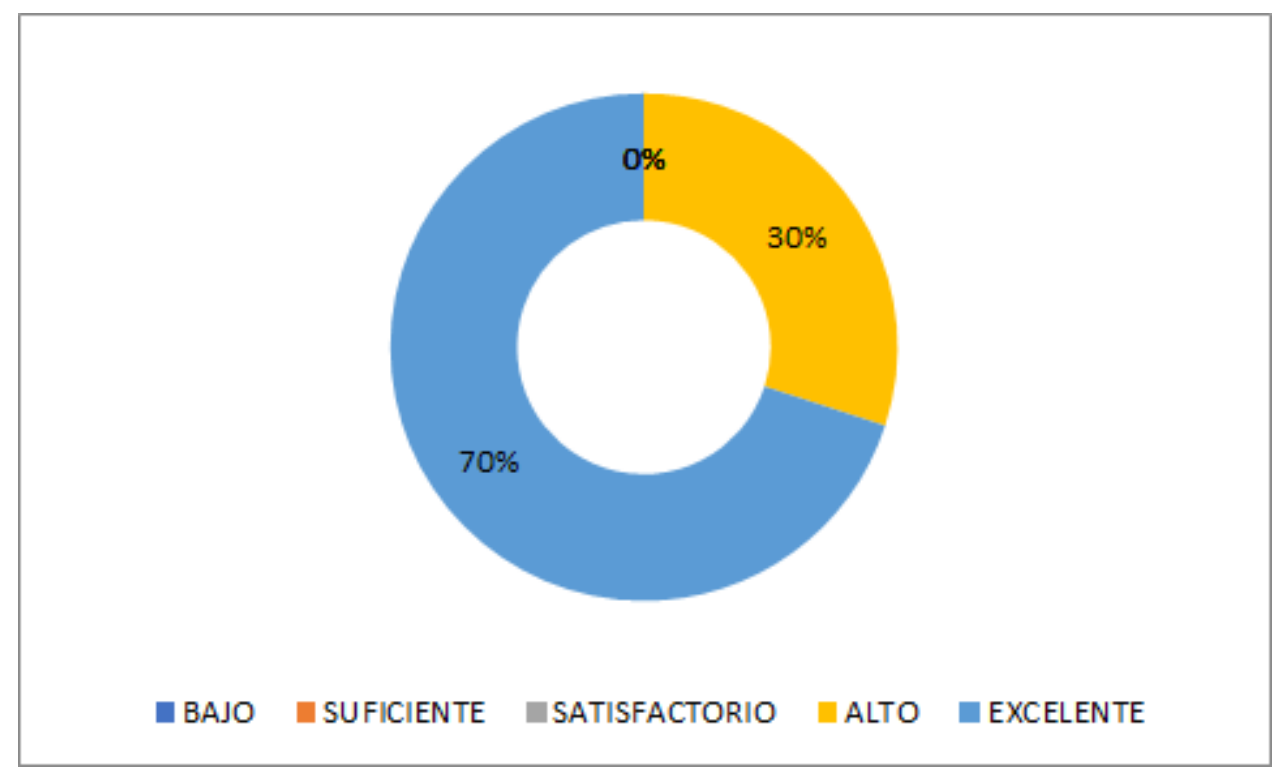

Gráfica 36: Resultados sobre la utilización permanentemente las prioridades de la empresa con respecto a las habilidades, aptitudes y valores de los aspirantes. 
De acuerdo con la utilización permanentemente los criterios físicos y de salud para determinar si el aspirante es apto para el cargo y existencia de pruebas para su ingreso, el $80 \%$ siente que es excelente, el 10\% contestó que es alto, y el 10\% dice que es satisfactorio, en este caso la opción suficiente y bajo no registró ningún valor (Gráfica 37).

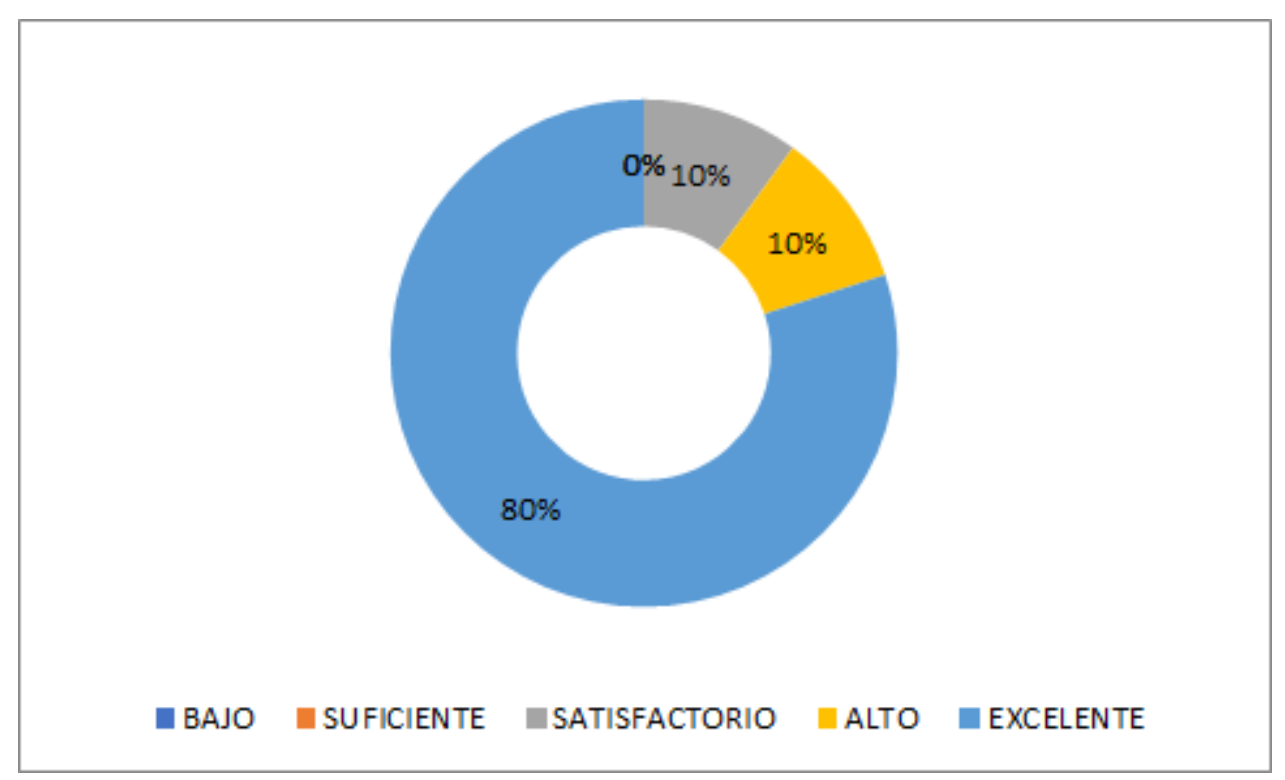

Gráfica 37: Resultados sobre la utilización de los criterios físicos y de salud para determinar si el aspirante es apto para el cargo y existencia de pruebas para su ingreso.

\section{Discusión de resultados.}

De acuerdo con los resultados expuestos en el cuestionario realizado a los directores de cada área en la empresa CIC TRAVEL y siguiendo con los objetivos planteados, se elaboró un diagrama de espina de pescado (diagrama 1) tomando en cuenta aquellos factores que de acuerdo a los resultados obtenidos de la encuesta se deben mejorar o fortalecer, por lo tanto, con el fin de establecer el plan de mejora se identificaron 6 factores de los cuales se realizó un seguimiento y análisis dando como resultado lo siguiente: 
- Selección: Se identificó opciones de mejora ya que los colaboradores que son seleccionados no cuentan con todas las competencias necesarias para el cargo al cual son contratados, y esto es debido a que no existe con una descripción especifica de las competencias necesarias para cada cargo; además se identificó una opción de fortalecimiento en el proceso de evaluación de los candidatos seleccionados con el fin de que sea un proceso más dinámico, y que a la vez permita identificar las falencias y fortalezas con las que debe contar cada candidato seleccionado de acuerdo a nivel del cargo.

- Inducción: Se identificó una oportunidad de fortalecimiento debido a que el proceso que se adelanta no tiene un impacto considerable en el colaborador recién ingresado por ende el conocimiento que se brinda en este proceso no es retenido por el colaborador, generando un desconocimiento de diferentes factores que incentivan el sentido de pertenencia por la empresa y que son de utilidad para el desempeño dentro de la empresa los cuales son el desconocimiento de las diferentes áreas de la empresa, misión, visión, valores y objetivó estratégico de la empresa.

- Entrenamiento: Se identificó oportunidades de mejora que permitan la disminución de los tiempos del proceso ya que los cursos programados no son efectuados en los tiempos estipulados; además los mismos llega a contener falencias ya que se quedan muy cortos, y no brindan un conocimiento claro y específico para el colaborador en su puesto de trabajo.

- Promoción: Se identificó una oportunidad de mejora ya que en la actualidad no se cuenta con un plan de promoción interno, generando en muchos colaboradores desmotivación y perdida de interés por su cargo llevándolos a renunciar de sus 
cargos por buscar un cargo mejor en otras empresas, y por ende perdida del conocimiento dentro de la empresa.

- Capacitación: Se identificaron opciones de mejora ya que los colaboradores recién ingresados en muchas ocasiones no tienen mucho conocimiento del cargo a desempeñar, generando de este modo inseguridades y desconocimiento de muchos de los procesos que en la empresa CIC TRAVEL además se evidencia en muchos casos falta de compromiso por parte de los compañeros de área de brindar las bases necesarias para adaptar al colaborador al nuevo cargo.

- Implementación y seguimiento estratégico G.H.: Se identificaron opciones de mejora ya debido a la mala comunicación que se tiene en el área, actualmente no se lleva un control de la misma de tal forma no se conoce las metas que se tienen para el mejoramiento de área y el desempeño de la misma dentro de la empresa CIC TRAVEL.

Analizando las opciones de mejora y fortalecimiento del área se puede deducir que actualmente son causales que generan efectos negativos al interior de la empresa, ocasionando aumento en los tiempos y proceso que en ocasiones llega a ser incensario o obsoletos para lo que se desea conseguir, además de un aumento en los costos y errores debidos a la mala gestión del talento humano. 


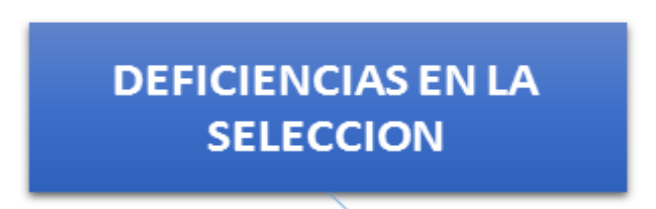

\section{FALTA DE INDUCCION}

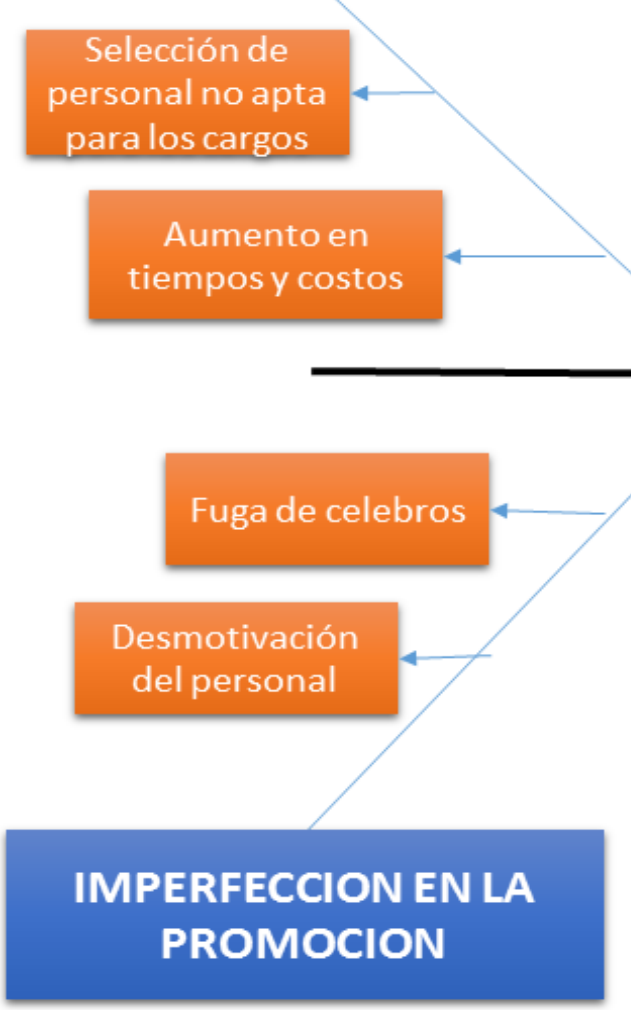

FALLO EN EL

ENTRENAMIENTO

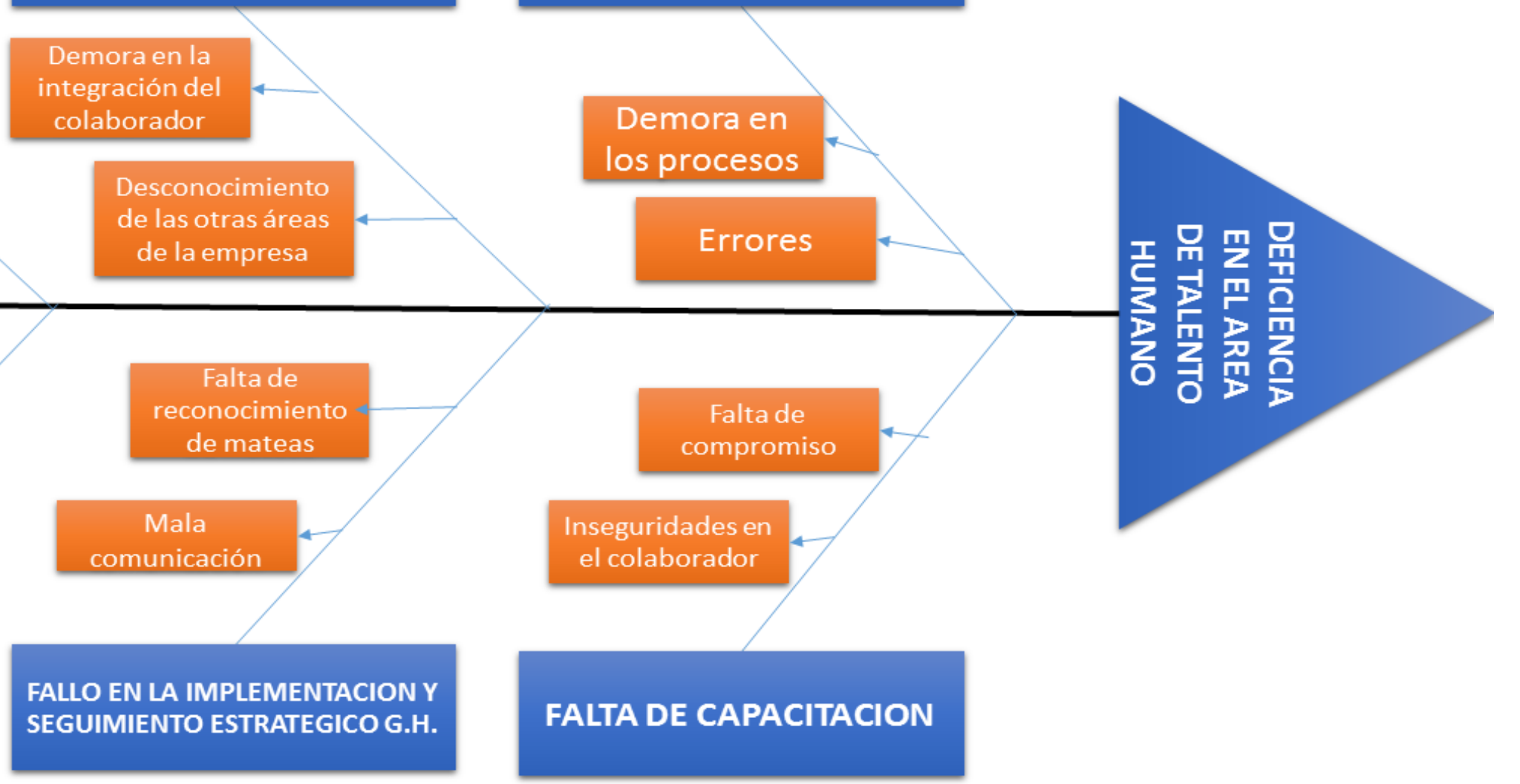

Diagrama 1: Espina de pescado. 
Resultado de las opciones de mejora y fortalecimiento identificadas en el diagrama de espina de pescado (diagrama 1) y el análisis de cada uno de estos factores por parte del grupo desarrollador del proyecto en la empresa CIC TRAVEL, se diseñó el diagrama como - como (diagrama 2), del cual se creó nueve (9) mecanismos innovadores encaminados al mejoramiento y fortalecimiento del área de talento humano de la empresa CIC TRAVEL, los cuales se evidencian en el diagrama 2 en la sección de propuestas de mejoramiento y fortalecimiento.

Para finalizar tomado en cuenta los factores encontrados en el diagrama de espina de pescado y el diagrama "como - como" se logró diseñar un plan de implementación y fortalecimiento el cual cuenta en primer lugar con 7 opciones de implementación las cuales son:

1. Mejorar y actualizar los perfiles necesarios para cada cargo considerando las competencias que se requieren para el cargo y las necesidades que posee cada dirección.

2. Desarrollo de un acta de entrega del cargo o proceso acompañado de un instructivo con la finalidad de tenerlo en las bases de datos de la empresa en caso de que no se logre realizar una entrega formal del cargo.

3. El desarrollo de un manual de lecciones aprendidas con la finalidad de dejar registrados los errores que se han cometido en el cargo y asegurar la no repetición de estos por la nueva persona en el cargo.

4. Desarrollar un programa de vacantes y postulaciones internas para los colaboradores que puedan ser promovidos cuando se tenga disponibilidad de vacantes.

5. Crear controles que permitan evaluar el área de talento humano y el desempeño del área. 
6. Fijar metas y objetivos que se deben cumplir en un periodo determinado de tiempo con la finalidad de evaluar el cumplimiento del área.

7. Búsqueda de cursos gratuitos en el SENA que permita la adquisición y fortalecimiento de habilidades en los colaboradores.

Y en el segundo lugar opciones de fortalecimiento los cuales estas descritas a continuación:

1. Optimizar el proceso de entrevista de selección a través de un programa de evaluación específico para cada cargo de acuerdo a la estructura organizacional de la empresa, en donde se evalué las competencias necesarias para él cargo a desempeñar dentro de la empresa.

2. Diseñar un programa de inducción para todos los colaboradores recién ingresados utilizando mecanismos como: videos educativos, presentaciones interactivas, evaluación al final de la jornada, entre otros que logren generar cultura y sentido de pertenencia desde el inicio.

Con este plan de mejora se espera que la empresa CIC TRAVEL fortalezca aquellas falencias que en la actualidad cuenta, e implemente nuevos procesos y de este modo la empresa logre un mejor desarrollo en el mercado, además que gracias a este plan de mejora y fortalecimiento se quiere que la empresa pueda diseñar nuevos productos adaptarse a nuevos mercados y posicionarse como una de las mejores empresas del sector turístico. 


\section{Diagrama 2: Como - Como.}

\begin{tabular}{|c|c|c|}
\hline $\begin{array}{l}\text { Aspecto a mejorar } \\
\text { en la empresa. }\end{array}$ & $\begin{array}{l}\text { Alternativas a mejora y } \\
\text { fortalecer. }\end{array}$ & $\begin{array}{l}\text { Propuestas del plan de } \\
\text { mejora y fortalecimiento. }\end{array}$ \\
\hline \multirow{6}{*}{$\begin{array}{l}\text { Deficiencias el airea de } \\
\text { talento humano. }\end{array}$} & Deficiencia en la selección. & $\begin{array}{l}\text { 1. Mejorar y actualizar los perfiles necesarios para cada da cargo considerando las conpetencias } \\
\text { que se requieren parn el cargo y las necesidades que posee cada dirección. } \\
\text { 2. Dinamizar el proceso de entrevistas creando un programa de evaluación especifico para cada } \\
\text { cargo que permita simular un ambienté laboral real tomando en cuenta las competencias } \\
\text { necesarias para el cargo a desempetiar en la empresa. }\end{array}$ \\
\hline & Falencia en el proceso de indueción. & $\begin{array}{l}\text { 1. Diseftar un programa de inducción para todos los colaboradores recién ingresados utilizando } \\
\text { mecanismos como: videos educarivos, presentaciones interactivas, evaluación al final de la } \\
\text { jornada, entre otros que logren generar culnura y sentido de pertenencia desde el inicio. }\end{array}$ \\
\hline & $\begin{array}{l}\text { Falencia en el proceso de } \\
\text { capacitación }\end{array}$ & $\begin{array}{l}\text { 1. Desarnollo de un acta de entrega del cargo o proceso acompaniado de un instructivo con la } \\
\text { finalidad de tenerlo en las bases de datos de la empresn en caso de que no se logre realizar una } \\
\text { entrega formal del cargo. } \\
\text { 2. El desarrollo de un manusl de lecciones apreadidas con la finalidad de dejar registrados los } \\
\text { errores que se ban cometido en el cargo y asegurar la no repetición de estos por la nueva } \\
\text { persona en el cargo. }\end{array}$ \\
\hline & Imperfección en la promoción & $\begin{array}{l}\text { 1. Desarrollar un programa de vacantes y postulaciones internas para los colaboradores que } \\
\text { puedau ser promovidos cuando se tenga disponibilidad de vacantes. }\end{array}$ \\
\hline & $\begin{array}{l}\text { Fallo en la implementación y } \\
\text { seguimiento estratégico G.H. }\end{array}$ & $\begin{array}{l}\text { 1. Crear controles que permitan evalnar el área de talento humano } y \text { el desempenio del área. } \\
\text { 2. Fijar tuetas y objetivos que se deben cumplir en un periodo determinado de tiempo con la } \\
\text { finalidad de evaltar el cumplimiento del área. }\end{array}$ \\
\hline & Fallo en el entrenamiento & $\begin{array}{l}\text { 1. Búsqueda de cursos gratuitos en el SENA que permita la adquisición y fortalecimiento de } \\
\text { babilidades eu los colaboradores. }\end{array}$ \\
\hline
\end{tabular}




\section{Conclusiones.}

Dados los resultados y la discusión presentada anteriormente, se presentan las siguientes conclusiones en respuesta a los objetivos planteados:

- Gracias a la investigación teórica hecha por parte del grupo investigador, se determinó la importancia e impacto que tiene el área de talento humano en la empresa CIC TRAVEL; siendo esta un eje articulador de los diferentes procesos que allí se desarrollan.

- Con ayuda de las herramientas que se plantearon y se desarrollaron en el proyecto, se logró establecer mecanismos innovadores (diagrama de "espina de pescado" y diagrama “como - como"), los cuales no solo fortalecerán el área de talento humano, sino que también a la empresa en general, lo que evidenciará cambios organizacionales de impacto en el mundo empresarial.

- El programa de fortalecimiento propuesto, permite que se integren procesos tanto a nivel personal como a nivel organizacional, proyectando un crecimiento global de la empresa, manteniendo una estructura consistente para mantenerse reconocida en el mercado de las agencias de viaje.

Producto del cumplimiento de los objetivos planteados y el desarrollo del plan propuesto, se programó una reunión con el Gerente General Andrés Rincón y la Directora Financiera Claudia Rincón para socializar los resultados de este trabajo investigativo para su consideración e integración dentro de su empresa, esperando que se ponga en marcha en el segundo semestre del 2019. 


\section{Recomendaciones.}

De acuerdo con el proceso que se adelantó en la empresa CIC TRAVEL en el transcurso de la investigación, creación y desarrollo del plan de mejora se recomienda que:

- Se implemente el plan de mejora diseñado por el grupo desarrollador del proyecto con el fin de que se solucione las falencias con las que cuenta actualmente el área de talento humano de la empresa, debido a lo anterior se recomienda que dé prioridad a los mecanismos establecidos como opción de mejora y si es posible llevar paralelo a lo que hemos establecido, de tal modo se espera que la empresa realice controles semanales del progreso del plan de mejora.

- En segunda instancia en tal caso de no ser adoptados los mecanismos establecidos por el plan de mejora se recomienda al área de talento humano priorizar aquellos factores, los cuales se identificaron gracias a la aplicación del cuestionario y el análisis realizado por el grupo desarrollador del proyecto con el fin de mejorar y fortalecer el área de talento humano de la empresa CIC TRAVEL. 


\section{Agradecimientos.}

Por el cumplimiento y colaboración al proyecto que se adelantó en la empresa CIC TRAVEL el grupo investigador del proyecto integrado por Juan Camilo Cuervo y Miguel Angel Nope agradece al señor Andrés Rincón Gerente General de la empresa CIC TRAVEL por abrirnos las puertas de su empresa y permitirnos desarrollar el proyecto en tan importante entidad, a la señora Claudia Rincón Directora de Financiera, la cual nos brindó un espacio en su área donde proporcionó información importante de la empresa acerca de sus colaboradores y diversos procesos que se desarrollan en la actualidad y para finalizar a la profesora Sara Teresa Sandoval por ser una guía y apoyo en el desarrollo de este trabajo. 


\section{Referencias.}

- Corma Francisco. (2017). El CAMVAS de la innovación.

- Gary Dessler. (2001). Administración del personal.

- Aristizábal Escobar Jorge, Murcia Cabra Héctor Horacio y Suárez guzmán Johanna Carolina (2013); gestión y fortalecimiento empresarial con innovación, trabajó de investigación.

- Ikujiro Nonaka, Hirotaka Takeuchi. (1999). La organización creadora de conocimiento.

- Idalberto Chiavenato. (2000). la administración de recursos humanos (octava edición).

- Galeano Luis Jairo. (2010) La administración del talento humano.

- Alles Martha. (2006). desarrollo del talento humano.

- Myriam Astrid Ramírez López (2015) . Diego Fernando Sánchez Marín, Los planes de carrera como estrategia para lograr "Inplacement" en la organización. Recuperado de la $\quad$ lago http://www.ceipa.edu.co/lupa/index.php/lupa/article/view/135/265.

- Abrajan, M., Contretas, J., \& Montoya, S. (2009). Grado de satisfacción laboral y condiciones de trabajo: una exploración cualitativa. Enseñanza e Investigación en Psicología, 14 (1). 105-118.

- Burga, G., \& Wiesse, S. (2018). Motivación y desempeño laboral administrativo en una empresa agroindustrial de la región Lambayeque. Chiclayo: Universidad Católica Santo Toribio de Mogrovejo. Perú. 
- baggini (2006), gestión del talento humano en la empresa y su importancia, Peoplenet, en línea: https://blog.peoplenext.com.mx/gestión-del-talento-humano-enla-empresa-y-su-importancia.

- Eslava Arnao, Edgar (2004); Gestión del talento humano, como promotor del desarrollo organizacional; Uiversidad Militar de Colombia; trabajo de doctorado.

- Dolan, Valle, Jackson y Schuler (2015); Gestión de recursos humanos; Uiversidad de California.

- Hernández, Fernández, y Baptista, (2014); metodología de la investigación, 5ta edición, escuela superior de guerra naval. 


\section{Anexos.}

\section{ENCUESTA APLICADA A LOS TRABAJADORES DE LA EMPRESA CIC TRAVEL}

\section{OBSERVACIONES IMPORTANTES:}

1. Las respuestas obtenidas mediante la aplicación del presente instrumento SE MANEJARÁN CON FINES EDUCATIVOS.

2. Le agradecemos contar con su participación y su más sincera respuesta a las preguntas realizadas.

3. Usted no deberá pagar ningún monto por participar, ni recibirá ningún incentivo económico ni de ninguna naturaleza por tal motivo.

4. NO existe ningún riesgo para su integridad ni física ni psicológica al participar.

5. Por ningún motivo se le solicitará su nombre ni apellidos para participar, le recordamos que este estudio es cualitativo y con un $100 \%$ de ANONIMATO de los participantes.

6. Si Usted ha decidido participar, le será entregado un cuestionario que debe diligenciar de manera libre, sincera y $100 \%$ voluntaria.

\section{CRITERIOS:}

Respetado trabajador (a) Señorita, Señora, Señor le agradecemos su participación le agradecemos tener en cuenta la siguiente valoración para diligenciar correctamente la encuesta:

*Obligatorio

\section{ESTRUCTURACIÓN DEL PLAN DE GESTIÓN HUMANA *}

Marca solo un óvalo por fila.

Lajo Suficiente Satisfactorio Alto Excelente
estrategias de gestión humana,
son conocidas y se están
trabajando uniformemente en toda
la empresa.
El plan estratégico de gestión
humana esta alineado totalmente
al direccionamiento estratégico de
la empresa y funciona de manera
optima

2. IMPLEMENTACIÓN Y SEGUIMIENTO PLAN ESTRATÉGICO G.H. *

Marca solo un óvalo por fila.

La ejecución del plan de gestión
humana esta integrado a las de
otras áreas de la empresa.
$\begin{aligned} & \text { El plan de gestión humana se } \\ & \text { evalúa permanentemente en toda } \\ & \text { la empresa. }\end{aligned}$




\section{RECLUTAMIENTO}

Marca solo un ovalo por fila.

Bajo Sufliente Satisfactorio Auto Excelente

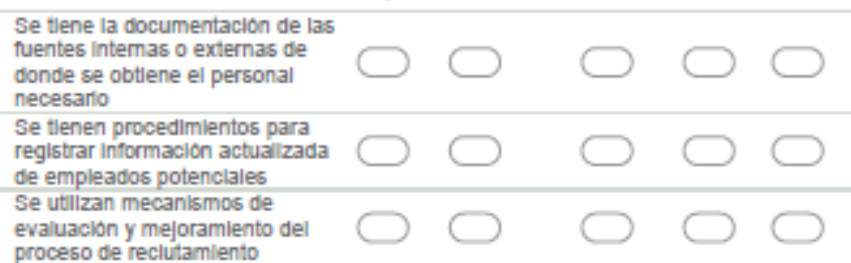

\section{SELECCION *}

Marca salo un ovalo por nila.

Bajo Suffclente Satisfactorio Alto Excelente

Se utiliza permanentemente $e$

proceso de seleccion (entrevistas.

pruebas, vertficacion de

antecedentes, referenclas, etc.

Se utilizan permanentemente las

prioridades de la empresa con

respecto a las habllidades,

aptitudes y valores de los

aspirantes.

Se utilizan permanentemente los

criterios físicos y de salud para

determinar sl el aspirante es apto

para el cargo y existencla de

pruebas para su ingreso.

\section{CONTRATACION}

Marca solo un ovalo por nla.

\begin{tabular}{l} 
Bajo Suficlente Satisfactorio Aito Excelente \\
\hline $\begin{array}{l}\text { Loliticas de contratacion } \\
\text { consultas en la elaboracion de los } \\
\text { contratos laborales }\end{array}$
\end{tabular}

\section{INDUCCION *}

Marca solo un ovalo por flia.

Bajo Suffclente Satisfactorio Aito Excelente

Se utillzan mecanismos para

Informar al nuevo empleado

aspectos basicos como: Historla,

evolucion y oojettvos,

Organigrama, Reglamento de

Trabajo, Funciones y relaciones

de coordinacion con otras

dependencias de la empresa.

se utillzan mecanismos para

promover y medir la adaptacion

de un (a) trabajador (a) nuevo (a) 
7. CAPACITACION *

Marca salo un ovalo por fila.

Bajo Sunciente Satisfactorio Alto Excelente

Los programas de capacilacion se

desarrollan permanentemente y

son aprovechados por los

trabajadores de la organizacion

La capacitacion se desarolla

sobre criterios claros conocidos y

utllizados por todas las areas de

la organizacion

Se realiza mejoramiento e

Innovacion de los programas de

capactacion en todas las areas

yio procesos de la empresa

Se evidenclan los logros en los

funcionarios capacitados y la

apllocion de los conoptos

aplicacion de los conceptos

adquindos en su labor diana,

operativa o tecnica en todas las

areas 0 procesos

\section{ENTRENAMIENTO *}

Marca salo un ovalo por fila.

Bajo Suficlente Satisfactorio Alto Excelente

La aplicacion de los criterios que
evaluan el desarrollo del
empleado en su labor dlaria
funclona de manera optima
Los logros obtenlidos en la
aplicacion del proceso de
entrenamiento en los funclonarios,
tanto en el ambito administrattio
como operattvo o tecnico, se
evidenclan por medlo de
Indicadores en todas las areas o
procesos

\section{PROMOCION *}

Marca solo un ovalo por nila.

Bajo Suficlente Satisfactorio Aito Excelente

La aplicacion de criterios para
promover trabajadores (mertito,
antigoedad, etc.) funcionan de
manera optima
Se evidenclan en todas las areas
o procesos, datos estadisticos
que permiten visualizar los
criterios de promocion, los cargos
promovidos y su efectividad en la
productividad de la organizacion.


10. EVALUACION DE DESARROLLO

Marca solo un ovalo por nla.

Bajo Suflciente Satisfactorio Aito Excelente

La aplicacion de un proceso de

valoracion y Meritos que reveli

necesldades de mejoramiento en

los trabajadores funciona de

manera excelente

Se manela un slstema de

evaluacion de desempeflo con

objettvos y tactores significattvos

para cada cargo, proceso o area

de trabajo.

11. COMPENSACION

Marca solo un ovalo por flla.

Bajo Sufflente Satisfactorio Aito Excelente

La aplicacion de criterios con

equidad para determinar el salano

asignado a un puesto de trabajo.

la periodicldad de su reajuste y lass

poifticas salariales

La aplicacion de Indlcadores de

gestion para deteminar la escala

salurial frente a su Industria

Elatist fiente a su industria

El sistema de pago de nomina

funclona de manera optima y con
la uitima tecnologia en el sector.

12. BIENESTAR SOCIAL *

Marca salo un ovalo por nla.

Bajo Suficlente Satisfactorio Alto Excelente

El desarrollo y segulmiento de los

programas de Blenestar Soclal

funciona de manera optima

Los programas que generan un

amblente que propicle la

colaboracion y voluntad del

trabajador, se evidenclan con

indlcadores en todas las areas 0

procesos

Se evidenclan claramente en tod

la empresa estadisticas que

reflelen el aumento de 1

productividad, disminucion de

ausentismo y accidentes de

trabalo, como consecuencla de I

impiementacion y ejecucion de

impiementadion y ejecucion

La aplicacion de mecanlismos de

comunicacion para dar a conocer

a los empleados los programas de

blenestar existentes funciona de

manera optima 
13. MANEJO LABORAL *

Marca solo un ovalo por fila.

Bajo Suficiente Satisfactorio Alto Excelente

La aplicacion del reglamento
Intemo de trabajo funclona de
manera optima
El proceso para la liquidacion del
personal funciona de manera
excelente y con la utima
tecnologla en el sector

14. SALUD OCUPACIONAL *

Marca salo un ovalo por fila.

Bajo Suffclente Satisfactorio Aito Excelente

La aplicacion de programas de

mejoramiento y mantenimiento de

las condiciones de vida y salud de

los trabajadores funciona de

manera optima

Se evidenclan claramente en toda

la empresa, que los programas

generan prevencion de todo daho

para la salud de las personas,

dertvado de las condlclones de

trabalo

La aplicacion de las medidas de

proteccion a las personas contra

los rlesgos dertvados de la

organizacion laboral que puedan

afectar la salud indlvidual o

colectiva en los lugares de

trabajo, funciona de manera

optima 


\section{ESTRUCTURACIÓN DEL PLAN DE GESTIÓN HUMANA}

6
Bajo
Suficiente Satisfactorio
Alto
Excelente

4

2
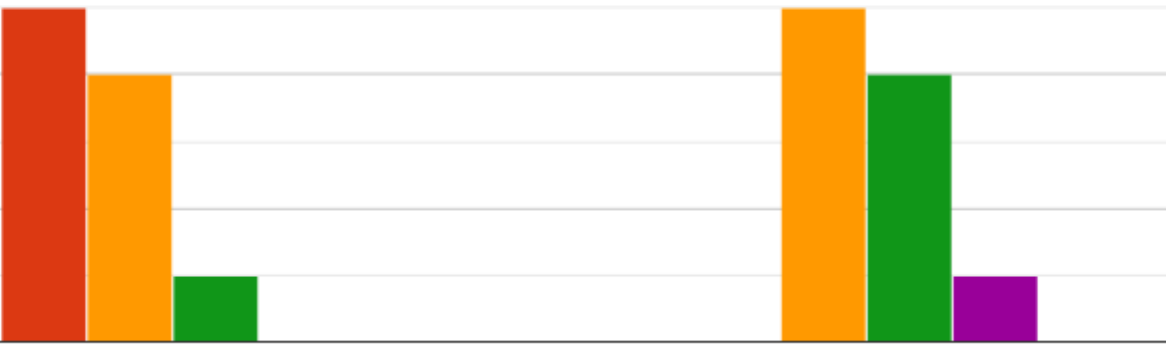

La misión, políticas, metas y estrategias de gestión

El plan estratégico de gestión humana esta alineado humana, son conocidas y se están trabajando totalmente al direccionamiento estratégico de la empresa uniformemente en toda la empresa. y funciona de manera optima

\section{IMPLEMENTACIÓN Y SEGUIMIENTO PLAN ESTRATÉGICO G.H.}

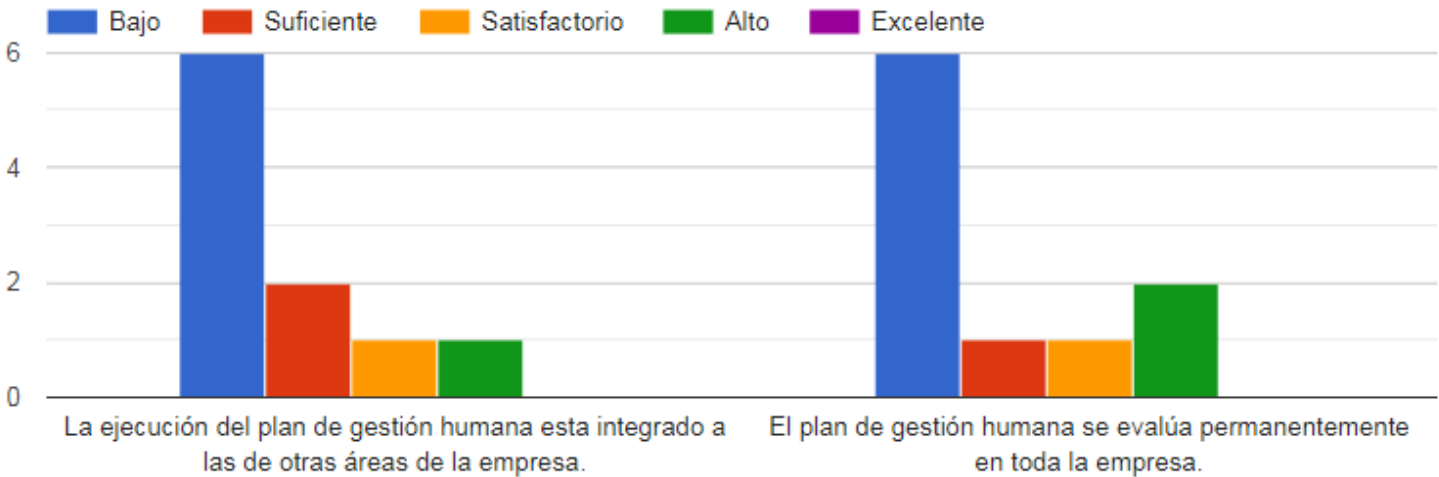

\section{RECLUTAMIENTO}

6

4

2

0

Se tiene la documentación de las fuentes internas o externas de donde se obtiene el personal necesario
Se tienen procedimientos para registrar información actualizada de empleados potenciales
Se utilizan mecanismos de evaluación y mejoramiento del proceso de reclutamiento 


\section{SELECCIÓN}

8
Bajo
Suficiente
Satisfactorio
Alto
Excelente
Bajo
Suficiente

6

6

Excelente

4

4

2

Se utiliza permanentemente el proceso de selección (ent.

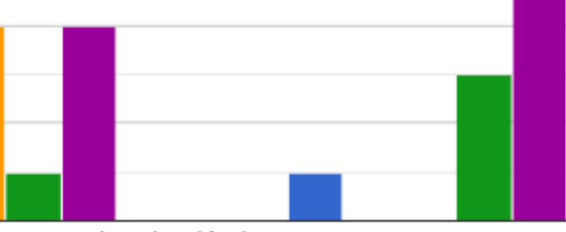

Se utilizan permanentemente las prioridades de la empresa con respecto a I..

\section{CONTRATACIÓN}

6

Bajo Suficiente $\square$ Satisfactorio

4

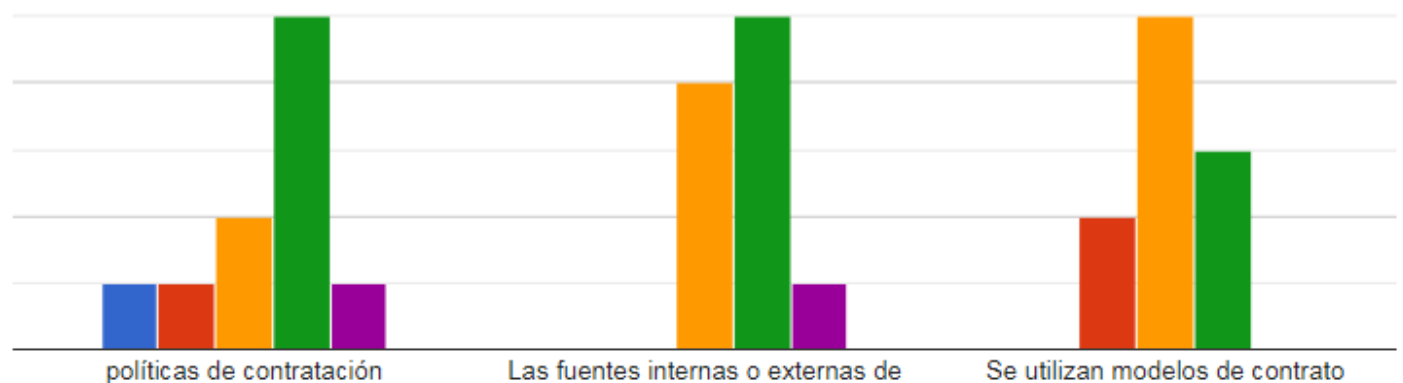

políticas de contratación

contratos laborales

\section{INDUCCIÓN}

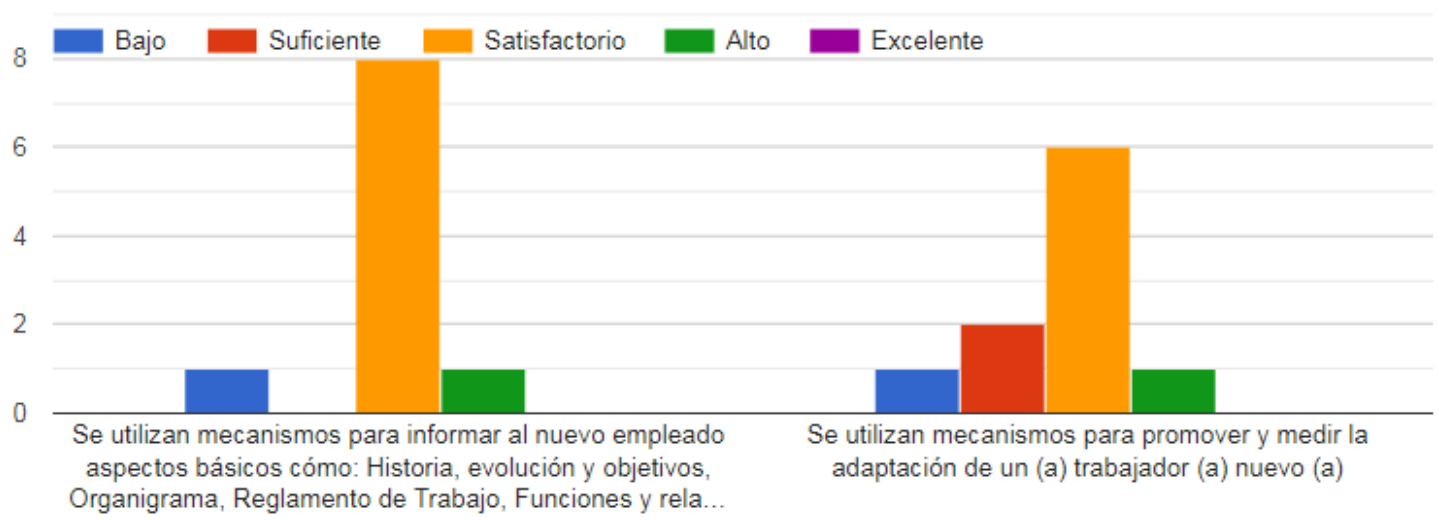




\section{CAPACITACIÓN}

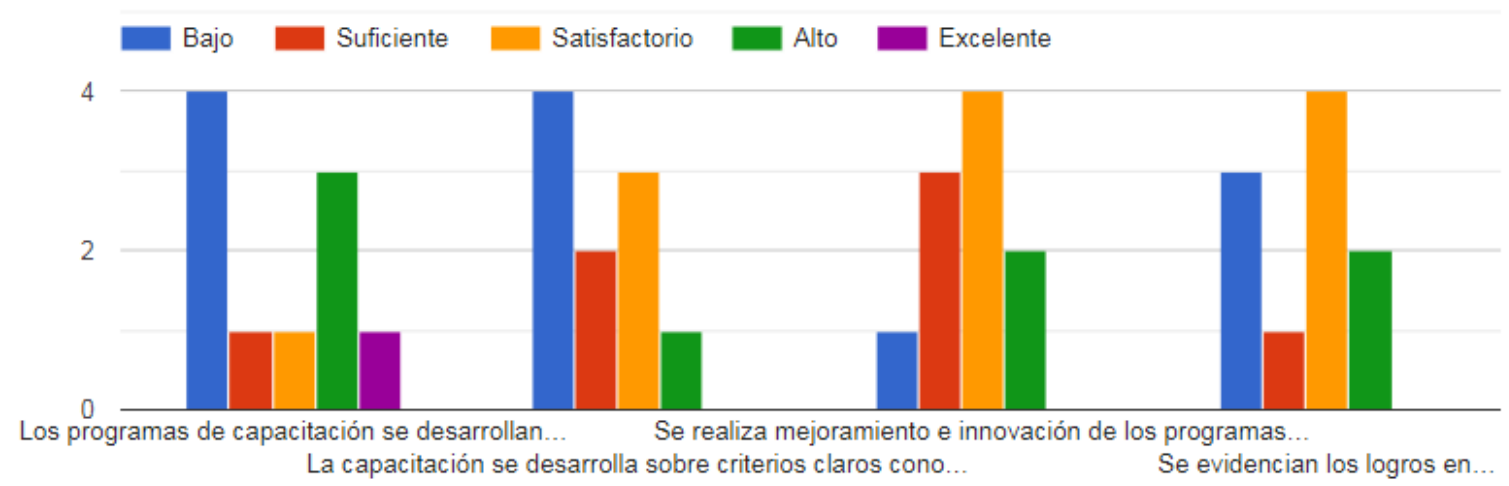

\section{ENTRENAMIENTO}

6
Bajo
Suficiente
Satisfactorio
Alto
Excelente

4

2

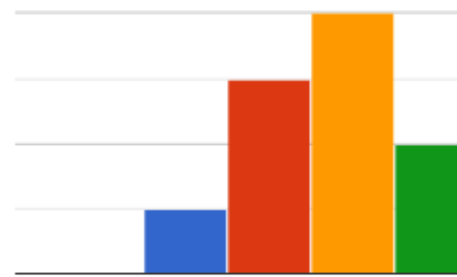

La aplicación de los criterios que evalúan el desarrollo del empleado en su labor diaria funciona de manera optima

Los logros obtenidos en la aplicación del proceso de entrenamiento en los funcionarios, tanto en el ámbito administrativo como operativo o técnico, se evidencian..

\section{PROMOCIÓN}

Bajo Suficiente Satisfactorio $\square$ Alto $\square$ Excelente

4

0 La aplicación de criterios para promover trabajadores (mérito, antigüedad, etc.) funcionan de manera optima

Se evidencian en todas las áreas o procesos, datos estadísticos que permiten visualizar los criterios de promoción, los cargos promovidos y su efectividad en la.. 


\section{EVALUACIÓN DE DESARROLLO}

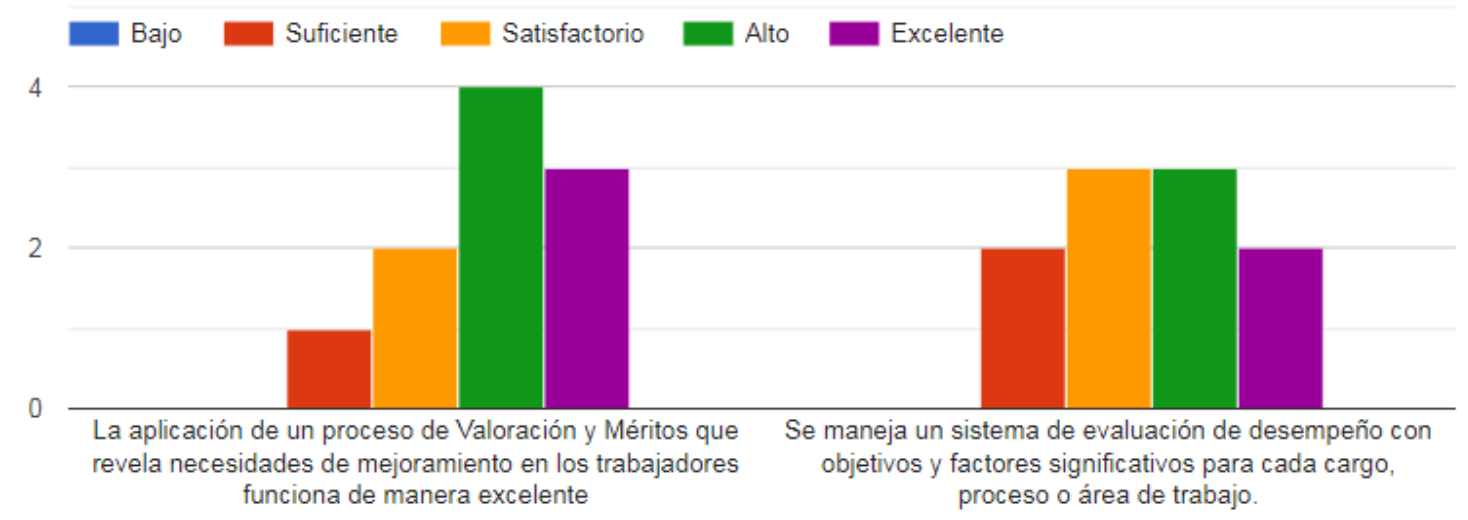

\section{COMPENSACIÓN}

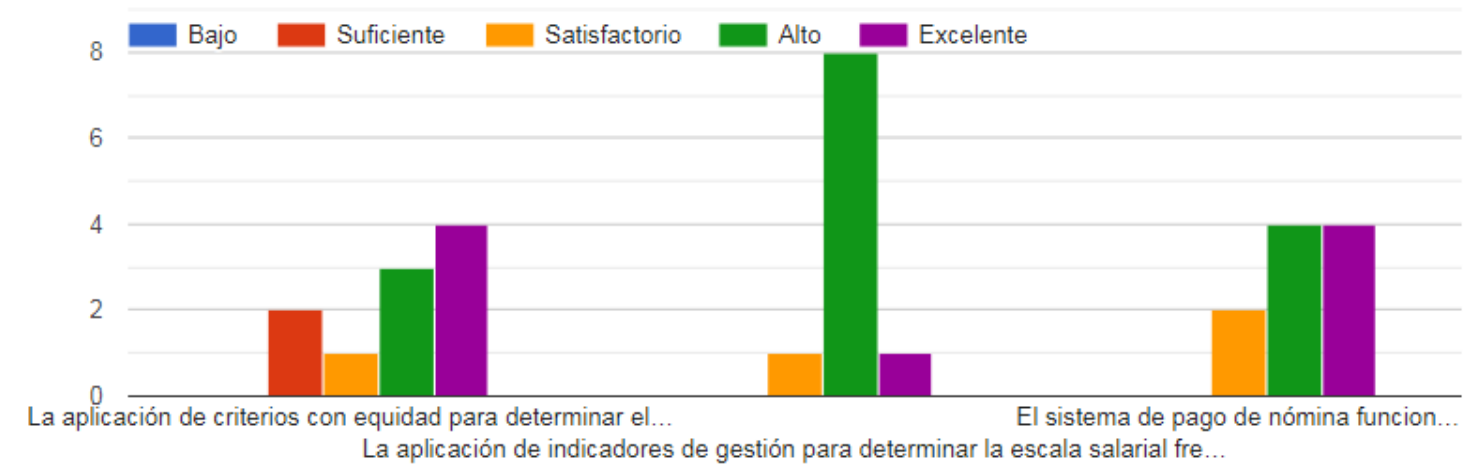

\section{BIENESTAR SOCIAL}

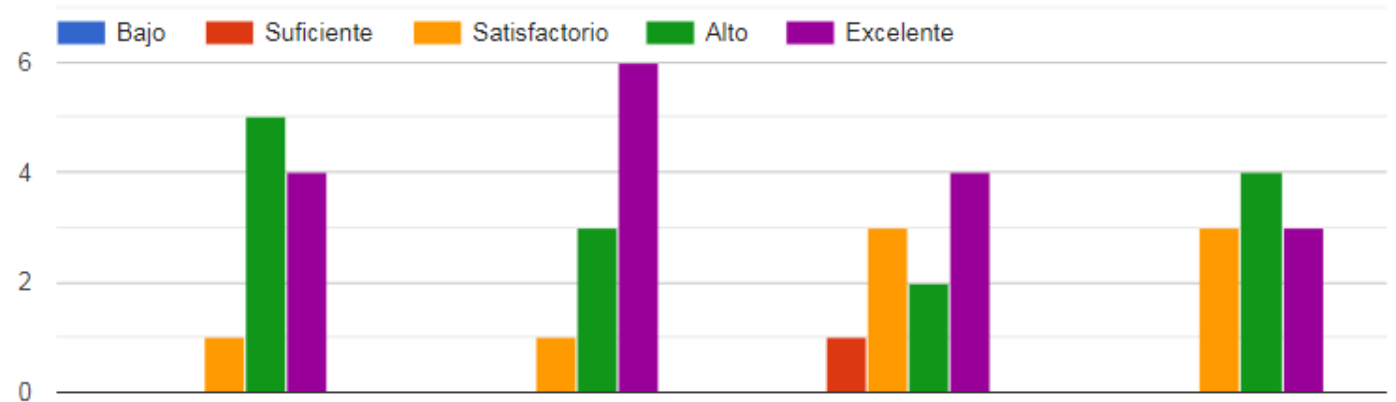

El desarrollo y seguimiento de los programas d...

Se evidencian claramente en toda la empresa estadístic.

Los programas que generan un ambiente que propicie I.

La aplicación de mecanism. 


\section{MANEJO LABORAL}

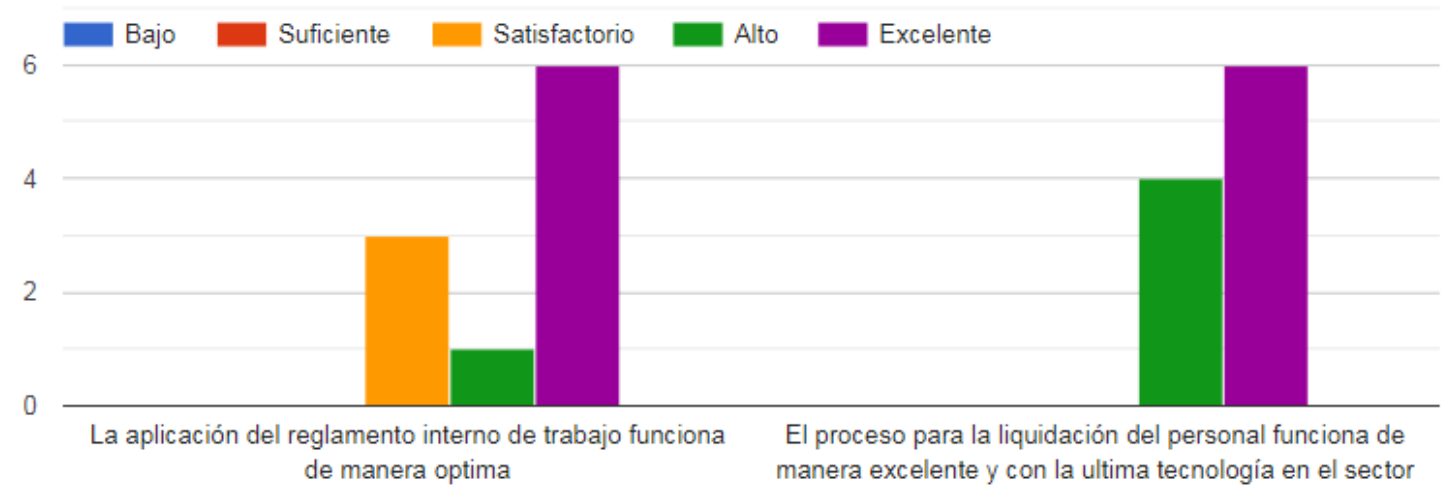

\section{SALUD OCUPACIONAL}

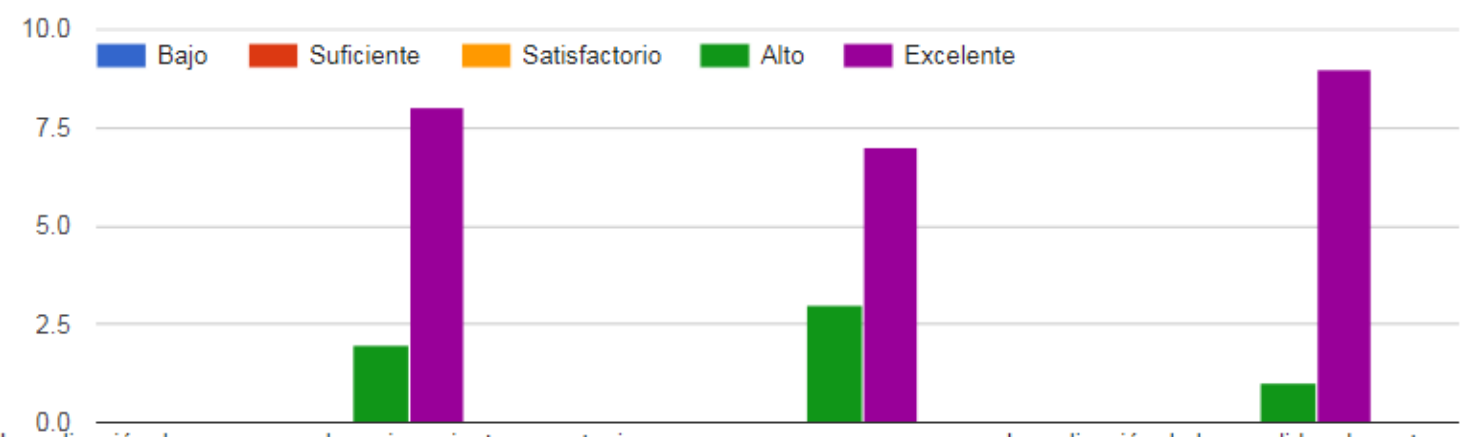

La aplicación de programas de mejoramiento y manteni.

La aplicación de las medidas de prote.. Se evidencian claramente en toda la empresa, que los programas generan $p .$. 